\title{
unesp
}

PAULO HENRIQUE MARIANO MARFIL

ESTUDO REOLÓGICO DE SISTEMAS

GELATINA/COLÁGENO/AMIDO PARA OBTENÇÃO DE GÉIS E APLICAÇÃO EM GOMAS DIETÉTICAS DE GELATINA

São José do Rio Preto - SP 


\title{
ESTUDO REOLÓGICO DE SISTEMAS
} GELATINA/COLÁGENO/AMIDO PARA OBTENÇÃO DE GÉIS E APLICAÇÃO EM GOMAS DIETÉTICAS DE GELATINA

\author{
Dissertação apresentada para obtenção do \\ título de mestre em Engenharia e Ciência de \\ Alimentos, área de Engenharia de Alimentos \\ junto ao Programa de Pós-graduação em \\ Engenharia e Ciência de Alimentos do \\ Instituto de Biociências, Letras e Ciências \\ Exatas da Universidade Estadual Paulista \\ "Júlio de Mesquita Filho" Campus de São José \\ do Rio Preto. \\ Orientadora: Profa. Dra. Vânia Regina \\ Nicoletti Telis \\ Co-orientadora: Dra. Geórgia Álvares Castro \\ Fernandes
}

São José do Rio Preto - SP 


\section{ESTUDO REOLÓGICO DE SISTEMAS GELATINA/COLÁGENO/AMIDO PARA OBTENÇÃO DE GÉIS E APLICAÇÃO EM GOMAS DIETÉTICAS DE GELATINA}

Dissertação apresentada para obtenção do título de mestre em Engenharia e Ciência de Alimentos, área de Engenharia de Alimentos junto ao Programa de Pós-graduação em Engenharia e Ciência de Alimentos do Instituto de Biociências, Letras e Ciências Exatas da Universidade Estadual Paulista "Júlio de Mesquita Filho" Campus de São José do Rio Preto.

BANCA EXAMINADORA

Profa. Dra. Vânia Regina Nicoletti Telis (Presidente / Orientadora - DETA / IBILCE)

Profa. Dra. Rosiane Lopes da Cunha ( $2^{\circ}$ Examinador - FEA / UNICAMP)

Profa. Dra. Célia Maria Landi Franco

$\left(3^{\circ}\right.$ Examinador - DETA / IBILCE)

São José do Rio Preto, 18 de março de 2010. 


\section{DADOS CURRICULARES}

\section{PAULO HENRIQUE MARIANO MARFIL}

16/01/1984 - Indiaporã - SP

FILIAÇÃO

Mauricio Orlando Marfil

Leide Souza Mariano Marfil

$2003 / 2007$

Curso de graduação em Engenharia de Alimentos - Instituto de Biociências, Letras e Ciências Exatas da UNESP, Campus de São José do Rio Preto - SP

$2008 / 2010$

Curso de Pós-graduação em Engenharia e Ciência de Alimentos, nível Mestrado, no Instituto de Biociências, Letras e Ciências Exatas da UNESP, Campus de São José do Rio Preto - SP 
"De tudo ficaram três coisas: A certeza de que estamos sempre começando... A certeza de que é preciso continuar... A certeza de que podemos ser interrompidos antes de terminar... Façamos da interrupção um novo caminho; Da queda um passo de dança; Do medo uma escada; Do sonho uma ponte; E da procura... Um encontro.” 
Às pessoas que mais amo e admiro, meus pais Maurício e Leide, que sempre me incentivaram nos estudos e nunca mediram esforços para proporcionar o meu crescimento e minha felicidade.

A Ana Carolina, por todo amor, carinho e apoio diário. Por ser esta pessoa maravilhosa que Deus colocou em minha vida. 


\section{AGRADECIMENTOS}

Em especial, à Prof. Dra. Vânia Regina Nicoletti Telis, por todo o aprendizado, seriedade e dinamismo no decorrer deste trabalho e de todos os anos que trabalhamos juntos. Pelo exemplo de competência e dedicação, pela orientação segura e fiel, pela preocupação com o meu trabalho, pelas sugestões e pela grande amizade.

À Prof. Dra. Célia Maria Landi Franco, pelas sugestões durante o exame de qualificação, pela ajuda nas discussões sobre os resultados de microscopia e pela disponibilidade em participar como membro titular da banca examinadora.

Ao Prof. Dr. José Francisco Lopes Filho, pelas sugestões durante o exame de qualificação.

À Prof. Dra. Rosiane Lopes da Cunha, pela ajuda na técnica de microscopia laser confocal e pela disponibilidade na correção deste trabalho participando como membro titular da banca examinadora.

Ao Dr. Paulo Filemon Paolucci Pimenta e Fernanda Gambogi Oliveira, chefe e técnica, respectivamente, do Laboratório de Entomologia Médica (CPqRR/FIOCRUZ) pela análise do material no microscópio laser confocal e microscópio eletrônico de varredura.

À Prof. Dra. Maria Aparecida Mauro pelo uso de seu laboratório e equipamentos.

À Dra. Geórgia Álvares Castro Fernandes, pela co-orientação deste trabalho, pela disponibilidade em sempre ajudar e por todas as sugestões.

Às empresas Gelita, Corn Products, Tovani Benzaquen, e Firmenich pela doação de amostras de materiais.

À Universidade Estadual Paulista (UNESP / IBILCE) por ter proporcionado a realização de um grande sonho e os melhores anos de minha vida.

À CAPES pela bolsa de estudos e à FAPESP pelo auxílio financeiro.

Aos professores de graduação e pós-graduação, por todos os ensinamentos e por contribuírem com a minha formação e crescimento profissional, em especial professora Cida, João Cláudio, Roger e Javier. 
Aos técnicos de laboratório, em especial ao Newton, pela paciência e ajuda constante e também à secretária Sueli, pela atenção e disponibilidade em ajudar.

Aos amigos de graduação, pois mesmo distantes, mantemos vivo nosso contato, nossa amizade e carinho, em especial Augusto, Raphael, Fabtcho, Ln, Magel, Luana, Flavinha, Terumi, Ellen e Kelly.

Aos amigos de pós-graduação em especial Lina, Kelly e Alex, pelo apoio e amizade sincera.

Aos colegas de laboratório, pelo convívio, discussões acadêmicas, momentos de descontração e pela ajuda e apoio constante.

Aos meus amigos de república, em especial Harvey, Matheus e Rafael, muito obrigado pela amizade verdadeira e pela agradável convivência.

Às pessoas que mais amo e admiro, meus pais Maurício e Neide, que sempre me incentivaram nos estudos e nunca mediram esforços para proporcionar o melhor a mim e meu irmão. Muito obrigado pelo amparo e carinho, pela dedicação na educação dos filhos, pelo exemplo de bondade, responsabilidade e respeito.

À Ana Carolina, que sempre esteve disposta a me ajudar em tudo. Muito obrigado pelo amor infinito, pelo carinho, compreensão, companheirismo verdadeiro e incentivo. Por ser esta pessoa tão especial e amiga, que me faz muito feliz. Amo você!

Ao meu irmão Pedro, pelos momentos felizes, pelas risadas e brincadeiras, pelo incentivo e apoio constantes.

À minha família, em especial avô Dito, avó Preta, tio Ronaldo, tia Cidinha e tia Lu, obrigado pela confiança e incentivo prestados em todos os momentos, pela torcida permanente.

À minha segunda família, Sr. Sérgio, D. Vera, Jr e Bruninho, por todos os momentos juntos, por serem pessoas tão especiais e pela torcida permanente.

A todos aqueles que contribuíram, direta ou indiretamente, para a realização deste trabalho.

E, finalmente a Deus, pelo dom da vida, pelas oportunidades oferecidas e pela iluminação em mais uma etapa vencida. 


\section{ÍNDICE}

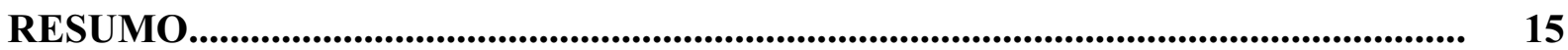

ABSTRACT ............................................................................................................. 16

Capítulo 1 - Introdução e objetivos........................................................................................ 17

1.1 Introdução geral......................................................................................... 18

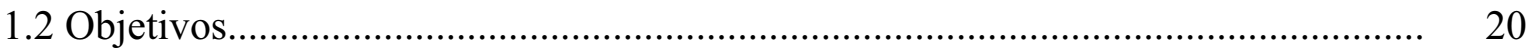

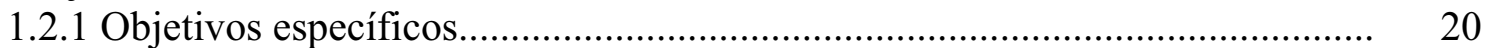

1.3 Organização do trabalho em capítulos........................................................................ 21

Capítulo 2 - Revisão bibliográfica.............................................................................

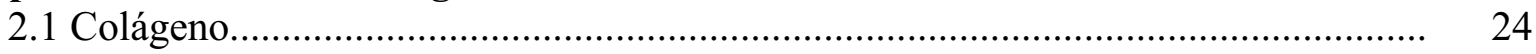

2.2 Gelatina

2.3 Amido de milho modificado.............................................................................. 27

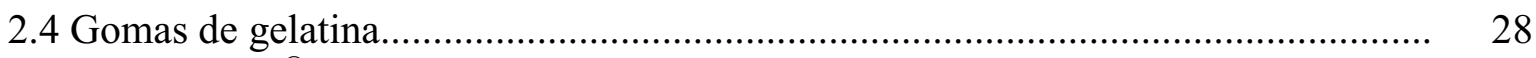

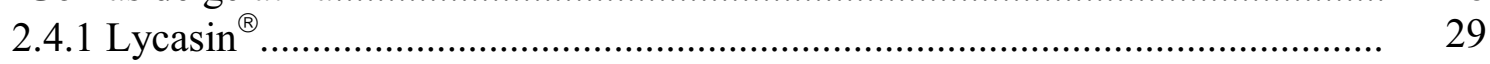

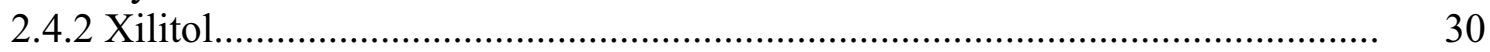

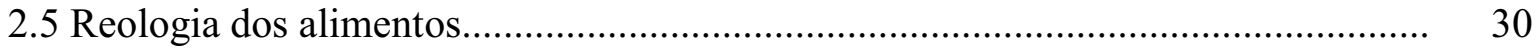

2.6 Comportamento reológico sob cisalhamento oscilatório........................................... 31

2.6.1 Rampa de freqüência............................................................................. 34

2.6.2 Rampa de temperatura................................................................................ 35

2.6.3 Análise do ângulo de fase $(\delta)$.................................................................. 35

2.7 Comportamento reológico em compressão.............................................................. 36

2.8 Propriedades ópticas.................................................................................. 38

2.9 Microscopia............................................................................................... 40

Capítulo 3 - Estudo reológico de soluções gelatina / colágeno hidrolisado e RESUMO...... aplicação em gomas dietéticas de gelatina............................................... 42

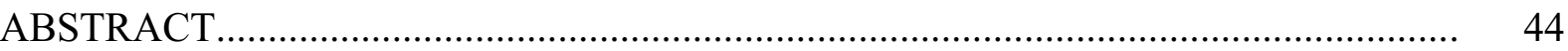

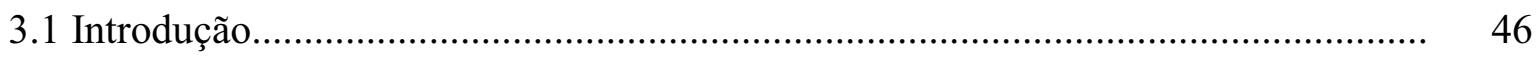

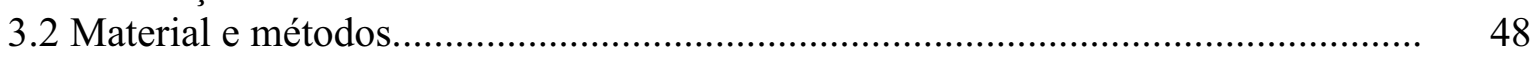

3.2.1 Material......................................................................................... 48

3.2.2 Preparo das amostras para ensaios reológicos.......................................... 48

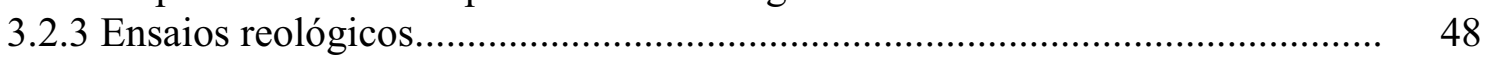

3.2.4 Preparo das gomas............................................................................. 49

3.2.5 Ensaios reológicos em compressão - (TPA)................................................ 51

3.2.6 Determinação das propriedades ópticas..................................................... 51

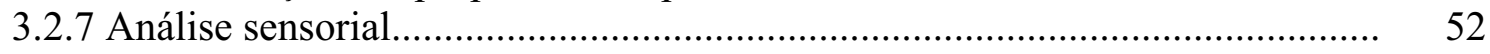

3.2.8 Microscopia eletrônica de varredura (MEV) ............................................. 52

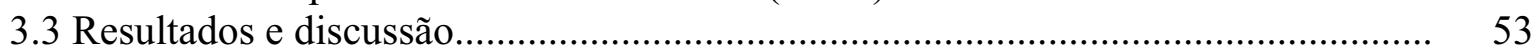

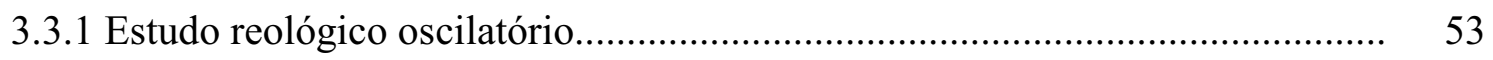

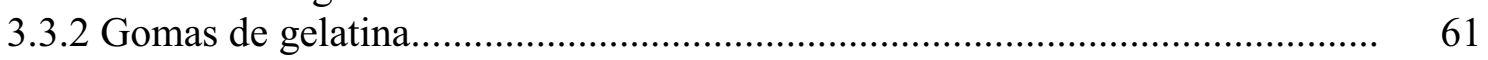

3.3.2.1 Estudo reológico por compressão..................................................... 61

3.3.2.2 Propriedades ópticas....................................................................... 65

3.3.2.3 Análise sensorial.......................................................................... 67

3.3.2.4 Microscopia eletrônica de varredura (MEV)...................................... 67

3.4 Conclusões........................................................................................................ 68 


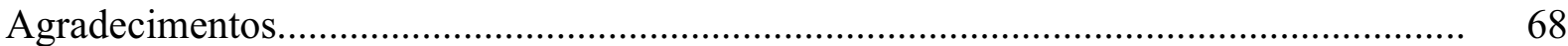

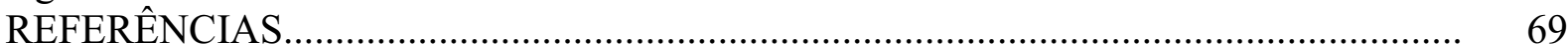

Capítulo 4 - Estudo reológico e microestrutural de soluções aquosas de gelatina e amido de milho modificado.............................................................................. 71

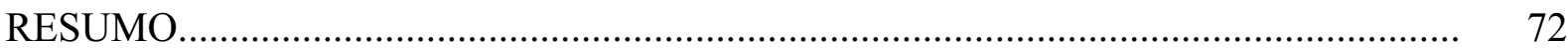

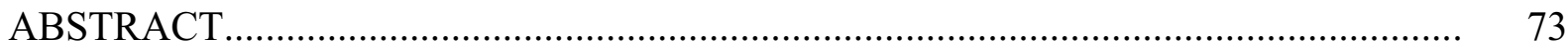

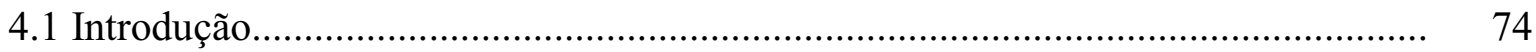

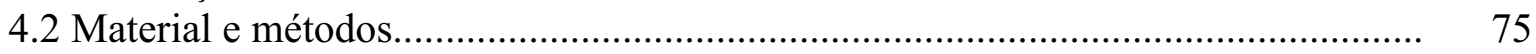

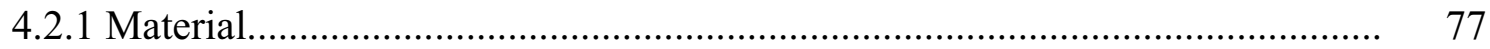

4.2.2 Preparo das amostras para ensaios reológicos............................................. 77

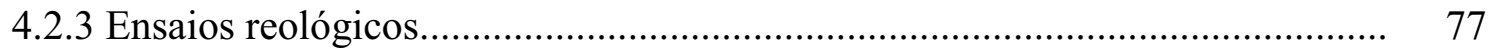

4.2.4 Microscopia Laser Confocal (MLC) .......................................................... 78

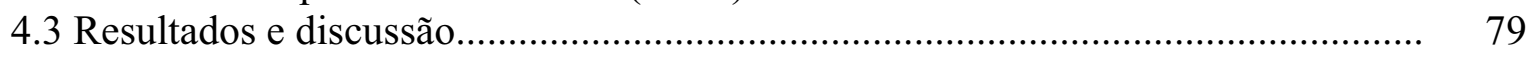

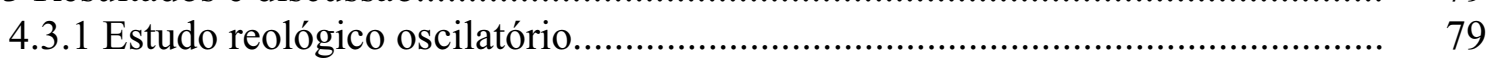

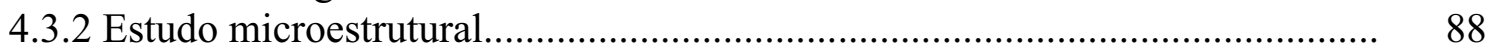

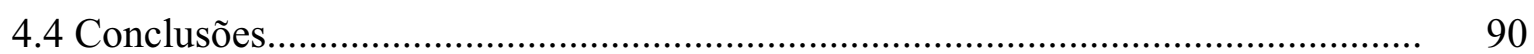

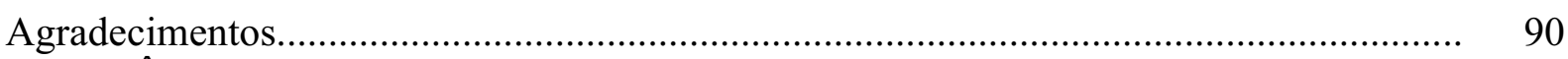

REFERÊNCIAS

Capítulo 5 - Texture and microstructure of gelatin / corn starch-based gummy confections.......................................................................................................... 95

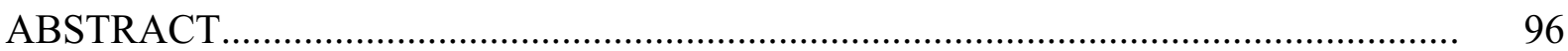

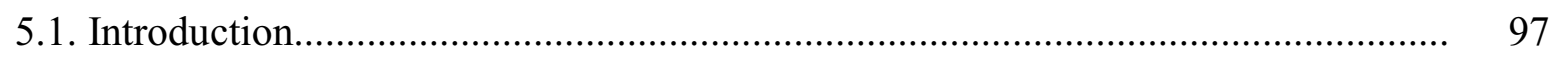

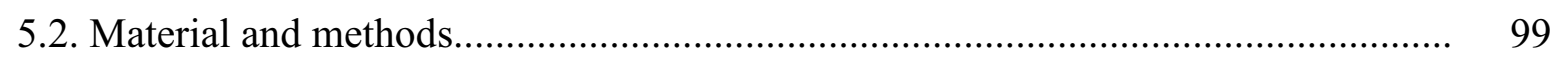

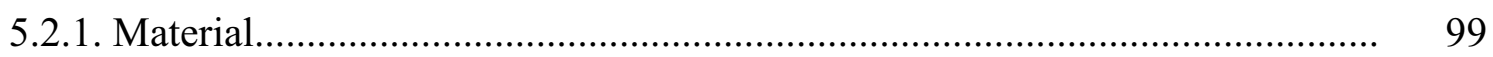

5.2.2. Preparation of gelatin/corn starch gels..................................................... 99

5.2.3. Mechanical properties...................................................................... 100

5.2.4. Opacity ............................................................................................. 101

5.2.5. Scanning electronic microscopy (SEM) .................................................. 102

5.2.6. Confocal laser scanning microscopy (CLSM) ......................................... 102

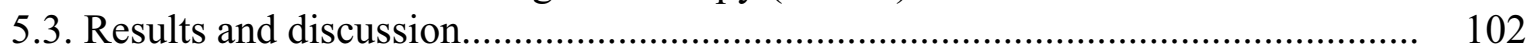

5.3.1. Mechanical properties............................................................................ 102

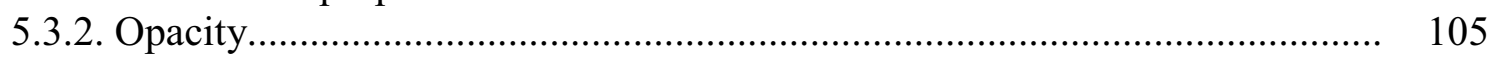

$\begin{array}{ll}\text { 5.3.3 Microscopy structure } & 106\end{array}$

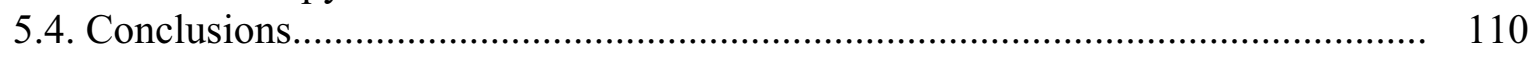

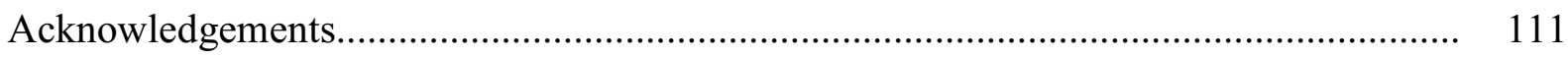

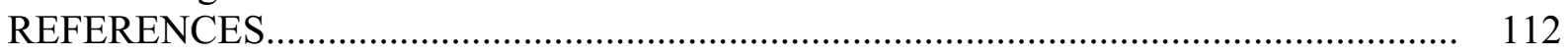

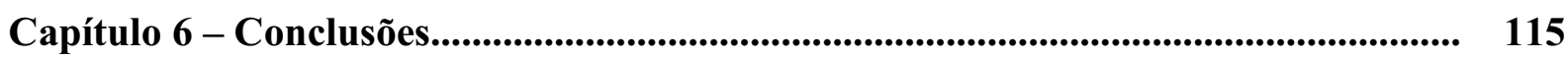

Capítulo 7 - Referências bibliográficas............................................................... 118

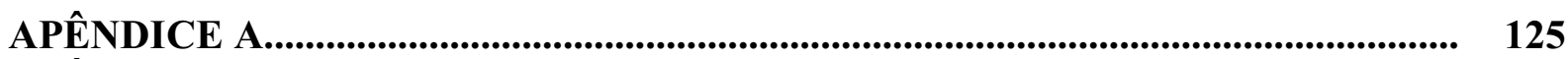

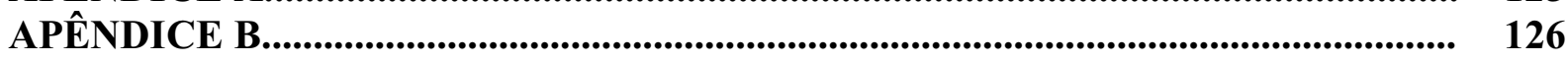




\section{LISTA DE TABELAS}

Tabela 3.1 - Planejamento experimental para preparo das gomas de gelatina.............

Table 5.1 - Formulations of gelatin and AMCS gels of groups 1 and 2

Table 5.2 - Hardness, fracturability, stringiness, adhesiveness, springiness and opacity values of gelatin and AMCS gels (Group 1).

Table 5.3 - Hardness, fracturability, stringiness, adhesiveness, springiness and opacity values of gelatin and AMCS gels containing $8 \mathrm{wt} \%$ gelatin and 0-5 wt\% AMCS (Group 2) 


\section{LISTA DE FIGURAS}

\section{Capítulo 2}

Figura 2.1 - Estrutura repetida da gelatina, responsável pela estrutura em tripla hélice (BUREY, et al., 2008).....

Figura 2.2 - Resposta da tensão e deformação de um líquido Newtoniano e de um sólido perfeitamente elástico em testes dinâmicos. Linhas sólidas $=$ deformação. Linhas pontilhadas = tensão. $\mathbf{A}=$ Sólido elástico, tensão e deformação em fase. $\mathbf{B}$ = Líquido Newtoniano, tensão e deformação defasados em $90^{\circ} . \mathbf{C}=$ Material viscoelástico, tensão e deformação com defasagens menores que $90^{\circ}$

Figura 2.3 - Variação do ângulo de fase $(\delta)$ com a freqüência $(\omega)$ para materiais típicos. A linha do limite superior se refere a um fluido Newtoniano $(\delta$ $=\pi / 2)$ e a do limite inferior a um sólido Hookeano $(\delta=0)$ (STEFFE, 1996)

Figura 2.4 - Curva característica do perfil de textura (Adaptado de BOURNE, KENNY e BARNARD, 1978 apud STEFFE, 1996).

Capítulo 3

Figura 3.1 - Processo de elaboração das gomas de gelatina

Figura 3.2 - Variação do ângulo de fase $(\delta)$ com a freqüência $(\omega)$ para gelatina e colágeno hidrolisado puros, nas concentrações de 4 e $10 \%$. ( $\square=4 \%$

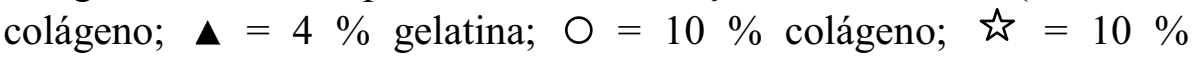
gelatina)

Figura 3.3 - Módulos de armazenamento (G') e dissipação ( $\left.G^{\prime \prime}\right)$ na faixa de freqüências de 0,1 a 100 rad.s $^{-1}$ de soluções aquosas de gelatina e colágeno hidrolisado. (A) 4\% sólidos totais. (B) 10\% sólidos totais. Símbolos abertos $=G^{\prime}$, fechados $=G^{\prime \prime}$. Proporção, (\% em massa), gelatina e colágeno hidrolisado, respectivamente: $\square=0: 100$; $\triangle=25: 75 ; \quad \bigcirc=50: 50 ; \quad \Sigma=75: 25 ; \square=100: 0$.

Figura 3.4 - Efeito da concentração de gelatina sobre o módulo de armazenamento (G`) nas soluções contendo gelatina e colágeno hidrolisado. Símbolos abertos $=10 \%$ de sólidos totais. Símbolos fechados $=4 \%$ de sólidos totais

Figura 3.5 - Efeito da concentração de gelatina e colágeno (\% em massa) sobre o módulo de armazenamento $\left(G^{`}\right)$ na região de baixa freqüência angular $\left(0,1\right.$ a $\left.1,0 \mathrm{rad} . \mathrm{s}^{-1}\right)$ a $20{ }^{\circ} \mathrm{C}$. Sólidos totais $=10 \%$. Proporção, $(\% \mathrm{em}$ massa), gelatina e colágeno hidrolisado, respectivamente: $\square=0: 100$; $\triangle=25: 75 ; \quad \bigcirc=50: 50 ; \quad$ 咛 $=75: 25 ; \quad \square=$ 100:0 
Figura 3.6 - Módulo de armazenamento $\left(G^{\prime}\right)$ em função do tempo nas rampas de temperatura estudadas para diferentes soluções aquosas de gelatina e colágeno hidrolisado, todas com $4 \%$ de sólidos totais. Proporção, $(\%$ em massa), gelatina e colágeno hidrolisado, respectivamente: $\square=0: 100 ; \quad \Delta=25: 75 ; \quad \bigcirc=50: 50 ; \quad$ 次 $=75: 25 ; \quad \square=$ 100:0

Figura 3.7 - Módulo de armazenamento $\left(G^{\prime}\right)$ em função do tempo nas rampas de temperatura estudadas para diferentes soluções aquosas de gelatina e colágeno hidrolisado, todas com $10 \%$ de sólidos totais. Proporção, (\% em massa), gelatina e colágeno hidrolisado, respectivamente: $\square=0: 100 ; \Delta=25: 75 ; \bigcirc=50: 50 ; \zeta=75: 25 ; \square=100: 0 \ldots \ldots \ldots$

Figura 3.8 - Módulo de armazenamento $\left(G^{`}\right)$ em função de aquecimento de 20 a 80 ${ }^{\circ} \mathrm{C}$, para diferentes concentrações de gelatina, nos sistemas contendo gelatina e colágeno hidrolisado (10 \% de sólidos totais). Proporção, (\% em massa), gelatina e colágeno hidrolisado, respectivamente:

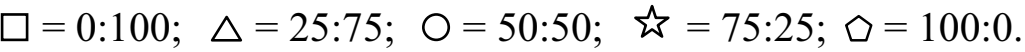

Figura 3.9 - Superfície de resposta do parâmetro dureza, variando-se concentração de gelatina e de colágeno hidrolisado.

Figura 3.10 - Gráficos de contorno dos parâmetros avaliados no teste TPA, variando-se concentração de gelatina e de colágeno hidrolisado. (A) Gomosidade. (B) Mastigabilidade.

Figura 3.11 - Superfície de resposta do parâmetro adesividade, variando-se concentração de gelatina e de colágeno hidrolisado.

Figura 3.12 - Superfície de resposta do parâmetro opacidade, variando-se concentração de gelatina e de colágeno hidrolisado.

Figura 3.13 - Relação linear da diferença de cor em função da massa de gelatina e colágeno hidrolisado utilizada na elaboração dos géis a base de xarope de maltitol e xilitol

Figura 3.14 - Microscopia eletrônica de varredura (MEV) de uma goma contendo (A) apenas gelatina e (B) gelatina com colágeno hidrolisado (ponto central: $9 \%$ de gelatina e $5 \%$ de colágeno hidrolisado)

\section{Capítulo 4}

Figura 4.1 - Variação do ângulo de fase $(\delta)$ com a freqüência $(\omega)$ para gelatina nas concentrações de 4 e $10 \%$ e para AMMA na concentração de $10 \%$. ( $\Delta=4 \%$ gelatina; $\boldsymbol{\Sigma}=10 \%$ gelatina; $\bullet=10 \%$ amido).

Figura 4.2 - Módulos de armazenamento $\left(G^{\prime}\right)$ e dissipação $\left(G^{\prime \prime}\right)$ na faixa de freqüências de 0,1 a 100 rad.s ${ }^{-1}$ de solução aquosa de amido de milho modificado (10\%) a $20{ }^{\circ} \mathrm{C}$. (A) Antes do aquecimento. (B) Depois do aquecimento. Símbolos abertos $=G^{\prime}$, fechados $=G^{\prime \prime}$ 
Figura 4.3 - Módulos de armazenamento ( $\left.G^{\prime}\right)$ e dissipação ( $\left.G^{\prime \prime}\right)$ na faixa de freqüências de 0,1 a $100 \mathrm{rad} . \mathrm{s}^{-1}$ de solução aquosa de gelatina e amido de milho modificado (10\% sólidos totais). Símbolos abertos $=\mathrm{G}^{\prime}$, fechados $=G^{\prime \prime}$. Proporção, (\% em massa), gelatina e amido de milho modificado, respectivamente: $\square=0: 100 ; \Delta=25: 75$; $\bigcirc=50: 50$; 放 $=75: 25 ; \square=100: 0$

Figura 4.4 - Efeito da concentração de gelatina sobre o módulo de armazenamento $\left(G^{\prime}\right)$ nas suspensões contendo gelatina e amido de milho modificado de forma ácida ( $10 \%$ de sólidos totais).

Figura 4.5 - Imagens seriadas obtidas no microscópio laser confocal de géis de gelatina (G) / amido modificado (A) (distância entre os cortes seriados de $3 \mu \mathrm{m})$. A) $12,5: 87,5$; B) $25: 75$; C) $37,5: 62,5$; D) $50: 50$; E) $75: 25 \ldots \ldots$.

Figura 4.6 - Módulo de armazenamento $\left(G^{\prime}\right)$ em função do tempo nas rampas de temperatura estudadas para diferentes suspensões aquosas de gelatina e amido de milho modificado, todas com $10 \%$ de sólidos totais. Proporção, (\% em massa), gelatina e amido modificado, respectivamente: $\square=0: 100 ; \Delta=25: 75 ; \quad O=50: 50 ; \quad \square=75: 25$; $\checkmark=100: 0$

Figura 4.7 - Módulo de armazenamento $\left(G^{`}\right)$ em função de aquecimento de 20 a 80 ${ }^{\circ} \mathrm{C}$, para diferentes concentrações de gelatina, nos sistemas contendo gelatina e amido de milho modificado (10\% de sólidos totais). Proporção, (\% em massa), gelatina e amido modificado, respectivamente: $\square=0: 100 ; \Delta=25: 75 ; O=50: 50$; 柁 $=75: 25$; $\checkmark=100: 0$

\section{Capítulo 5}

Figure 5.1 - Schematic diagram showing processing steps used to prepare gelatin and AMCS gel samples.

Figure 5.2 - Texture profile analysis of gelatin:AMCS gels (10 wt $\%$ solids) in different proportions, respectively: 10:0 (closed squares); 9:1 (open triangles); 8:2 (closed circles); 7:3 (open stars); 0:10 (cross).

Figure 5.3 - Texture profile analysis of gelatin:AMCS gels containing $8 \mathrm{wt} \%$ gelatin and different AMCS contents: $0 \%$ (closed squares); $1 \%$ (open triangles); $2 \%$ (closed circles); $3 \%$ (open stars); $4 \%$ (cross); $5 \%$ (plus signs).

Figure 5.4 - SEM images of blended systems containing $8 \mathrm{wt} \%$ gelatin and zero (A), $1 \mathrm{wt} \%$ (B), $3 \mathrm{wt} \%$ (C) and $5 \mathrm{wt} \%$ (D) AMCS

Figure 5.5 - CSLM images of blended systems containing zero (A), 1 wt $\%$ (B), 2 $\mathrm{wt} \%$ (C), $3 \mathrm{wt} \%$ (D), $4 \mathrm{wt} \%$ (E) and $5 \mathrm{wt} \%$ (F) AMCS. Grayish (or reddish) regions are rich in gelatin. 
Figure 5.6 - CSLM images of cross-sections of 8G1S (A, B, C) and 8G5S (D, E, F) samples showing some AMCS in the gelatin network (distance

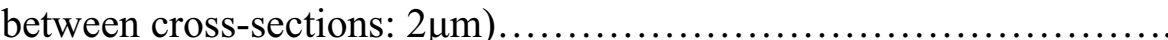

APÊNDICE A

Figura A1 - Escala hedônica facial de cinco pontos utilizada para análise sensorial com crianças.

Figura A2 - Escala hedônica de nove pontos utilizada para análise sensorial com adultos

APÊNDICE B

Figura B1 - Micrografias de varredura de grânulos de amido de milho modificado de forma ácida (A-D), gelatina (E-H) e colágeno hidrolizado (I-L) não tratados 


\section{RESUMO}

O comportamento reológico de soluções aquosas de gelatina e colágeno hidrolisado (4 e $10 \%$ de sólidos totais) e de gelatina e amido de milho modificado de forma ácida (AMMA) (10\% de sólidos totais) foi estudado através de testes dinâmicos oscilatórios em um reômetro de tensão controlada com geometria cone e placa $(60 \mathrm{~mm}$ de diâmetro e distância de trabalho de $52 \mu \mathrm{m})$. Para todas as concentrações, o módulo de armazenamento, G', aumentou com aumento da freqüência angular. Como esperado, os valores dos módulos correspondentes aos platôs aumentou com o aumento da concentração de gelatina e os valores de G’ foram maiores nas soluções contendo amido. Os valores de G` e $G^{\prime \prime}$ aumentaram com a diminuição da temperatura. O colágeno hidrolisado não apresentou comportamento de gel. A substituição de $25 \%$ de gelatina por amido de milho modificado resultou em valores similares de G' nas amostras contendo somente gelatina. Foi realizado um estudo de separação de fases nas suspensões aquosas de gelatina e AMMA através de microscopia laser confocal, sendo observado que os biopolímeros co-existem, sem separação de fases na amostra em que gelatina e AMMA representam, respectivamente, 37,5 \% e 62,5 \% dos sólidos totais. Em geral, os demais sistemas apresentaram separação de fases, sendo esta mais pronunciada à medida que as amostras foram ficando enriquecidas com gelatina ou amido. Também foi estudado o comportamento reológico por compressão e as propriedades colorimétricas de gomas de gelatina dietéticas enriquecidas com colágeno hidrolisado e preparadas à base de xarope de maltitol e xilitol. A análise dos parâmetros de textura e o estudo colorimétrico permitiram observar que não há efeitos significativos $(\mathrm{p}<0,05)$ na interação entre concentração de gelatina e colágeno hidrolisado quanto à dureza das amostras. Além disso, a maior concentração destes componentes resultou numa maior opacidade. O comportamento reológico por compressão e as propriedades ópticas de géis de gelatina com AMMA também foram estudados. A adição de AMMA aos géis de gelatina resultou numa grande mudança de estrutura. A adição de $1 \%$ de AMMA resultou num gel termodinamicamente estável, sendo que em maiores concentrações de amido o resultado é uma incompatibilidade termodinâmica, evidenciada pelo maior número de espaços vazios e grânulos não entumescidos. Por outro lado, há um aumento da dureza e opacidade e uma diminuição da pegajosidade e adesividade. 


\begin{abstract}
The rheological behavior of aqueous solutions of gelatin and hydrolyzed collagen (4 and $10 \%$ total solids) or gelatin and acid modified corn starch (AMCS) (10\% total solids) was studied. A controlled stress rheometer fitted with a cone and plate geometry $(60 \mathrm{~mm}$, gap $52 \mu \mathrm{m})$ was used for the dynamic oscillatory shear tests. For all concentrations, the storage modulus increased with the increasing angular frequency. As expected, the modulus plateau values increased with gelatin concentration increasing and $G^{\prime}$ was higher in the solutions with modified corn starch. $G^{\prime}$ and $G^{\prime \prime}$ values attained the highest observed values at lower temperatures. Hydrolyzed collagen did not show gel formation ability. When $25 \%$ of the gelatin content was substituted by AMCS, the observed values of $G^{\prime}$ were similar to those corresponding to pure gelatin suspensions. A phase separation study was carried out with gelatin and AMCS aqueous suspensions using confocal laser scanning microscopy. The results showed that the two biopolymers co-exist, without phase separation in a system containing $37,5 \%$ of gelatin and $62,5 \%$ of AMCS (based in a $10 \mathrm{wt} \%$ total solids). In general, the others systems showed phase separation, which was more intense with increasing gelatin/AMCS concentration. The rheological behavior in compression and the optical proprieties of diet gelatin gummy enriched with hydrolyzed collagen were also studied. The gummies were prepared with maltitol syrup and xilitol. The analysis of texture and opacity parameters showed that significant effects $(p<0.05)$ were not observed in the interaction between the two factors with regard to samples hardness. High concentrations of gelatin and hydrolyzed collagen resulted in a high opacity. The rheological behavior in compression and the optical proprieties of gelatin/AMMA gels were also studied. When AMCS was introduced into gelatin gels, the system structure changed in a dramatically manner. The addition of 1 $\mathrm{wt} \%$ AMCS formed a thermodynamically stable gel. However, increasing AMCS concentration modified the structure of gelatin network, showing a thermodynamic incompatibility, a higher number of hollow zones and unswollen starch granules. In addition, increasing hardness and opacity and decreasing stringiness and adhesiveness was observed.
\end{abstract}




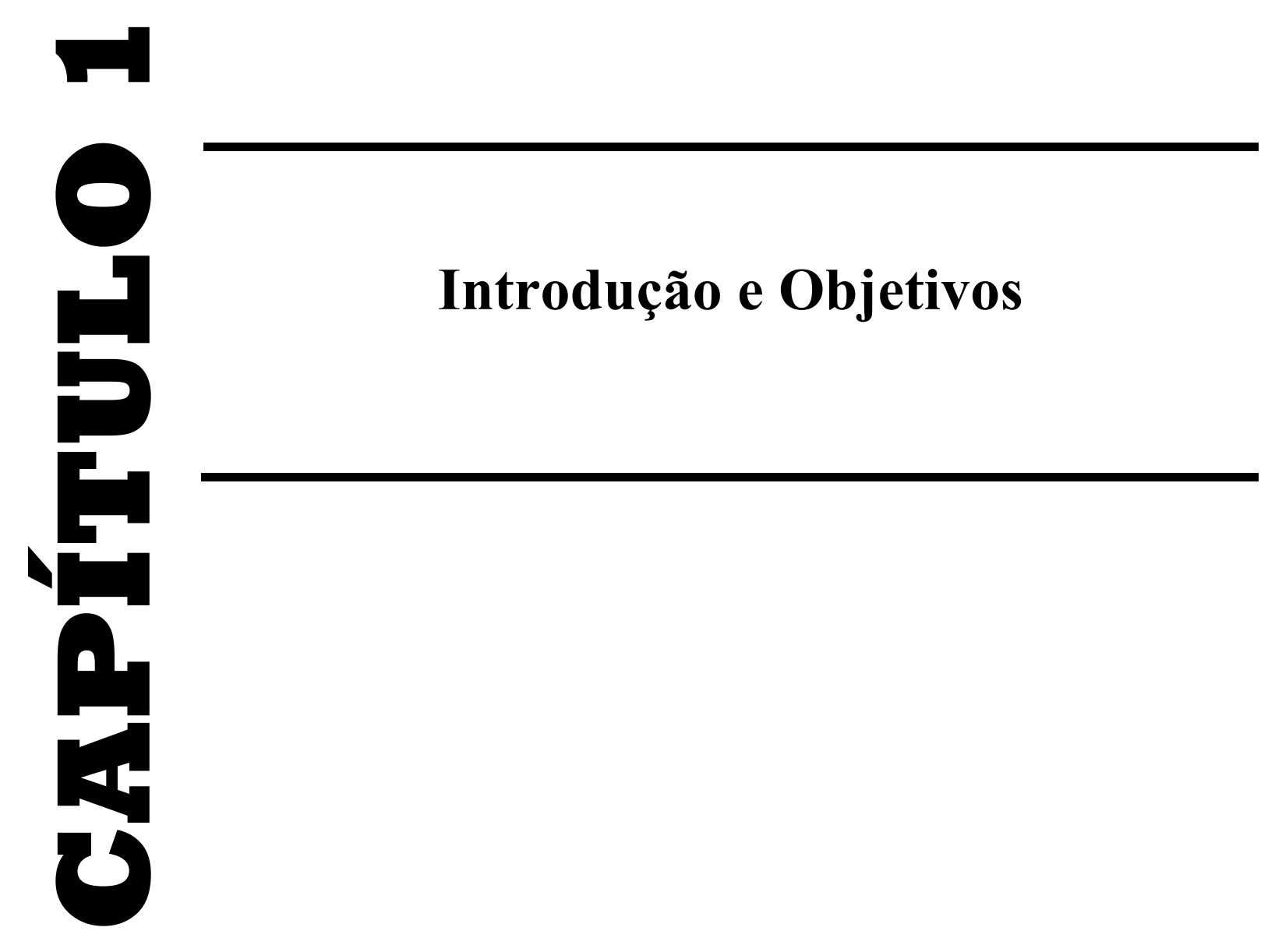




\subsection{INTRODUCÃO GERAL}

Proteínas e polissacarídeos são biopolímeros que contribuem para as propriedades estruturais e de textura de alimentos através de seu poder de agregação ou gelificação. Grande parte dos alimentos processados pode ser classificada como colóides alimentícios e muitos deles contêm hidrocolóides - biopolímeros hidrofílicos de alto peso molecular - adicionados com o objetivo de controlar sua estabilidade e propriedades reológicas (DICKINSON, 2003). Além da indústria de produtos alimentícios, os biopolímeros encontram cada vez mais aplicações na indústria farmacêutica, de cosméticos, engenharia biomédica, embalagens biodegradáveis e outros.

Existem grandes diferenças entre as propriedades funcionais dos vários biopolímeros, dependendo de sua estrutura química e sensibilidade às condições da solução na qual são incorporados ( $\mathrm{pH}$, força iônica, presença de íons específicos). Atualmente, existe uma forte tendência no sentido de explorar as propriedades de misturas de diferentes biopolímeros, que podem resultar em materiais com diversas possibilidades de aplicação, como no caso de misturas de proteínas e polissacarídeos. Esses dois tipos de macromoléculas estão presentes em conjunto em vários tipos de alimentos e ambos contribuem para a estrutura, textura e estabilidade do produto através de seu comportamento espessante ou gelificante - associado em maior grau aos polissacarídeos -, ou surfactante - característico das proteínas (DOUBLIER et al., 2000; DICKINSON, 2003).

No Brasil, existe uma disponibilidade muito grande de resíduos de proteínas, principalmente colágeno, face à produção de animais de corte (bovinos, suínos e aves). No entanto, não existe um aproveitamento racional destas proteínas. Sugere-se que o colágeno exiba características semelhantes de ligação de água e de gordura em relação à miosina e actina, as principais proteínas na estabilização de emulsões em carnes processadas convencionalmente. O tecido conjuntivo, na forma "in natura" ou cozido, tem sido largamente utilizado na industrialização de produtos cárneos. Contudo, essa utilização é realizada, basicamente, como aproveitamento industrial de abatedouros. Mesmo assim, muito colágeno não é aproveitado, perdendo-se na forma de subprodutos (peles, tendões, aponevroses e órgãos) destinados à produção de ração animal e até mesmo desprezados, poluindo o meio ambiente (OLIVO e SHIMOKOMAKI, 2002).

As balas de goma são uma grande classe de confeitos de baixa cocção e com alto conteúdo de umidade (cerca de $20 \%$ ou mais) cuja textura é fornecida pelo agente gelificante 
utilizado, podendo ser goma arábica, ágar, gelatina, pectina e amidos especiais (JACKSON e LEES, 1973; QUEIROZ, 1999). Garcia (2000) cita que os fatores determinantes para a aceitação e preferência dos consumidores em relação às gomas de gelatina são sua textura, a boa claridade ou ausência de turbidez e a cor clara e brilhante.

As balas de gelatina ou gomas de gelatina são confeitos muito populares na Europa e Estados Unidos, disponíveis em vários formatos, cores e sabores, inclusive na sua forma tradicional de ursinhos. No Brasil, entretanto, as balas gelificadas são preferencialmente fabricadas com amidos (QUEIROZ, 1999).

O aparecimento da categoria de confeitos funcionais ou confeitos fortificados é uma tendência mundial englobando os produtos fortificados com vitaminas, minerais ou outros ingredientes com algum aspecto nutricional ou propriedade relacionada à saúde. Nesse sentido, a adição de colágeno hidrolisado a uma formulação tradicional à base de gelatina poderia resultar em um produto com um teor protéico superior aos produtos tradicionais. Ao mesmo tempo, se a sacarose e o xarope de glicose, geralmente utilizados nas formulações mais comuns, forem substituídos por ingredientes não-calóricos como o xilitol e o xarope de maltitol, o produto resultante poderia também ser considerado dietético.

Alimentos adicionados de agentes gelificantes como amido ou gelatina podem desenvolver uma rede tridimensional, definida como um gel. Quando submetidos ao cisalhamento, essa estrutura pode ser quebrada, diminuindo a viscosidade e esses materiais existem no estado sol. Em alimentos que mostram reversibilidade, a rede é reconstruída e o estado de gel obtido novamente. Materiais irreversíveis permanecem no estado sol. Para o estudo de transição sol-gel em alimentos, medidas reológicas em baixo ângulo de oscilação podem ser empregadas com sucesso através da análise do comportamento do módulo de armazenamento (G`) (STEFFE, 1996; BUREY et al., 2009).

Para o desenvolvimento de produtos formulados a partir da combinação de biopolímeros, uma etapa importante é o estudo reológico dessas misturas ainda no estado fluido (estado sol), uma vez que as características e o comportamento dos géis formados por esses compostos sozinhos ou combinados podem ser melhor compreendidos a partir desse estudo. 


\subsection{OBJETIVOS}

Com base nas considerações anteriores, o objetivo geral deste trabalho foi avaliar o comportamento reológico de misturas de gelatina e colágeno hidrolisado, de modo a obter subsídios para o desenvolvimento de uma goma de gelatina dietética e rica em proteínas que se distingue das tradicionais por não conter sacarose nem xarope de glicose, sendo ainda, fonte de proteína colagênica e apresentando textura elástica e consistência firme. Também através dos estudos reológicos, investigou-se a possibilidade da substituição de parte da gelatina por uma matéria-prima de menor custo, como é o caso do amido de milho modificado.

\subsubsection{Objetivos específicos}

De modo a atingir o objetivo geral exposto acima, o trabalho foi conduzido em etapas que se complementam entre si. De forma mais específica, foram investigados:

1) O comportamento reológico de soluções aquosas contendo gelatina e colágeno hidrolisado e aplicação destes componentes no desenvolvimento de balas de gelatina dietéticas enriquecidas com colágeno hidrolisado.

2) O comportamento reológico de soluções aquosas contendo gelatina e amido de milho modificado em diferentes proporções e numa ampla faixa de temperatura, avaliando-se a ocorrência de separação de fases entre esses componentes por microscopia laser confocal.

3) Estudo reológico e microestrutural (microscopia eletrônica de varredura e laser confocal) de géis elaborados com gelatina e amido de milho modificado numa base de xarope de maltitol e xilitol. 


\subsection{ORGANIZACẼO DO TRABALHO EM CAPÍTULOS}

O presente trabalho encontra-se estruturado da seguinte forma:

\section{Capítulo 1 - Introdução geral}

Capítulo 2 - Revisão bibliográfica: neste capítulo são apresentadas informações a respeito das proteínas e polissacarídeos utilizados, ou seja, informações sobre o colágeno hidrolisado, gelatina e amido de milho modificado. Também é discutida a importância do desenvolvimento de balas e confeitos funcionais, bem como as matérias-primas utilizadas na

formulação das gomas de gelatina dietéticas. É discutida a importância dos testes reológicos em cisalhamento oscilatório e em compressão, como forma de obtenção das propriedades mecânicas de alimentos. Também são apresentadas informações sobre propriedades ópticas e sobre o uso destas como parâmetros para controle de qualidade de produtos processados. Por fim, é discutida a importância do uso da microscopia como ferramenta para o estudo da microestrutura de diferentes sistemas, auxiliando, entre outros, no entendimento de interações entre diferentes compostos, como por exemplo, entre proteínas e polissacarídeos.

\section{Capítulo 3 - Estudo reológico de soluções gelatina/colágeno hidrolisado e aplicação em} gomas dietéticas de gelatina: este capítulo apresenta o estudo do comportamento reológico de soluções contendo gelatina e colágeno hidrolisado em diferentes proporções e numa ampla faixa de temperatura. Também foi estudada a aplicação de gelatina e colágeno hidrolisado em gomas de gelatina dietéticas, sendo analisadas as propriedades mecânicas dos géis obtidos sob compressão e suas propriedades colorimétricas. Após a obtenção de uma formulação otimizada, com características semelhantes a uma referência comercial, foi realizada uma análise sensorial e microestrural do produto final.

Capítulo 4 - Estudo reológico e microestrutural de soluções aquosas de gelatina e amido de milho modificado: neste capítulo apresenta-se uma investigação do comportamento reológico de suspensões aquosas de gelatina e amido de milho modificado em diferentes proporções e numa ampla faixa de temperatura. A ocorrência de separação de fases foi avaliada através da análise microestrutural dos géis obtidos por microscopia laser confocal. 
Capítulo 5 - Texture and microstructure of gelatin/corn starch-based gummy confections: este capítulo se constitui de um trabalho submetido à revista Food Hydrocolloids, no qual foi estudado a aplicação de gelatina e amido de milho modificado como agentes gelificantes numa base de xarope de maltitol e xilitol, visando obter uma bala de gelatina dietética substituindo-se parte da gelatina por amido de milho modificado, uma matéria-prima de menor custo. Os géis foram analisados por testes reológicos sob compressão e por colorimétrico. Uma investigação da microestrutura foi realizada por microscopia eletrônica de varredura (MEV) e microscopia laser confocal (MLC).

\section{Capítulo 6 - Conclusões}

\section{Capítulo 7 - Referências bibliográficas}




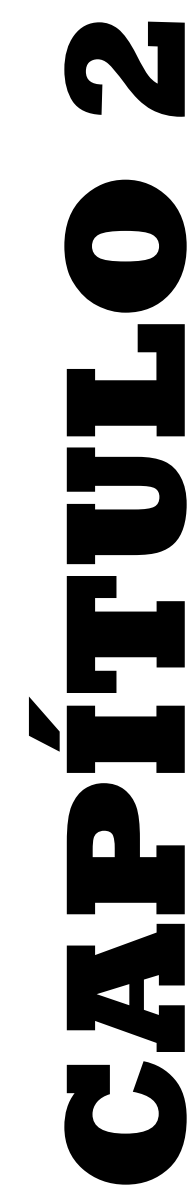

Revisão bibliográfica 


\subsection{COLÁGENO}

O colágeno é o componente principal dos tecidos conjuntivos, incluindo o tendão, as cartilagens, a pele e os tecidos vasculares. Em um mesmo animal é possível encontrar colágenos geneticamente distintos. Muitos deles têm sido caracterizados bioquimicamente, observando que cada tipo de tecido contém uma composição específica de colágeno.

A molécula de colágeno é composta de três cadeias polipeptídicas com seqüências repetidas de forma GLI-X-Y ao longo de seu comprimento, onde X e Y são quaisquer resíduos de aminoácidos. Nas três cadeias que compõem o colágeno, duas são iguais e uma diferente. Cada cadeia tem 1014 resíduos associados em seqüências de tripeptídeos. Cada cadeia é uma hélice levógira e as três se enrolam em uma super hélice dextrógira para dar a conformação final. O corpo principal de uma cadeia de colágeno contém uma glicina a cada três resíduos, mas existem regiões nos extremos que não apresentam essa periodicidade e são designadas como telopeptídeos. Por exemplo, o colágeno bovino tem 1014 resíduos com uma glicina a cada três posições, porém, tem 16 aminoácidos no extremo amino terminal (telopeptídeo N) e 25 no extremo carboxi terminal (telopeptídeo C) sem esta regularidade. Supõe-se que a estrutura dos telopeptídeos seja globular, embora sua conformação exata ainda seja desconhecida (OLIVO; SHIMOKOMAKI, 2002; WESS; ORGEL, 2000).

As moléculas do colágeno (massa molar de 300.000) são hélices triplas com cerca de $300 \mathrm{~nm}$ de comprimento e 1,5 nm de diâmetro. A integridade mecânica das moléculas de colágeno nos tecidos é freqüentemente melhorada pela associação das moléculas de colágeno em uma forma fibrilar específica e bem estabelecida, uma vez que pode ser facilmente visualizada por microscopia eletrônica. Essa forma fibrilar, onde cada molécula de colágeno está fortemente conectada à molécula vizinha, confere ao material uma alta resistência mecânica, uma vez que a força aplicada pode ser transmitida e distribuída entre as moléculas através dessas conexões. Entretanto, se o colágeno nativo for transformado em colágeno solúvel por hidrólise enzimática, ácida ou alcalina, essa resistência mecânica é perdida (FIGUEIRÓ et al., 2004; WESS; ORGEL, 2000).

O colágeno é largamente utilizado na indústria farmacêutica e cosmética, além de ser um biomaterial de uso bastante difundido na medicina, o que faz com que a maior parte dos trabalhos dedicados à investigação de suas propriedades seja baseada em colágeno de grau médico. As principais aplicações são como carreador de medicamentos (FRIESS, 1998; 
FRIESS; LEE, 1996) sensores biológicos (FIGUEIRÓ et al., 2004), pele artificial, produtos injetáveis para cirurgia plástica, coberturas de implantes e outros (FRIESS; SCHLAPP, 2001).

Mesmo considerando que existe um número relativamente alto de publicações sobre propriedades físico-químicas de colágeno em suspensão, existem dificuldades para a seleção das informações mais adequadas a cada aplicação.

\subsection{GELATINA}

A dissociação térmica ou química das cadeias polipeptídicas do colágeno forma o produto conhecido como gelatina. O colágeno insolúvel é convertido em gelatina solúvel por tratamentos hidrolíticos. A principal propriedade da gelatina é sua capacidade de formar géis estáveis em temperaturas menores que $40{ }^{\circ} \mathrm{C}$, desde que a concentração de gelatina na solução seja no mínimo de 1\%; em certos casos, essa transição sol-gel é reversível (NEKLYUDOV, 2003). Os géis de gelatina contêm ligações cruzadas ou "zonas de junção" formadas pelo retorno parcial à configuração "ordenada" de tripla hélice similar às seqüências do colágeno original, separadas ao longo do contorno da cadeia por resíduos peptídicos em conformação “desordenada” (ROSS-MURPHY, 1998; RENARD; VAN DE VELDE; VISSCHERS, 2006).

Uma gelatina típica contém $14 \%$ de umidade, $84 \%$ proteína e $2 \%$ de cinzas (RIX, 1990). A proteína consiste de uma mistura de aminoácidos, dos quais glicina, prolina e hidroxiprolina estão presentes em maior abundância. Moléculas de gelatina contêm repetidas seqüências de glicina-X-Y, onde $\mathrm{X}$ e $\mathrm{Y}$ são freqüentemente os aminoácidos prolina e hidroxiprolina (Figura 2.1).

As repetidas seqüências de aminoácidos de forma regular são necessárias para a formação da estrutura característica em tripla hélice na gelatina e em outras proteínas da família do colágeno. Essa estrutura é que afere a habilidade de formar gel sendo os segmentos em tripla hélice a base para as ligações cruzadas e a formação da rede tridimensional (CLARK et al., 1990). 


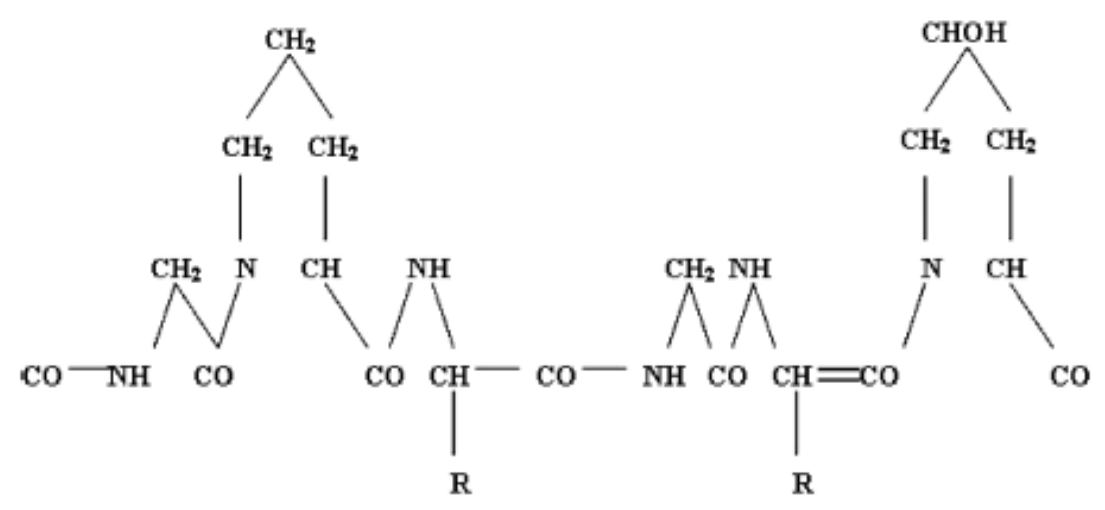

Glycine Proline $\quad$ Y Glycine $\quad X \quad$ Hydroxyproline

Figura 2.1 - Estrutura repetida da gelatina, responsável pela estrutura em tripla hélice (BUREY, et al., 2008).

A gelatina é considerada um alimento altamente digestível, ideal como um complemento em certos tipos de dietas. Tem apresentado, ao longo dos anos, aplicações na indústria de alimentos, fotográfica, cosmética e farmacêutica (BINSI et al., 2009). Recentemente, seu uso tem se expandido para novas aplicações como um colóide estabilizante, sendo agente de aeração e emulsificante. A fonte e tipo de colágeno influenciarão nas propriedades da gelatina resultante. As principais matérias-primas para produção de gelatina são peles e ossos bovinos e suínos. A força de gel, viscosidade e ponto de fusão da gelatina dependem do seu peso molecular e da distribuição e composição de aminoácidos.

A função da gelatina na bala de goma é de formar gel, ou seja, manter a estrutura e conferir textura. Ela pode ser encontrada nas formas pó, granular ou em folhas. As formas granular e em folha requerem pré-hidratação antes do uso, enquanto que a gelatina em pó pode ser incorporada sem pré-preparo. A força do gel da gelatina pode ser determinada de várias maneiras, sendo a mais utilizada o bloom gelometer. Quanto maior o bloom, maior força terá o gel formado. Nas balas do tipo "gelatine jellies" se utiliza gelatina com bloom 180. A quantidade de gelatina requerida para fabricação de um bom gel varia de 5 a $12 \%$ dependendo da textura que se quer e do bloom da gelatina. A gelatina não é solúvel em água fria, mas ela amolece quando hidratada e absorve água até dez vezes o seu peso. Uma maior quantidade de água e uma alta temperatura ou exposição prolongada ao calor pode reduzir a força do gel. Em geral, é normal a adição de soluções de açúcar ou xarope de glicose à solução de gelatina a uma temperatura menor que $82^{\circ} \mathrm{C}$. Qualquer adição de ácido deve ser feita no final do processo. 


\subsection{AMIDO DE MILHO MODIFICADO}

Estruturalmente, o amido é um homopolissacarídeo composto por cadeias de amilose e amilopectina. A amilose é formada por unidades de glicose unidas por ligações glicosídicas $\alpha-1,4$, originando uma cadeia linear. Já a amilopectina é formada por unidades de glicose unidas em $\alpha-1,4$ e $\alpha-1,6$, formando uma estrutura ramificada. As proporções em que essas estruturas aparecem diferem em relação às fontes botânicas, variedades de uma mesma espécie e, mesmo numa mesma variedade, de acordo com o grau de maturação da planta (ELIASSON, 2004; TESTER; KARKALAS; QI, 2004).

Ao contrário dos polímeros sintéticos, o amido é obtido a partir de fontes renováveis, sendo biossintetizado e estocado pelas plantas na forma de grânulos de tamanhos variáveis, que dependem da fonte. $\mathrm{O}$ amido é constituído de duas macromoléculas principais: a amilopectina, que é uma molécula ramificada, e a amilose, que é uma molécula essencialmente linear. Ambas possuem massa molar elevada. Os grânulos de amido apresentam birrefringência quando observados em microscópio óptico sob luz polarizada, o que indica certo grau de organização molecular. A parte linear das moléculas de amilopectina forma estruturas helicoidal duplas, estabilizadas por pontes de hidrogênio entre grupamentos hidroxila. São elas que dão origem às regiões cristalinas dos grânulos. A região amorfa é composta pelas cadeias de amilose e pelas ramificações da amilopectina.

Alguns fenômenos afetam as propriedades dos amidos. Um deles é a gelatinização, o processo de transformação do amido granular em pasta viscoelástica. Durante o aquecimento de dispersões de amido em presença de excesso de água, inicialmente ocorre o inchamento de seus grânulos até temperaturas nas quais ocorre o seu rompimento, com destruição da ordem molecular e mudanças irreversíveis nas suas propriedades. A temperatura na qual ocorre este tipo de transformação é chamada de temperatura de gelatinização.

Tem-se observado um considerável interesse no estudo dos sistemas proteínapolissacarídeo como forma de melhoria na textura dos alimentos e como desenvolvimento de novos produtos (ELEYA OULD; LENG; TURGEON, 2006).

Amidos nativos ou modificados são importantes ingredientes de muitos alimentos industrializados (ABD KARIM; NORZIAH; SEOW, 2000). São vastamente usados em muitas aplicações em alimentos, sozinhos ou junto a outros agentes gelificantes, por exemplo, em confeitos. 
O papel do amido nos confeitos é fornecer a estrutura e as principais características de textura. Amidos modificados por ácidos são obtidos pela adição de uma pequena quantidade de ácido numa suspensão do amido nativo e aquecida a temperaturas abaixo da temperatura de gelatinização produzindo amido hidrolisado (LEES, 1980). Quando o nível de cadeias hidrolisadas é obtido, a mistura é então neutralizada e o amido é filtrado e posteriormente seco. A hidrólise ácida na cadeia do amido resulta numa estrutura mais desintegrada e conseqüentemente em cadeias de menor peso molecular. Essa hidrólise ácida implica em grânulos de amido mais facilmente solúveis em água fervente (BELITZ; GROSCH, 1999) que se desintegram quando cozidos, fornecendo uma pasta de mais baixa viscosidade quando aquecida e mais elevada viscosidade no gel final quando comparado ao amido não modificado por ácidos (RIX, 1990; HERMANSSON; SVEGMARK, 1996).

\subsection{GOMAS DE GELATINA}

Os confeitos gelatinizados, como gomas de gelatina são compostos principalmente por açúcares como xarope de sacarose e glicose, combinados com componentes gelificantes como amido, gelatina ou pectina, acompanhado da acidificação, adição de sabor, aroma e corantes (BUREY et al., 2009).

Segundo a legislação brasileira, bala de goma é o produto preparado à base de gomas naturais, açúcares e adicionado de óleos essenciais ou extratos vegetais; ou define-se, ainda, bala de goma de amido ou bala americana como um produto preparado à base de goma de milho, açúcares e adicionada de aromatizantes (BRASIL, 1978).

No Brasil as balas de goma são preferencialmente fabricadas com amidos e-produtos à base de gelatina. Segundo a legislação brasileira não há um limite para utilização de agentes gelificantes em balas de goma (BRASIL, 1998).

As interações entre polissacarídeos e proteínas têm sido objeto de estudo por vários autores, principalmente com o objetivo de obter produtos com textura diferenciada e mesmo observar efeitos sinérgicos. Neste contexto, os confeitos como gomas se mostram ideais para esse tipo de estudo, pois são simples o suficiente para evitar a complexidade inerente dos sistemas biológicos, porém são produtos alimentícios reais (DEMARS; ZIEGLER, 2001).

Geralmente é feita a mistura dos açúcares que é aquecida até a ebulição e depois é adicionado o agente gelificante. A maior parte desses agentes é muito sensível à ação do 
calor. A sua adição à massa é feita ao final para evitar a hidrólise ou destruição pelo calor. Essa mistura final é depositada em moldes de amido. Outros métodos podem ser utilizados, como depósito em moldes de borracha ou derramamento em pranchas. Depois de levadas aos moldes, os confeitos são secos até o teor de umidade e textura desejados. De um modo geral, as gomas são confeitos que apresentam cerca de $20 \%$ de umidade e contêm uma significativa proporção de carboidratos de baixo peso molecular, como xaropes de sacarose e de milho.

Existe uma demanda por produtos sem adição de sacarose, principalmente por consumidores diabéticos. Há a necessidade de um maior desenvolvimento desses produtos, principalmente em relação a confeitos. Para o fabricante tradicional de balas e caramelos, o importante na fabricação dos dietéticos é a possibilidade de utilização dos equipamentos normais de fabricação desses produtos. É fundamental que o produto que substitui o complexo sacarose/xarope de milho apresente viscosidade suficiente para impedir a mobilidade das moléculas e, conseqüentemente, a formação de núcleos de cristalização. Esse produto deve possuir alta estabilidade, podendo ser aquecido sem que haja risco de caramelização ou escurecimento mesmo na presença de proteínas, isto é, não devem participar da reação de Maillard.

\subsubsection{Lycasin $^{\circledR}$}

A substituição de sacarose por outros edulcorantes é uma prática comum em alimentos e bebidas industrializados para obtenção de produtos de baixa caloria. A formulação de produtos com teor de sacarose reduzidos (dietéticos) requer um extenso conhecimento das propriedades e comportamento do edulcorante utilizado e dos fatores que podem afetar as características finais, principalmente sabor e textura, do produto dietético. É sabido que sacarose além do poder adoçante, funciona como agente de corpo e modificador de textura. Assim, a substituição de sacarose por outros edulcorantes pode afetar tanto as propriedades mecânicas como a percepção da textura pelo consumidor (MUÑOZ; PANGBORN; NOBLE, 1986; WILSON; BROWN, 1997; MORITAKA; NAITO, 2002).

O Lycasin $^{\circledR}$ é um xarope de maltitol obtido pela hidrogenação da D-maltose. Apresenta-se na forma de uma solução aquosa incolor. Sua solubilidade é comparativamente maior que a do sorbitol e sua viscosidade é menor, devido à massa molar. Na fabricação de 
bala de goma, a principal função do Lycasin $^{\circledR}$ é atuar como agente de corpo, sendo a sua função secundária atuar como adoçante. Este xarope é estável ao calor, o que possibilita o seu emprego a altas temperaturas na fabricação de balas.

\subsubsection{Xilitol}

O xilitol é um composto do grupo dos polióis, ou seja, é um álcool que apresenta um grupo hidroxila ligado a cada átomo de carbono (C) de sua molécula. Esse álcool tem a fórmula química $\mathrm{C}_{5} \mathrm{H}_{12} \mathrm{O}_{5}$ e pode ser encontrado em liquens, fungos, algas e vegetais, e também como um intermediário do metabolismo de carboidratos em animais, inclusive no homem. Esse álcool apresenta-se como um pó cristalino e branco, sem odor. Suas características químicas proporcionam sensação de frescor quando dissolvido na saliva, efeito explorado em pastilhas, chicletes e balas.

É um adoçante natural encontrado nas fibras de muitos vegetais, incluindo milho, framboesa, ameixa, entre outros. Também pode ser extraído de alguns tipos de cogumelo. Sua doçura relativa é igual à da sacarose e superior à de outros polióis, como sorbitol e manitol, também utilizados como adoçantes. O xilitol possui menor massa molar (140,0 g/mol) quando comparado à sacarose $(342,0 \mathrm{~g} / \mathrm{mol})$ o que implica numa redução aproximada de $40 \%$ do valor calórico. Outra vantagem deste adoçante é que não provoca cáries.

\subsection{REOLOGIA DOS ALIMENTOS}

Reologia é a ciência que estuda a deformação e escoamento dos materiais. A relação específica que se desenvolve entre a tensão aplicada e a deformação resultante para um determinado material pode ser expressa em termos de suas propriedades reológicas. Assim, esses dois parâmetros mecânicos (a tensão e a deformação) formam a base para a classificação dos materiais - sob o ponto de vista reológico - em três grupos principais: elásticos, plásticos e viscosos (VÉLEZ-RUIZ, 2002). Nos processos de engenharia, dados de viscoelasticidade podem ser muito úteis no entendimento de vários problemas (STEFFE, 1996). 
De acordo com Steffe (1996) e Vélez-Ruiz (2002) existem numerosos tópicos de interesse na indústria de alimentos que se relacionam à reologia:

- Aplicação e cálculos da engenharia de processos, envolvendo o projeto de uma grande variedade de equipamentos, tais como tubulações, bombas, extrusores, misturadores, trocadores de calor, viscosímetros e outros.

- Caracterização física de sólidos, líquidos e semi-sólidos.

- Desenvolvimento de novos produtos e reformulação.

- Controle de qualidade de produtos finais ou intermediários.

- Testes de vida de prateleira.

- Avaliação da textura correlacionando com a avaliação sensorial.

- Compreensão da estrutura dos materiais.

\subsection{COMPORTAMENTO REOLÓGICO SOB CISALHAMENTO OSCILATÓRIO}

Os ensaios reológicos sob cisalhamento oscilatório de baixa amplitude ou também chamado de ensaios reológicos dinâmicos, podem ser utilizados para determinação das propriedades viscoelásticas dos alimentos (RAO, 1999; MOHSENIN, 1986). Nos ensaios reológicos dinâmicos, o material é deformado periodicamente, por uma tensão que varia senoidalmente com o tempo. Um ensaio periódico, a uma freqüência de oscilação $\omega$, equivale quantitativamente a um teste não-estacionário no tempo $1 / \omega$, permitindo que se obtenha uma quantidade considerável de informações correspondentes em tempos muito curtos. Os testes dinâmicos permitem calcular o módulo de armazenamento $\left(G^{`}\right)$ e o módulo de dissipação mecânica $\left(G^{\prime \prime}\right)$ sobre uma grande faixa de freqüências. A dissipação mecânica está associada com a perda de energia e o aquecimento devido ao atrito entre as moléculas (MOHSENIN, 1986).

Um gel apresenta propriedades intermediárias entre um sólido (elástico) e um líquido (viscoso) e, portanto, apresenta comportamento viscoelástico (BARNES; HUTTON; WALTERS, 1989). Em um líquido perfeitamente viscoso a tensão depende apenas da taxa de deformação. Um líquido viscoso não tem "memória”, o trabalho mecânico necessário para produzir qualquer deformação é dissipado instantaneamente. Por outro lado, em um sólido perfeitamente elástico, a tensão depende somente da magnitude da deformação sofrida. $\mathrm{O}$ 
trabalho mecânico empregado na deformação é armazenado na forma de energia elástica. Uma substância viscoelástica apresenta um comportamento híbrido: ao mesmo tempo em que uma parte da energia recebida durante a sua deformação é armazenada, a outra é dissipada. A tensão depende da história da deformação; algum tempo se passa antes que o material “esqueça” sua forma anterior (GRAESSLEY, 1984).

Para ensaios reológicos oscilatórios, inicialmente se realiza uma varredura em deformação crescente para verificação da região de viscoelasticidade linear, mantendo-se a freqüência de oscilação constante. Todas as subseqüentes varreduras de freqüência são realizadas mantendo-se a deformação constante na faixa de viscoelasticidade linear. Quando materiais são testados na região de viscoelasticidade linear, as funções dos materiais não dependem da magnitude da tensão nem da intensidade da deformação ou da taxa de deformação (STEFFE, 1996). Assim, se trabalharmos numa região linear, a aplicação de uma tensão irá produzir como resposta uma deformação diretamente proporcional à tensão aplicada.

De acordo com Rao (1999), num teste oscilatório, a amostra de alimento é submetida a uma pequena força oscilatória ou deformação $\gamma(\mathrm{t})$ que varia senoidalmente com o tempo t, de acordo com a equação (2.1).

$$
\gamma(\mathrm{t})=\gamma_{0} \sin (\omega \mathrm{t})
$$

onde $\gamma_{0}$ é a amplitude máxima da deformação e $\omega$ é a freqüência angular. A deformação aplicada resulta em duas componentes de tensão na viscoelasticidade do material: uma componente elástica alinhada com a deformação e outra defasada em $90^{\circ}$ referente à componente viscosa. A diferenciação da equação (2.1) resulta na equação (2.2), a qual mostra a taxa de deformação $\dot{\gamma}(\mathrm{t})$ relacionada com a componente viscosa que é $\pi / 2$ radianos defasada com a deformação.

$$
\dot{\gamma}(\mathrm{t})=\gamma_{0} \omega \cos (\omega \mathrm{t})
$$

Para deformação dentro da faixa de viscoelasticidade linear, a equação (2.3) expressa a tensão produzida em termos de um módulo elástico ou de armazenamento $\left(G^{`}\right)$ e um módulo viscoso ou de dissipação (G“'). 


$$
\sigma_{0}=G^{\prime} \gamma_{0} \sin (\omega \mathrm{t})+G^{\prime \prime} \gamma_{0} \cos (\omega \mathrm{t})
$$

Para um material viscoelástico, a tensão resultante é também senoidal, mas mostra um ângulo de fase atrasado de $\delta$ radianos quando comparado com a deformação. $O$ ângulo de fase, $\delta$, varia numa faixa de 0 a $\pi / 2$ à medida em que o componente viscoso aumenta. A equação (2.4) também expressa a variação senoidal da tensão resultante.

$$
\sigma(\mathrm{t})=\sigma_{0} \sin (\omega \mathrm{t}+\delta)
$$

As expressões seguintes, derivadas das equações (2.3) e (2.4), definem o comportamento viscoelástico:

$$
\begin{gathered}
\mathrm{G}^{\prime}=\left[\frac{\sigma_{0}}{\gamma_{0}}\right] \cos \delta \\
\mathrm{G}^{\prime}=\left[\frac{\sigma_{0}}{\gamma_{0}}\right] \sin \delta \\
\tan \delta=\frac{\mathrm{G}^{\prime \prime}}{\mathrm{G}^{\prime}}
\end{gathered}
$$

onde $G^{\prime}(\mathrm{Pa})$ é o módulo de armazenamento, $\mathrm{G}^{\prime \prime}(\mathrm{Pa})$ o módulo de dissipação e tan $\delta$ é a tangente da razão entre o módulo de dissipação e o módulo de armazenamento.

O módulo de armazenamento, G', expressa a magnitude da energia que é armazenada no material ou recuperada por ciclo de deformação. Portanto, para um sólido perfeitamente elástico, toda a energia é armazenada, ou seja, G" é zero e a deformação e a tensão estarão em fase como na Figura 2.2(A). Por outro lado, para um fluido com propriedades nãoelásticas, toda a energia é dissipada na forma de calor, ou seja, neste caso, G’ é zero e a tensão e a deformação estarão defasadas em $90^{\circ}$ como pode ser observado na Figura 2.2(B).

Para um material específico, as magnitudes de $G^{\prime}$ e $G^{\prime \prime}$ são influenciadas pela freqüência, temperatura e deformação. Para valores de deformação dentro da faixa de deformação linear, G` e G” são independentes da deformação aplicada, como já discutido anteriormente. Essas funções viscoelásticas têm sido investigadas e possuem um papel muito importante no estudo reológico da estrutura dos polissacarídeos. 


\subsubsection{Rampa de Freqüência}

A rampa de freqüência é, provavelmente, o método mais comum de teste oscilatório porque mostra como o comportamento da viscosidade e da elasticidade dos materiais muda com a taxa de aplicação da deformação ou da tensão. Neste teste, a freqüência é aumentada enquanto a amplitude (tensão ou deformação) é mantida constante. Rampas de freqüência são usualmente utilizadas para comparação de diferentes produtos ou para comparação do efeito da adição de ingredientes e/ou processos de tratamento na viscoelasticidade dos alimentos. Os materiais usualmente apresentam características mais parecidas aos sólidos em altas freqüências (STEFFE, 1996).

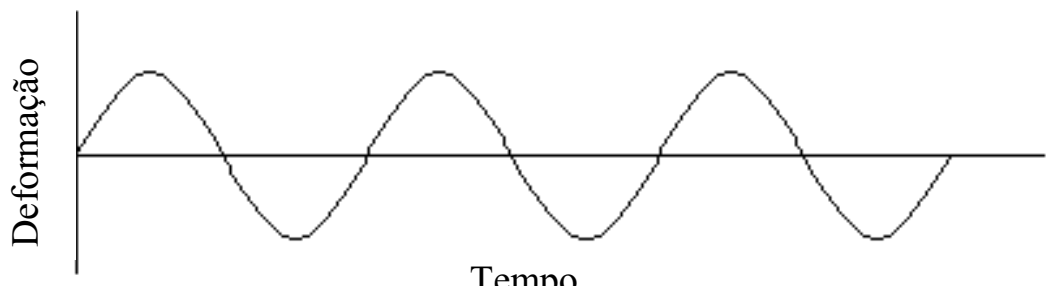

Tempo
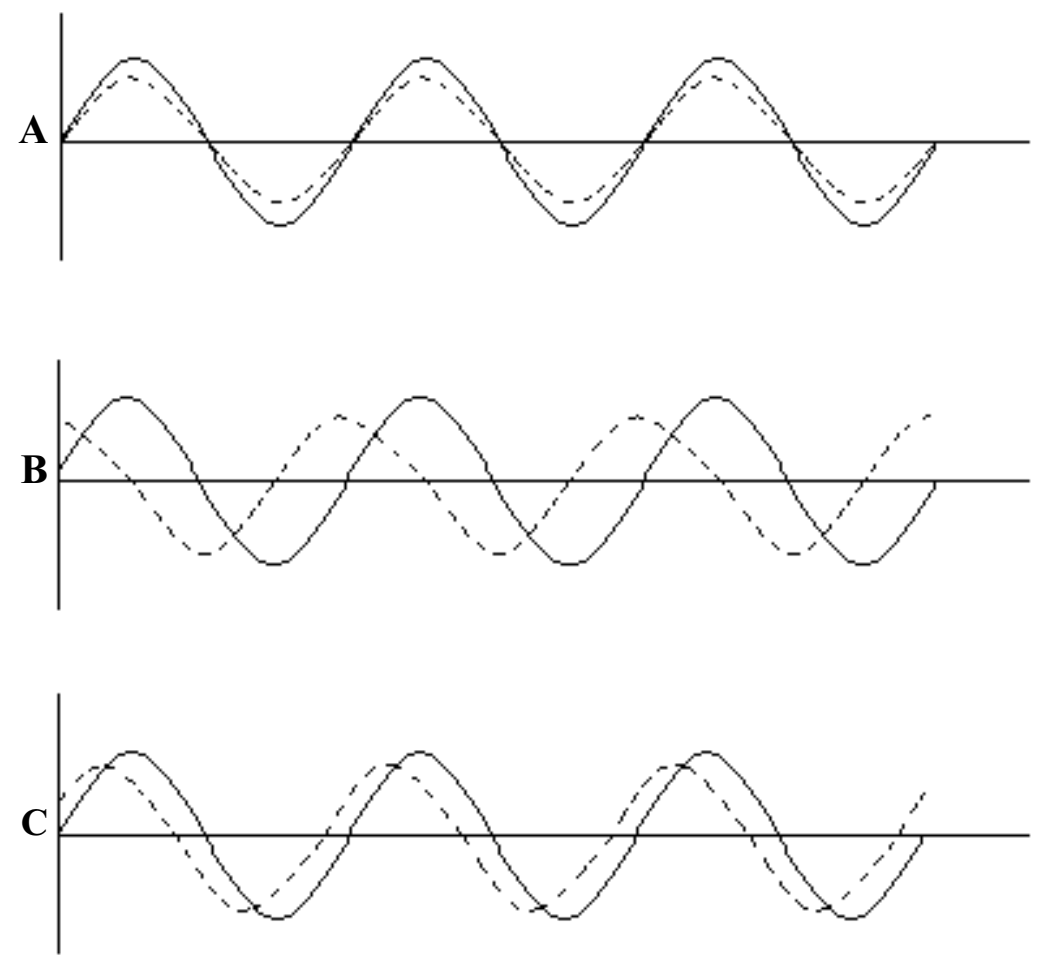

Figura 2.2 - Resposta da tensão e deformação de um líquido Newtoniano e de um sólido perfeitamente elástico em testes dinâmicos. Linhas sólidas $=$ deformação. Linhas pontilhadas $=$ tensão. $\mathbf{A}=$ Sólido elástico, tensão e deformação em fase. B = Líquido Newtoniano, tensão e deformação defasados em $90^{\circ} . \mathbf{C}=$ Material viscoelástico, tensão e deformação com defasagens menores que $90^{\circ}$. 
Quando se realiza uma varredura de freqüência, mantendo-se a temperatura constante, pretende-se avaliar a estrutura do sistema com base nas curvas dos módulos de armazenamento (G') e de dissipação (G”) (TELIS; KIECKBUSCH, 1997; TELIS; TELISROMERO; GABAS, 2005).

Quando se trabalha com soluções diluídas, os valores de G', são maiores que G' por toda a faixa de freqüência, sendo que nas maiores concentrações a diferença entre os módulos tende a diminuir. Para soluções concentradas, as curvas de G' e G', se interceptam durante a varredura de freqüência mostrando comportamento parecido ao dos sólidos nas freqüências mais altas. Segundo Steffe (1996), o ponto em que as curvas se interceptam ocorre quando $\mathrm{G}^{\prime}=\mathrm{G}^{\prime}$ ' e, este ponto corresponde a um ângulo de fase igual a $\pi / 4$. Quando se trata de um gel, os valores de G' serão significativamente maiores que G' por toda a faixa de freqüência estudada.

\subsubsection{Rampa de temperatura}

Neste tipo de ensaio, G’ e G“ são determinados em função da temperatura, numa freqüência $(\omega)$ fixa. Este teste é apropriado para estudo da formação de gel durante o resfriamento de uma dispersão aquecida (RAO; COOLEY, 1993), gelatinização de dispersões de amido durante o aquecimento e a formação de géis de proteínas. Esse tipo de teste é muito comum nos estudos de problemas que envolvem a temperatura como fonte de mudanças no comportamento reológico. Exemplos típicos associados com aquecimento são: derretimento de chocolates ou queijos através da fusão da gordura, gelificação para formar géis de pectina, soluções espessantes de amido gelatinizado, e aumento de consistência dos produtos cárneos e de ovos devida à desnaturação protéica (STEFFE, 1996).

\subsubsection{Análise do ângulo de fase (ס)}

De acordo com Steffe (1996); Menard (1999); Burey et al. (2009), a tendência de uma solução diluída ou concentrada apresentar um comportamento mais parecido com um fluido ou com um sólido ao longo de uma rampa de freqüências crescentes pode ser examinando 
com mais detalhes considerando-se a dependência do ângulo de fase $(\delta)$ em função da freqüência $(\omega)$. Ou seja, o ângulo de fase pode ser calculado através dos módulos de dissipação e de armazenamento, de acordo com a equação (2.7).

Resultados do ângulo de fase podem ser observados na Figura 2.3. O máximo valor do ângulo de fase corresponde aos fluidos Newtonianos é equivalente a $\pi / 2$ radianos ou 90 graus, enquanto que esse valor é nulo quando se trata de um sólido Hookeano. Assim, num ensaio de varredura de freqüência num material real, a resposta observada para o ângulo de fase estará entre os extremos elásticos (sólido Hookiano) e viscosos (fluido Newtoniano).

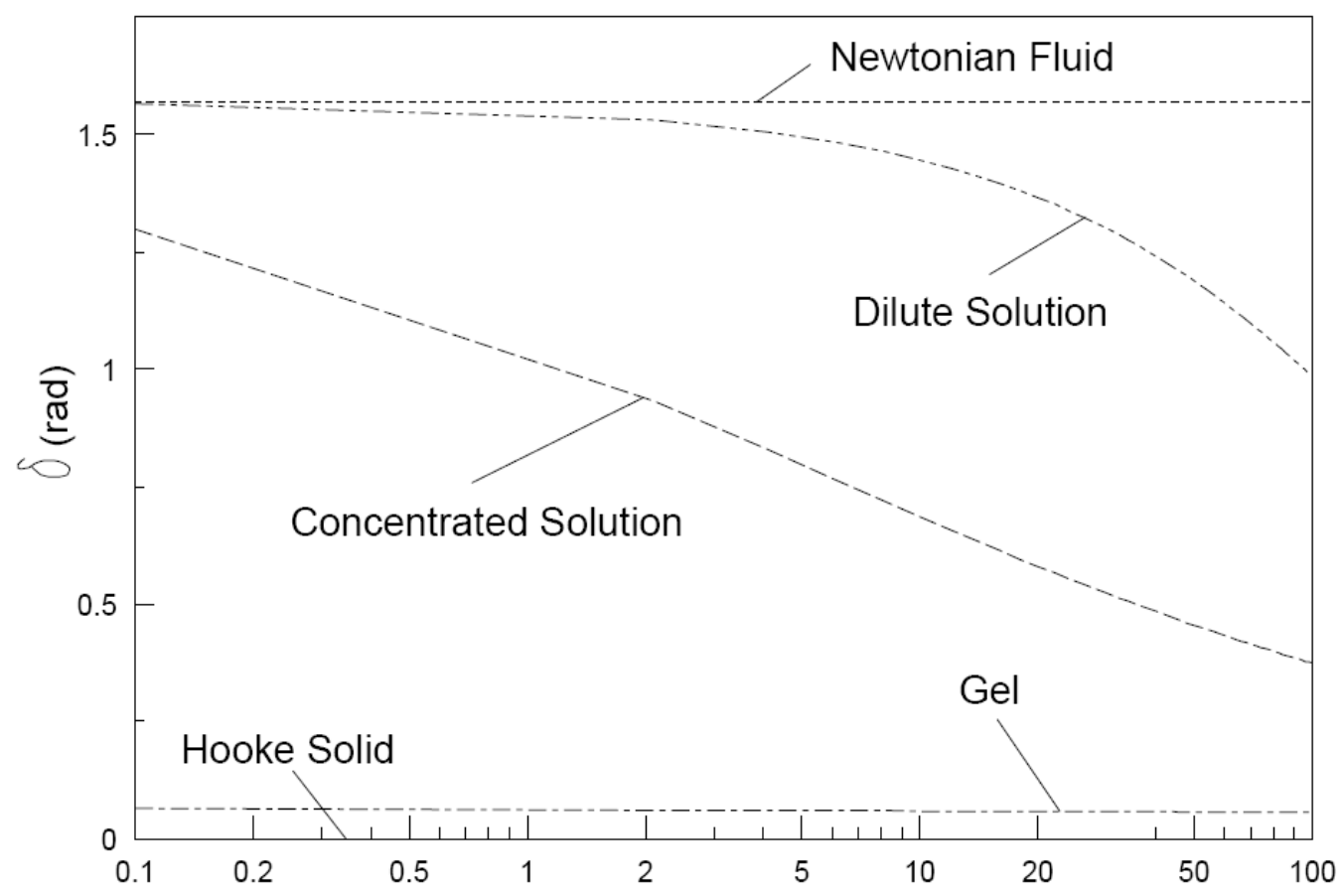

Figura 2.3 - Variação do ângulo de fase $(\delta)$ com a freqüência $(\omega)$ para materiais típicos. A linha do limite superior se refere a um fluido Newtoniano $(\delta=\pi / 2)$ e a do limite inferior a um sólido Hookeano $(\delta$ $=0)$. (STEFFE, 1996).

\subsection{COMPORTAMENTO REOLÓGICO EM COMPRESSÃO}

Existem duas formas de analisar o comportamento reológico de alimentos sob compressão: sensorialmente, com provadores, ou utilizando equipamentos. De um modo geral, investiga-se como os alimentos se deformam quando submetidos ao processo de mastigação e engolimento, ou seja, como é o comportamento da textura de um produto. 
Quando informações sobre o perfil de textura são geradas e interpretadas, esse teste é chamado de Análise de Perfil de Textura, também conhecido como TPA (Texture Profile Analysis).

Instrumentos de análise de perfil de textura (TPA) têm sido utilizados por muitos anos para a medida das propriedades de textura de alimentos (BOURNE, 1982). Os parâmetros de textura obtidos de uma curva força/deformação de um teste TPA têm sido correlacionados com características sensoriais para estimativa dos parâmetros de textura.

Num texturômetro, avalia-se uma amostra do produto, com forma geométrica bem definida. A amostra é colocada numa base plana e uma base cilíndrica se move de modo a comprimir o produto por duas vezes consecutivas, simulando as duas primeiras mordidas efetuadas em um alimento. Desta forma, este teste tenta refletir a percepção humana de textura. A Figura 2.4 apresenta a curva característica de uma análise de perfil de textura. Através desta curva, vários parâmetros de textura podem ser definidos (BOURNE, 1978; SZCZESNAIK; BRANDT; FRIEDMAN, 1963):

- Fraturabilidade: força necessária para a primeira grande queda na curva de força. Termos populares para fraturabilidade estão relacionados ao produto que se esfarela, que é quebradiço ou triturável.

- Dureza 1: força máxima medida durante a primeira compressão. Popularmente chamada de maciez, firmeza ou dureza.

- Área 1: área formada entre o eixo x (tempo) e a curva de força até atingir o maior pico (dureza 1), ou seja, refere-se ao trabalho realizado sobre a amostra durante a primeira "mordida".

- Adesividade: Área 3, abaixo da linha de força nula, representa o trabalho, provocado por uma força elástica, necessária para desprender o alimento, separando-o das placas de compressão. Termos populares para descrever esse parâmetro são: grudento e pegajoso.

- Força adesiva: máxima força negativa.

- Pegajosidade: medida da distância pela qual o alimento se estende antes de se desgrudar das placas que o comprimem.

- Dureza 2: máxima força medida durante a segunda compressão.

- Área 2: área abaixo da curva de força, durante a segunda compressão, até a força máxima medida; representa o trabalho realizado na amostra durante a segunda compressão. 
- Elasticidade: distância ou comprimento do ciclo de compressão durante a segunda “mordida". Termos populares são plasticidade e elasticidade.

- Coesividade: é a razão entre a área 2 dividida pela área 1.

- Mastigabilidade: equivale ao produto da gomosidade pela elasticidade. Termos populares conhecidos são macio, mole, mastigável ou duro. Uma amostra de produto não pode exibir mastigabilidade e gomosidade: a mastigabilidade se refere a alimentos sólidos e a gomosidade a alimentos semi-sólidos.

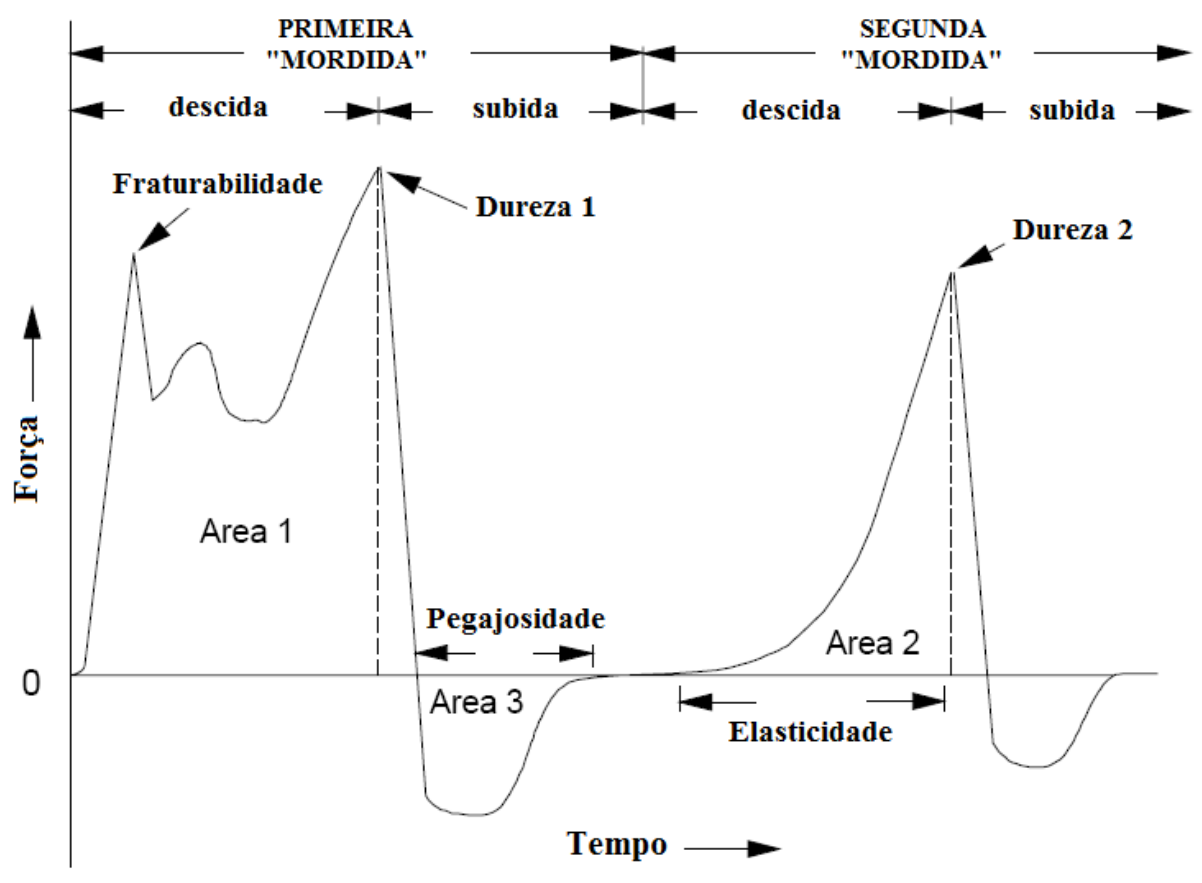

Figura 2.4 - Curva característica do perfil de textura (Adaptado de BOURNE; KENNY; BARNARD, 1978 apud STEFFE, 1996).

\subsection{PROPRIEDADES ÓPTICAS}

A aparência, a textura e o sabor estimulam os sentidos e provocam vários graus de reações de desejo ou rejeição. Através de um processo complexo, o consumidor escolhe um alimento pelo seu nível de qualidade sensorial. A cor é um dos principais parâmetros indicadores de qualidade e tem forte influência na aceitação do consumidor. 
Nas medidas instrumentais da cor de materiais opacos, a reflexão da luz sobre o objeto é detectada em uma escala de três elementos L*a*b* (sistema Hunter Lab e CIELAB), os quais eliminam a subjetividade envolvida na discussão de cor. Nesse sistema, $L^{*}$ define a luminosidade $\left(\mathrm{L}^{*}=0\right.$ preto e $\mathrm{L}^{*}=100$ branco) e $\mathrm{a}^{*}$ e $\mathrm{b}^{*}$ são responsáveis pela cromaticidade ( $+a^{*}$ vermelho e $-a^{*}$ verde, $+b^{*}$ amarelo e $-b^{*}$ azul).

Sabe-se que os corantes possuem um pequeno efeito na sensação do sabor/textura dos géis, como as gomas de gelatina, sendo responsáveis apenas pelas propriedades de aparência e uma possível ajuda na percepção do sabor (EDWARDS, 2000). A maior parte dos corantes é solúvel em água e adicionada em pequenas quantidades $(<1 \%)$, durante o processamento dos géis. De um modo geral, independentemente da cor escolhida para as gomas de gelatina, estas devem apresentar a máxima transparência possível, uma vez que este é um dos parâmetros de qualidade avaliado pelos consumidores.

Os parâmetros $\mathrm{L}^{*} \mathrm{a}^{*} \mathrm{~b}$ * podem ser obtidos com uso de um colorímetro trabalhando com $\mathrm{D}_{65}$ e luz do dia. A diferença de cor $(\Delta \mathrm{E})$ pode ser calculada através dos parâmetros definidos acima, utilizando a equação (2.8):

$$
\Delta E=\sqrt{\left(L-L^{*}\right)^{2}+\left(a-a^{*}\right)^{2}+\left(b-b^{*}\right)^{2}}
$$

onde $\mathrm{L}^{*}, \mathrm{a}^{*} \mathrm{e} \mathrm{b}^{*}$ devem ser os parâmetros colorimétricos de uma referência da qual deseja-se obter a diferença de cor.

A opacidade (Y) pode ser obtida de acordo com a relação entre a opacidade de cada amostra sobre o padrão preto $\left(\mathrm{Y}_{\mathrm{p}}\right)$ e padrão branco $\left(\mathrm{Y}_{\mathrm{b}}\right)$, conforme a equação (2.9):

$$
\mathrm{Y}=\left(\mathrm{Y}_{\mathrm{p}} / \mathrm{Y}_{\mathrm{b}}\right) \times 100
$$

A opacidade assim medida (entre 0 e 100\%) apresenta uma escala arbitrária. 


\subsection{MICROSCOPIA}

A microscopia é uma técnica que pode ser usada para complementar as informações obtidas através de medidas das propriedades físicas, reológicas e de textura dos alimentos. Por outro lado, muitos engenheiros de alimentos ainda ignoram a importância da microestrutura por algumas razões importantes, como:

- A ênfase da indústria de alimentos no último século tem sido o desenvolvimento de processos seguros e confiáveis para produção em larga escala de produtos tradicionais.

- Engenheiros de alimentos ainda têm pouco conhecimento sobre os fundamentos de ciência ligados às propriedades estruturais dos alimentos.

- As técnicas auxiliam no estudo da microestrutura, mas não foram desenvolvidas para fornecer informações importantes para engenheiros, como por exemplo, informações quantitativas (AGUILERA, 2000).

Avanços na tecnologia computacional e o desenvolvimento de programas de análise mais sofisticados têm permitido uma rápida análise de imagens de microestrutura, possibilitando a obtenção de informações como área, comprimento, volume e formas, entre outras dos diferentes componentes de cada sistema.

A microscopia eletrônica de varredura (MEV) é uma ferramenta muito útil para examinar a superfície dos componentes microestruturais. Amostras são colocadas sob suportes, algumas vezes fraturadas e cobertas com um componente metálico. A visualização das amostras permite uma análise tri-dimensional da estrutura dos diferentes sistemas.

Atualmente, a microscopia laser confocal (MLC) tem sido uma ferramenta valiosa na obtenção de imagens de alta resolução. Com a combinação dos princípios de fluorescência e da microscopia, a microscopia confocal pode ser utilizada como ferramenta, para visualização da estrutura morfológica de géis, inclusive da distribuição de seus constituintes na matriz. Pela microscopia confocal a laser pode ser possível investigar o arranjo estrutural tanto por superfície como por profundidade (interior da matriz do gel), viabilizando com isso a obtenção de maiores informações sobre a estrutura dos biofilmes.

A MLC é uma ferramenta eficaz para a visualização de grânulos de amido de diferentes fontes botânicas durante o processamento e na aplicação final. A MLC não requer preparações difíceis como secagem e metalização, como no caso da MEV. Além disso, essa técnica não limita a observação de grânulos de amido nativos, bem como pode ser usada para 
visualizar o processo de gelatinização e os resíduos de grânulos nas pastas de amido também podem ser observados (VAN DE VELDE; RIEL; TROMP, 2002).

$\mathrm{Na}$ microscopia laser confocal, o contraste é obtido por diferenças na fluorescência. No caso de mistura de ingredientes alimentícios poliméricos, um marcador precisa ser adicionado por dissolução nas amostras. Assim, as moléculas deste marcador irão difundir pela amostra de acordo com a acessibilidade e afinidade. Imagens mais específicas podem ser obtidas por marcações covalentes de um dos componentes do sistema. É esperado que a presença do marcador não mude as propriedades dos componentes nas amostras e, como conseqüência, não afete a estrutura da imagem a ser analisada (TROMP et al., 2001).

A Rodamina B é um marcador específico de proteínas. Van de Velde, Riel \& Tromp (2002) estudaram a morfologia de grânulos de diferentes fontes botânicas de amido através de MLC e mostraram que, em ausência ou em baixas concentrações de proteína, o marcador Rodamina B liga-se aos grânulos de amido enquanto que, em sistemas contendo altas concentrações de proteína, grânulos de amido apresentam-se com um orifício em preto e o marcador liga-se à fase protéica. 


\section{Estudo reológico de soluções gelatina / colágeno hidrolisado e aplicação em gomas dietéticas de gelatina}

Artigo será submetido para publicação no periódico Journal of applied polymer science 


\title{
Estudo reológico de soluções gelatina / colágeno hidrolisado e aplicação em gomas dietéticas de gelatina
}

\author{
MARFIL, P. H. M. ${ }^{1}$; FERNANDES, G. A. C. ${ }^{2}$; TELIS, V. R. N. ${ }^{1, *}$ \\ ${ }^{1}$ Departamento de Engenharia e Tecnologia de Alimentos, UNESP - Universidade Estadual Paulista, 15054-000. \\ São José do Rio Preto, São Paulo, Brasil; \\ ${ }^{2}$ Gelita do Brasil, 30190-002, Mococa, São Paulo, Brasil. \\ ${ }^{*}$ Corresponding author. \\ E-mail address: vanianic@ibilce.unesp.br \\ Telephone number: 551732212255 \\ Fax number: 551732212299
}

\section{RESUMO}

O comportamento reológico de soluções aquosas de gelatina e colágeno hidrolisado (4 e $10 \%$ de sólidos totais) foi estudado utilizando testes dinâmicos oscilatórios em um reômetro rotacional de tensão controlada com geometria cone e placa (60 mm, gap $52 \mu \mathrm{m})$. Um sistema Peltier foi utilizado na base da geometria para controle de temperatura. $\mathrm{O} \mathrm{pH}$ médio das soluções contendo $4 \%$ de sólidos solúveis foi de $6,16 \pm 0,08$ e com $10 \%$ de sólidos solúveis foi de 5,82 \pm 0,04. Em todas as concentrações, o módulo de armazenamento, G', aumentou com o aumento da freqüência angular. Como esperado, o valor dos módulos observados na região de platô aumentou com o aumento da concentração de gelatina. O início do platô variou com a concentração de gelatina: essa posição foi deslocada no sentido da menor freqüência para as mais altas concentrações de gelatina. Os valores de G`e G” aumentaram com a diminuição da temperatura. O colágeno hidrolisado não apresentou comportamento de gel. Também foram estudados o comportamento reológico por compressão e as propriedades ópticas e microestruturais de gomas de gelatina dietéticas enriquecidas com colágeno hidrolisado. As gomas foram preparadas à base de xarope de maltitol e xilitol, sendo 
utilizadas concentrações de gelatina de 7 a $11 \%$ e de colágeno hidrolisado de 2 a $8 \%$, de acordo com um planejamento fatorial do tipo central composto. Os géis apresentaram $\mathrm{pH}$ médio de $6,16 \pm 0,12$ e teor de sólidos solúveis entre 77,3 e $82,1{ }^{\circ}$ Brix. Foram avaliados parâmetros de textura, utilizando testes de análise de perfil de textura (TPA) em um texturômetro, e de opacidade e diferença de cor a partir de um estudo colorimétrico. Os dados foram analisados através de superfície de resposta, não sendo observados efeitos significativos $(p<0,05)$ na interação entre as concentrações de colágeno hidrolisado e gelatina quanto à dureza das amostras. A maior concentração de gelatina e de colágeno hidrolisado resultou numa maior opacidade e numa diferença de cor crescente expressa por uma relação linear $\left(\mathrm{R}^{2}>0,98\right)$. $\mathrm{O}$ aumento na concentração de gelatina foi responsável pelos maiores valores de dureza, sendo a formulação contendo $9 \%$ de gelatina e $5 \%$ de colágeno hidrolisado a que apresentou textura mais próxima de uma referência comercial. A microestrutura da bala obtida na formulação ótima foi estudada por microscopia eletrônica de varredura (MEV). A análise sensorial do produto final mostrou aceitação por $86,4 \%$ do público infantil e $83,9 \%$ dos adultos.

\section{ABSTRACT}

The rheological behavior of aqueous solutions of gelatin and hydrolyzed collagen ( 4 and 10 wt $\%$ ) was studied using dynamic oscillatory shear tests in a controlled stress, rotational, rheometer fitted with a cone and plate geometry $(60 \mathrm{~mm}$, gap $52 \mu \mathrm{m})$. A Peltier system in the bottom plate provided the temperature control. $\mathrm{pH}$ values were $6,16 \pm 0,08(4 \mathrm{wt} \%)$ and 5,82 $\pm 0,04(10 \mathrm{wt} \%)$. For all concentrations, the storage modulus, G', increased with the increasing angular frequency. As expected, the modulus plateau value increased with the increasing of gelatin concentration. The onset of the modulus plateau varied with gelatin concentration: its position was shifted to lower angular frequencies for higher gelatin concentrations. $G^{\prime}$ and $G^{\prime \prime}$ values increased at lower temperatures. Hydrolyzed collagen did not show gel formation ability. Rheological behavior under compression, as well as optic and microstructural properties of diet gelatin gummies enriched with hydrolyzed collagen were also studied. The gummies were prepared with maltitol syrup and xilitol, gelatin (7 to 11 $\mathrm{wt} \%$ ) and hydrolyzed collagen ( 2 to $8 \mathrm{wt} \%$ ), according to a central composite design. Gels 
showed a $\mathrm{pH}$ value of $6.16 \pm 0.12$ and 77.3 e $82.1{ }^{\circ}$ Brix of soluble solids. Parameters of texture, opacity and color difference were evaluated using a texturometer and a colorimeter. The results were analyzed using a surface-response experimental design and significant effects $(p<0.05)$ in the interaction between gelatin and collagen concentrations were not observed in relation to hardness. The higher concentrations of gelatin and hydrolyzed collagen resulted in a higher opacity and a crescent color difference expressed by a linear relation $\left(\mathrm{R}^{2}>0.98\right)$. The increase in gelatin concentration was responsible by the increasing of hardness. The gel formulation that showed the most similar texture comparing with the commercial gummies contained $9 \mathrm{wt} \%$ of gelatin and $5 \mathrm{wt} \%$ of hydrolyzed collagen. The microstructure of the optimized gummy formulation was studied by scanning electron microscopy (SEM). Sensorial analyses of the final product showed $86.4 \%$ acceptance from children and $83.9 \%$ from adults. 


\subsection{INTRODUCẼ̃O}

Misturas de biopolímeros têm sido extensivamente estudadas nas últimas décadas devido à grande importância que estes podem exercer nas propriedades dos alimentos e nas formulações (PLUCKNETT et al., 2000; NORTON; FRITH, 2001; TOLSTOGUZOV, 2003)

Proteínas são biopolímeros que contribuem para as propriedades estruturais e de textura de alimentos através de seu poder de agregação ou gelificação. O colágeno é o componente principal dos tecidos conjuntivos, incluindo o tendão, as cartilagens, a pele e os tecidos vasculares. A dissociação térmica ou química das cadeias polipeptídicas do colágeno forma o produto conhecido como gelatina. O colágeno insolúvel é convertido em gelatina solúvel por tratamentos hidrolíticos. A principal propriedade da gelatina - e responsável pela sua funcionalidade - é sua capacidade de formar géis estáveis em temperaturas menores que $40{ }^{\circ} \mathrm{C}$. Além da indústria de produtos alimentícios, os biopolímeros encontram cada vez mais aplicações na indústria farmacêutica, de cosméticos, engenharia biomédica, embalagens biodegradáveis e outros.

As moléculas do colágeno (massa molar de 300.000) são hélices triplas com cerca de $300 \mathrm{~nm}$ de comprimento e $1,5 \mathrm{~nm}$ de diâmetro. A integridade mecânica das moléculas de colágeno nos tecidos é freqüentemente melhorada pela associação das moléculas de colágeno em uma forma fibrilar específica e bem estabelecida, uma vez que pode ser facilmente visualizada por microscopia eletrônica. Essa forma fibrilar, onde cada molécula de colágeno está fortemente conectada à molécula vizinha, confere ao material uma alta resistência mecânica, uma vez que a força aplicada pode ser transmitida e distribuída entre as moléculas através dessas conexões. Entretanto, se o colágeno nativo for transformado em colágeno solúvel por hidrólise enzimática, ácida ou alcalina, essa resistência mecânica é perdida (FIGUEIRÓ et al., 2004; WESS; ORGEL, 2000). O colágeno hidrolisado vem sendo avaliado como um ingrediente que permite aumentar o teor protéico de alimentos, porém sem ser o responsável pela formação de gel.

A gelatina é considerada um alimento altamente digestível, ideal como um complemento em certos tipos de dietas. Tem apresentado, ao longo dos anos, aplicações na indústria de alimentos, fotográfica, cosmética e farmacêutica (BINSI et al., 2009). Recentemente, seu uso tem se expandido para novas aplicações como um colóide estabilizante, sendo agente de aeração e emulsificante. A fonte e tipo de colágeno influenciarão nas propriedades da gelatina resultante. As principais matérias-primas para 
produção de gelatina são peles e ossos bovinos e suínos. A força de gel, viscosidade e ponto de fusão da gelatina dependem do seu peso molecular e da distribuição e composição de aminoácidos.

Os géis de gelatina contêm ligações cruzadas ou "zonas de junção" formadas pelo retorno parcial à configuração "ordenada" de tripla hélice similar às seqüências do colágeno original, separadas ao longo do contorno da cadeia por resíduos peptídicos em conformação “desordenada” (ROSS-MURPHY, 1998; RENARD; VAN DE VELDE; VISSCHERS, 2006).

As balas de gelatina ou gomas de gelatina são confeitos muito populares na Europa e Estados Unidos, disponíveis em vários formatos, cores e sabores, inclusive na sua forma tradicional de ursinhos. No Brasil, entretanto, as balas gelificadas são preferencialmente fabricadas com amidos. Os produtos à base de gelatina ainda representam uma pequena parcela das vendas de balas e confeitos, com potencial de crescimento (QUEIROZ, 1999).

O aparecimento da categoria de confeitos funcionais ou confeitos fortificados é uma tendência mundial englobando os produtos fortificados com vitaminas, minerais ou outros ingredientes com algum aspecto nutricional ou propriedade relacionada à saúde.

As balas de goma são uma grande classe de confeitos de baixa cocção e com alto conteúdo de umidade (cerca de $20 \%$ ou mais) cuja textura é fornecida pelo agente gelificante utilizado, podendo ser goma arábica, ágar, gelatina, pectina e amidos especiais (JACKSON; LEES, 1973; QUEIROZ, 1999). Entretanto, a maioria desses confeitos consiste de sacarose, xarope de glucose, amido, gelatina e água, com um número de componentes utilizados em pequenas quantidades como ácidos, aromas e corantes (BUREY et al., 2009). Garcia (2000) cita que os fatores determinantes para a aceitação e preferência dos consumidores em relação às gomas de gelatina são sua textura, a boa claridade ou ausência de turbidez e a cor clara e brilhante.

Os objetivos do presente estudo foram: 1) avaliar o comportamento reológico de suspensões de gelatina e de colágeno hidrolisado, bem como de suas misturas, buscando entender o comportamento viscoelástico e as características dos géis formados a partir desses compostos puros ou combinados entre si; 2) otimizar a proporção de gelatina e colágeno hidrolisado com o fim de obter a textura adequada a uma bala de gelatina dietética, avaliandose as propriedades mecânicas, ópticas, estruturais e aceitação dos géis formados. 


\subsection{MATERIAL E MÉTODOS}

\subsubsection{Material}

Para os ensaios reológicos, utilizou-se gelatina extraída de pele bovina, com força de gel de 240 bloom, colágeno hidrolisado Hidrogel ${ }^{\circledR}$ (Gelita, Mococa, Brasil) e água destilada.

Para o preparo das gomas de gelatina, utilizou-se, além da gelatina, colágeno hidrolisado e água, uma base de xarope de maltitol (Lycasin ${ }^{\circledR}$, Roquette, Lestrem, França) e xilitol (Tovani Benzaquen, São Paulo, Brasil).

\subsubsection{Preparo das amostras para ensaios reológicos}

Gelatina e colágeno hidrolisado foram dissolvidos em água destilada, com auxílio de um bastão de vidro. Foram preparadas suspensões contendo diferentes proporções dos biopolímeros de modo a obter-se sistemas com concentração total de 4 e 10 \% (em massa) de sólidos totais. Em ambos os casos, isto é, para ambas as concentrações totais de sólidos, esse total foi constituído de gelatina e colágeno hidrolisado nas seguintes proporções: 0:100; 25:75; 50:50; 75:25; 100:0 (gelatina:colágeno, \% em massa), respectivamente.

Os compostos foram pesados em balança analítica (MARCONI, JK 200, Piracicaba, Brasil) e o valor do pH da solução resultante foi medido com auxílio de um pHmetro digital (TECNAL, Tec-3MP, Piracicaba, Brasil). As soluções ficaram imersas em banho aquecido a $30{ }^{\circ} \mathrm{C}$ por 12 horas visando a hidratação dos polímeros, sendo que os ensaios começaram a ser realizados na temperatura de $20^{\circ} \mathrm{C}$.

\subsubsection{Ensaios reológicos}

Testes oscilatórios foram realizados em um reômetro AR-2000ex (TA Instruments, Delaware, USA), utilizando geometria cone e placa ( $2^{\circ} 0$ ' $11^{\prime \prime}$ ) com um espaçamento de 52 
$\mu \mathrm{m}$. Amostras de 2,0 $\mathrm{mL}$ foram utilizadas, inseridas no reômetro com auxílio de uma pipeta automática. A programação de cada ensaio reológico seguiu as seguintes etapas:

- Varredura de freqüência $\left(0,1 \mathrm{a} 100 \mathrm{rad} . \mathrm{s}^{-1}\right)$ a $20^{\circ} \mathrm{C}$.

- Rampa de aquecimento até $80^{\circ} \mathrm{C}\left(2{ }^{\circ} \mathrm{C} / \mathrm{min} ; 1 \mathrm{rad} . \mathrm{s}^{-1}\right)$.

- Isotérmico a $80{ }^{\circ} \mathrm{C}$ por 10 minutos $\left(1 \mathrm{rad}^{-1}{ }^{-1}\right)$.

- Resfriamento até $20{ }^{\circ} \mathrm{C}\left(2{ }^{\circ} \mathrm{C} / \mathrm{min} ; 1 \mathrm{rad} . \mathrm{s}^{-1}\right)$.

- Isotérmico a $20^{\circ} \mathrm{C}$ por 1 hora $\left(1 \mathrm{rad} . \mathrm{s}^{-1}\right)$.

- Varredura de freqüência $\left(0,1\right.$ a $\left.100 \mathrm{rad}^{-1} \mathrm{~s}^{-1}\right)$ a $20^{\circ} \mathrm{C}$.

- Resfriamento até $5{ }^{\circ} \mathrm{C}\left(2{ }^{\circ} \mathrm{C} / \mathrm{min} ; 1 \mathrm{rad} . \mathrm{s}^{-1}\right)$.

Os ensaios foram realizados em duplicata.

\subsubsection{Preparo das gomas}

As gomas de gelatina foram elaboradas a partir de uma base de Lycasin ${ }^{\circledR}$ e xilitol na proporção, em massa de 6:1, respectivamente. Esses ingredientes foram misturados e aquecidos até a ebulição $\left(125^{\circ} \mathrm{C}\right)$ e posteriormente resfriados a $90{ }^{\circ} \mathrm{C}$. Paralelamente, gelatina e colágeno hidrolisado foram dissolvidos em água aquecida $\left(70-80{ }^{\circ} \mathrm{C}\right)$ e levados a um banho a $60{ }^{\circ} \mathrm{C}$ por 30 minutos para eliminação de bolhas de ar. Posteriormente, essa solução contendo gelatina e colágeno hidrolisado foi misturada à base de Lycasin ${ }^{\circledR}$ e xilitol, com auxílio de um bastão de vidro (Figura 3.1). O pH das amostras foi medido com um pHmetro digital (TECNAL, Tec-3MP, Piracicaba, Brasil). O teor de sólidos solúveis foi medido com o uso de um refratômetro digital (ATAGO, PAL-3, Tókio, Japão) que trabalha na faixa de 0 $93{ }^{\circ}$ Brix. Por fim, a mistura resultante foi resfriada até $60{ }^{\circ} \mathrm{C}$ e depositada em moldes cilíndricos de silicone, previamente untados com óleo vegetal, que possuem um diâmetro de $37 \mathrm{~mm}$ e altura de $20 \mathrm{~mm}$. Todas as matérias-primas foram pesadas em balança analítica (MARCONI, JK 200, Piracicaba, Brasil).

Foi utilizado um delineamento estatístico composto central rotacional de segunda ordem, com base na metodologia de superfície de resposta (MSR). Foram realizados 11 ensaios, sendo quatro referentes aos pontos do planejamento fatorial completo $2^{\mathrm{n}}(\mathrm{n}=2)$, quatro pontos axiais e três repetições do ponto central, como pode ser observado na Tabela 3.1. Vale ressaltar que, para obter os limites inferiores e superiores do delineamento foi 
necessária a realização de pré-testes observando valores mínimos para formação de gel e limites máximos que impediam a elaboração do produto final.

Após 24 horas de secagem em temperatura ambiente, as amostras foram submetidas aos ensaios reológicos de compressão (Análise de Perfil de Textura) e ao estudo colorimétrico.

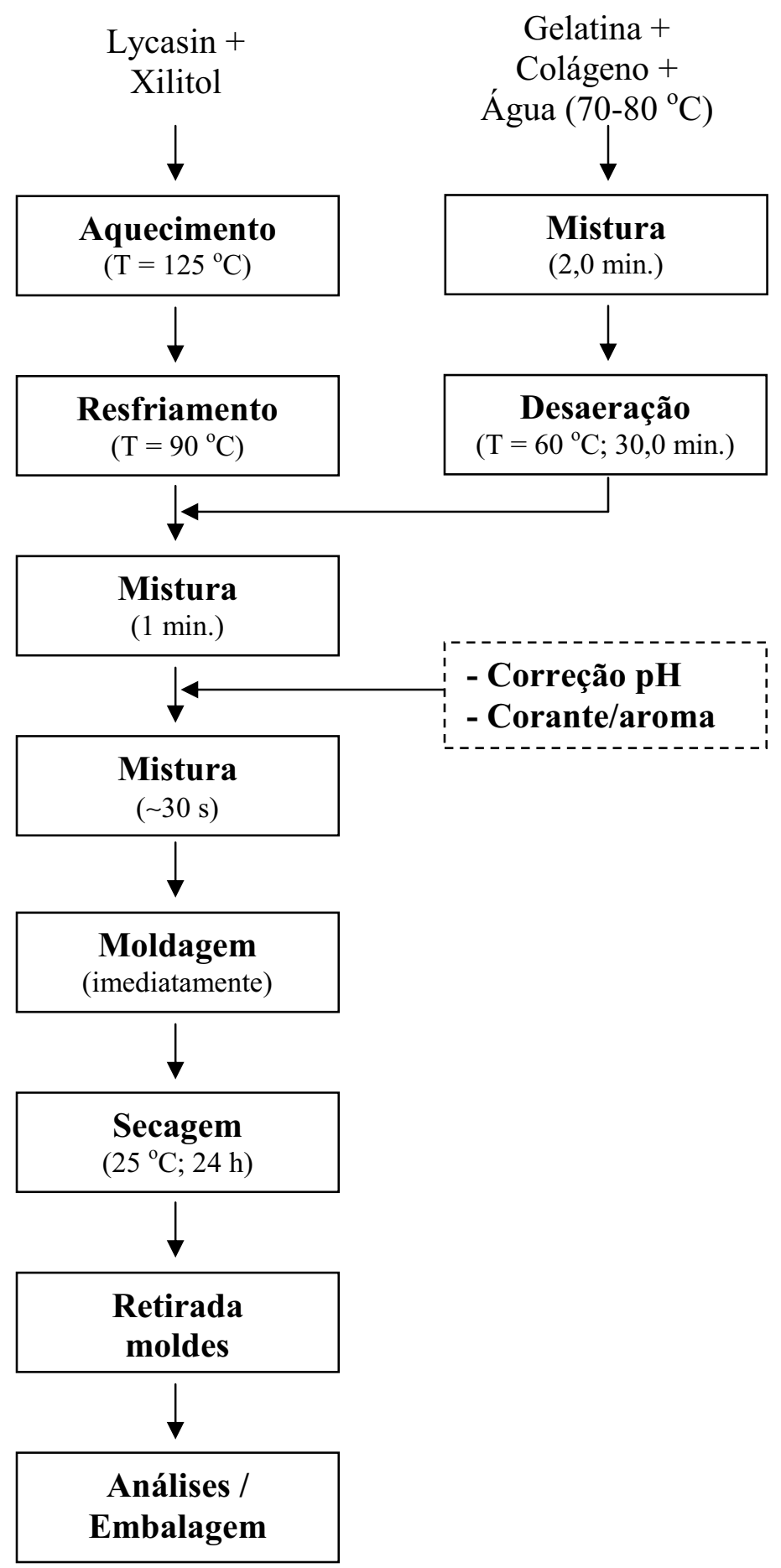

Figura 3.1 - Processo de elaboração das gomas de gelatina. 
Tabela 3.1 - Planejamento experimental para preparo das gomas de gelatina.

\begin{tabular}{|c|c|c|c|c|c|c|c|c|c|c|}
\hline \multirow{4}{*}{ Ensaio } & \multicolumn{10}{|c|}{ Fatores } \\
\hline & \multicolumn{5}{|c|}{$\begin{array}{c}\text { Gelatina } \\
\text { (\% em massa) }\end{array}$} & \multicolumn{5}{|c|}{$\begin{array}{l}\text { Colágeno hidrolisado } \\
\text { (\% em massa) }\end{array}$} \\
\hline & $-\alpha$ & -1 & 0 & +1 & $+\alpha$ & $-\alpha$ & -1 & 0 & +1 & $+\alpha$ \\
\hline & 6,17 & 7,00 & 9,00 & 11,00 & 11,83 & 0,76 & 2,00 & 5,00 & 8,00 & 9,24 \\
\hline 1 & \multicolumn{5}{|c|}{7,00} & \multicolumn{5}{|c|}{2,00} \\
\hline 2 & \multicolumn{5}{|c|}{7,00} & \multicolumn{5}{|c|}{8,00} \\
\hline 3 & \multicolumn{5}{|c|}{11,00} & \multicolumn{5}{|c|}{2,00} \\
\hline 4 & \multicolumn{5}{|c|}{11,00} & \multicolumn{5}{|c|}{8,00} \\
\hline 5 & \multicolumn{5}{|c|}{6,17} & \multicolumn{5}{|c|}{5,00} \\
\hline 6 & \multicolumn{5}{|c|}{11,83} & \multicolumn{5}{|c|}{5,00} \\
\hline 7 & \multicolumn{5}{|c|}{9,00} & \multicolumn{5}{|c|}{0,76} \\
\hline 8 & \multicolumn{5}{|c|}{9,00} & \multicolumn{5}{|c|}{9,24} \\
\hline $9(\mathrm{C})$ & \multicolumn{5}{|c|}{9,00} & \multicolumn{5}{|c|}{5,00} \\
\hline $10(\mathrm{C})$ & \multicolumn{5}{|c|}{9,00} & \multicolumn{5}{|c|}{5,00} \\
\hline $11(\mathrm{C})$ & \multicolumn{5}{|c|}{9,00} & \multicolumn{5}{|c|}{5,00} \\
\hline
\end{tabular}

\subsubsection{Ensaios reológicos em compressão - (TPA)}

Foi utilizada a metodologia de Análise de Perfil de Textura (TPA) para a determinação dos parâmetros de dureza, fraturabilidade, adesividade, elasticidade, coesividade, gomosidade e mastigabilidade das gomas resultantes, realizada em texturômetro TA.XT2i com probe cilíndrico de 49,2 $\mathrm{mm}$. Os ensaios foram conduzidos com velocidade pré-teste de 2,0 $\mathrm{mm} / \mathrm{s}$, velocidade de teste de $1,0 \mathrm{~mm} / \mathrm{s}$ e pós-teste de $5,0 \mathrm{~mm} / \mathrm{s}$, taxa de compressão de $40,0 \%$ e realizados em triplicata.

\subsubsection{Determinação das propriedades ópticas}

A opacidade (Y) foi calculada utilizando um colorímetro (HUNTERLAB, COLORFLEX, Reston, USA) e seu cálculo foi realizado automaticamente pelo programa Universal software 3.2 (Hunter Lab Associates Laboratory, Reston, USA, 1997) de acordo com a relação entre a opacidade de cada amostra sobre o padrão preto $\left(\mathrm{Y}_{\mathrm{p}}\right)$ e padrão branco $\left(\mathrm{Y}_{\mathrm{b}}\right)$, conforme a equação (3.1):

$$
\mathrm{Y}=\left(\mathrm{Y}_{\mathrm{p}} / \mathrm{Y}_{\mathrm{b}}\right) \times 100
$$


A opacidade assim medida (entre 0 e 100\%) apresenta uma escala arbitrária. A determinação das propriedades ópticas foi realizada nos mesmos géis utilizados para a análise de perfil de textura, considerando que este teste é não-destrutivo. Em cada amostra, foram realizadas oito medidas de opacidade girando-a em $45^{\circ}$. Também foram tomados os valores dos parâmetros $L^{*}, a^{*}$ e $b^{*}$ e foi calculada a diferença de cor, $\Delta \mathrm{E}$, dada pela equação (3.2), tomando como referência uma goma de gelatina elaborada somente com gelatina na concentração de $8 \%\left(\mathrm{~L}^{*}=39,22 ; \mathrm{a}^{*}=1,10 ; \mathrm{b}^{*}=2,82\right)$.

$$
\Delta E=\sqrt{\left(L-L^{*}\right)^{2}+\left(a-a^{*}\right)^{2}+\left(b-b^{*}\right)^{2}}
$$

\subsubsection{Análise sensorial}

Foi realizado um teste de aceitação entre 40 crianças na faixa etária de 4 a 12 anos, utilizando uma escala hedônica facial de cinco pontos (Apêndice A) e entre 40 adultos de 18 a 50 anos utilizando uma escala hedônica de nove pontos, variando de desgostei muitíssimo a gostei muitíssimo (Apêndice A). A bala foi elaborada na formulação otimizada nos ensaios mecânicos, sendo adicionado aroma de morango (Firmenich, Cotia, Brasil) e corante (Firmenich, Cotia, Brasil) característico deste sabor.

\subsubsection{Microscopia eletrônica de varredura (MEV)}

A microestrutura do gel correspondente à formulação do ponto central (Tabela 3.1) foi analisada por MEV. Amostras foram fixadas em solução de glutaraldeído 2,5\% em tampão cacodilato de sódio $1 \mathrm{M}$ por 24 horas e posteriormente desidratadas em soluções de concentrações crescentes de etanol. Em seguida, o material foi seco no aparelho de ponto crítico utilizando $\mathrm{CO}_{2}$ líquido e acetona. Géis foram fraturados, montados em suportes sob fita dupla face de carbono e metalizados em ouro. O material foi analisado em microscópio eletrônico de varredura JEOL 5600 SEM utilizando voltagem de $7 \mathrm{kV}$. 


\subsection{RESULTADOS E DISCUSSÃO}

\subsubsection{Estudo reológico oscilatório}

\section{- Varredura de Freqüência}

Inicialmente, realizou-se um estudo do comportamento do ângulo de fase das suspensões, que combina o comportamento de G`e G". As curvas obtidas foram comparadas com o comportamento típico de alguns materiais, como sugerido por Steffe (1996).

Na Figura 3.2 estão apresentadas curvas do comportamento de gelatina e colágeno hidrolisado puros, nas concentrações de sólidos totais de 4 e $10 \%$. Foi observado que as suspensões contendo apenas gelatina, nas duas concentrações estudadas apresentaram uma variação do ângulo de fase constante por toda a faixa de freqüência avaliada $\left(0,1\right.$ a $\left.100 \mathrm{rad} . \mathrm{s}^{-1}\right)$ e com valores de $\delta$ quase nulos, ou seja, típico comportamento de gel, como era esperado. $\mathrm{O}$ colágeno hidrolisado, quando analisado numa concentração de $4 \%$ se assemelhou a uma solução diluída, com valores de ângulo de fase em torno da região dos fluidos Newtonianos. Esses valores diminuíram quando a concentração foi aumentada para $10 \%$, passando a apresentar um comportamento próximo ao de uma solução concentrada.

A Figura 3.3 apresenta o comportamento dos módulos G` e G“ referentes aos sistemas compostos por gelatina e colágeno hidrolisado, nas concentrações totais de 4 \% e $10 \%$. Notese que os gráficos foram elaborados na mesma escala, permitindo observar que a maior concentração de sólidos elevou os valores de G`e G” de forma global.

Como era esperado, o módulo de armazenamento $\left(G^{\prime}\right)$ foi sempre maior que o de dissipação (G") nos sistemas que continham gelatina, evidenciando o comportamento de gel desse polímero. Observou-se também que, à medida que a concentração de gelatina aumentou, houve um aumento nos valores de $G^{\prime}$ (módulo do platô). É sabido que o platô reflete a estrutura da rede formada por interações intermoleculares não-covalentes em soluções de gelatina (BOHIDAR; DUBIN; OSADA, 2003). 


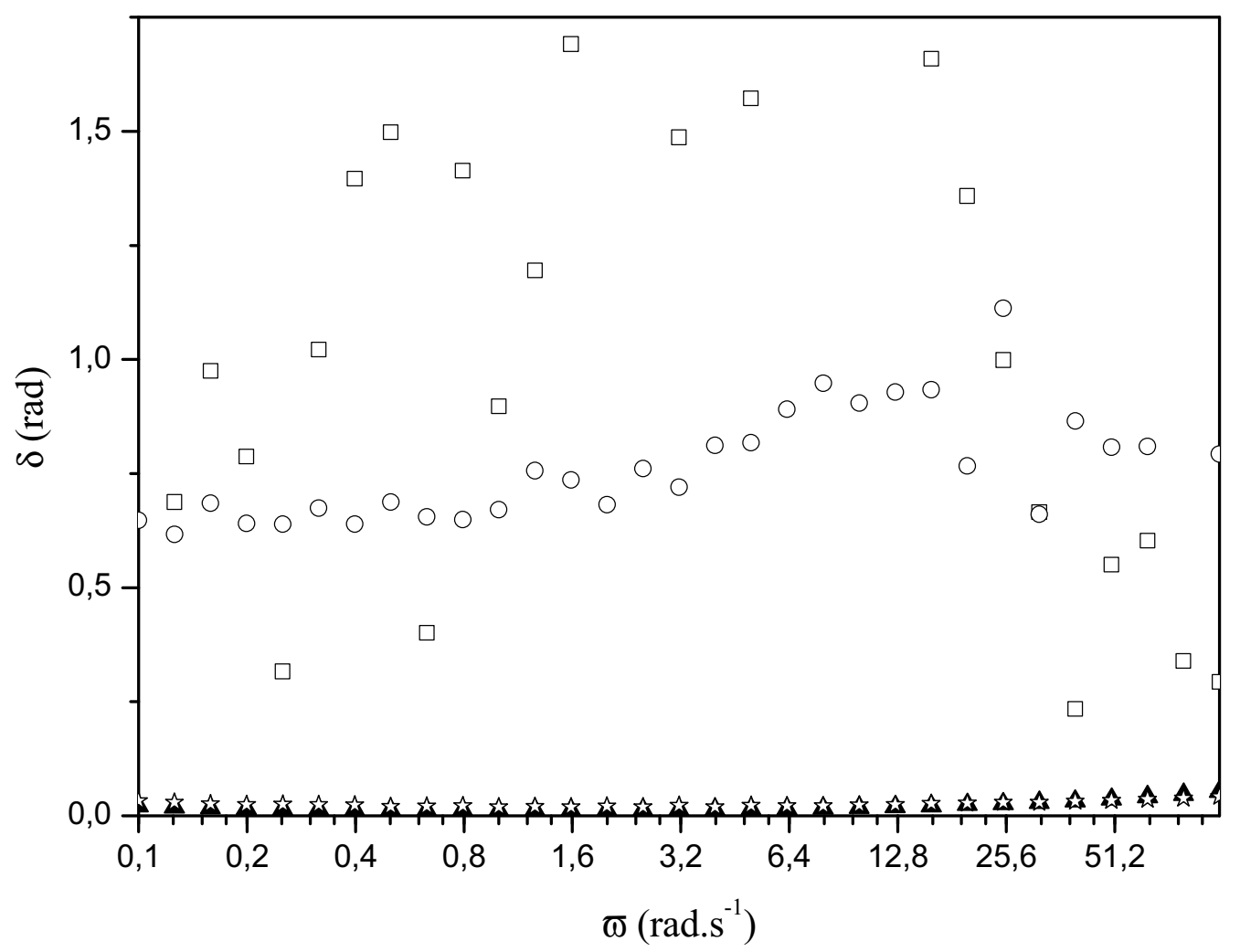

Figura 3.2 - Variação do ângulo de fase $(\delta)$ com a freqüência $(\omega)$ para gelatina e colágeno hidrolisado puros, nas concentrações de 4 e $10 \%$. $(\square=4 \%$ colágeno; $\boldsymbol{\Delta}=4 \%$ gelatina; $O=10 \%$ colágeno; $=10 \%$ gelatina).

A forte relação que a concentração de gelatina exerce sobre o máximo valor do módulo de armazenamento $\left(G^{\prime}\right)$ das soluções contendo gelatina e colágeno hidrolisado pode ser representada por uma função exponencial (equação 3.3), como pode ser observado na Figura 3.4. Esse máximo valor de $G^{\prime}$ é observado nos ensaios reológicos ao final da etapa isotérmica, a $20^{\circ} \mathrm{C}$ por 1 hora na freqüência de $1 \mathrm{rad} \cdot \mathrm{s}^{-1}$.

$$
\mathrm{y}=\mathrm{K} \cdot\left(\mathrm{x}^{\mathrm{n}}\right)
$$

onde x é a fração mássica de gelatina na suspensão e $\mathrm{K}$ e n são parâmetros de ajuste do modelo. A equação (3.3) apresentou bom ajuste $\left(\mathrm{R}^{2}>0,999\right)$ aos dados experimentais sendo que os valores dos parâmetros $\mathrm{K}(\mathrm{Pa})$ e $\mathrm{n}$ obtidos foram, respectivamente, $1,26 \times 10^{6} \pm 2,59 \mathrm{x}$ $10^{5}$ e $2,59 \pm 0,09$. O valor de $\mathrm{n}$ observado foi maior que a unidade, o que demonstra a forte influência que a concentração de gelatina exerce sobre os valores de $\mathrm{G}^{\text {’. }}$ 

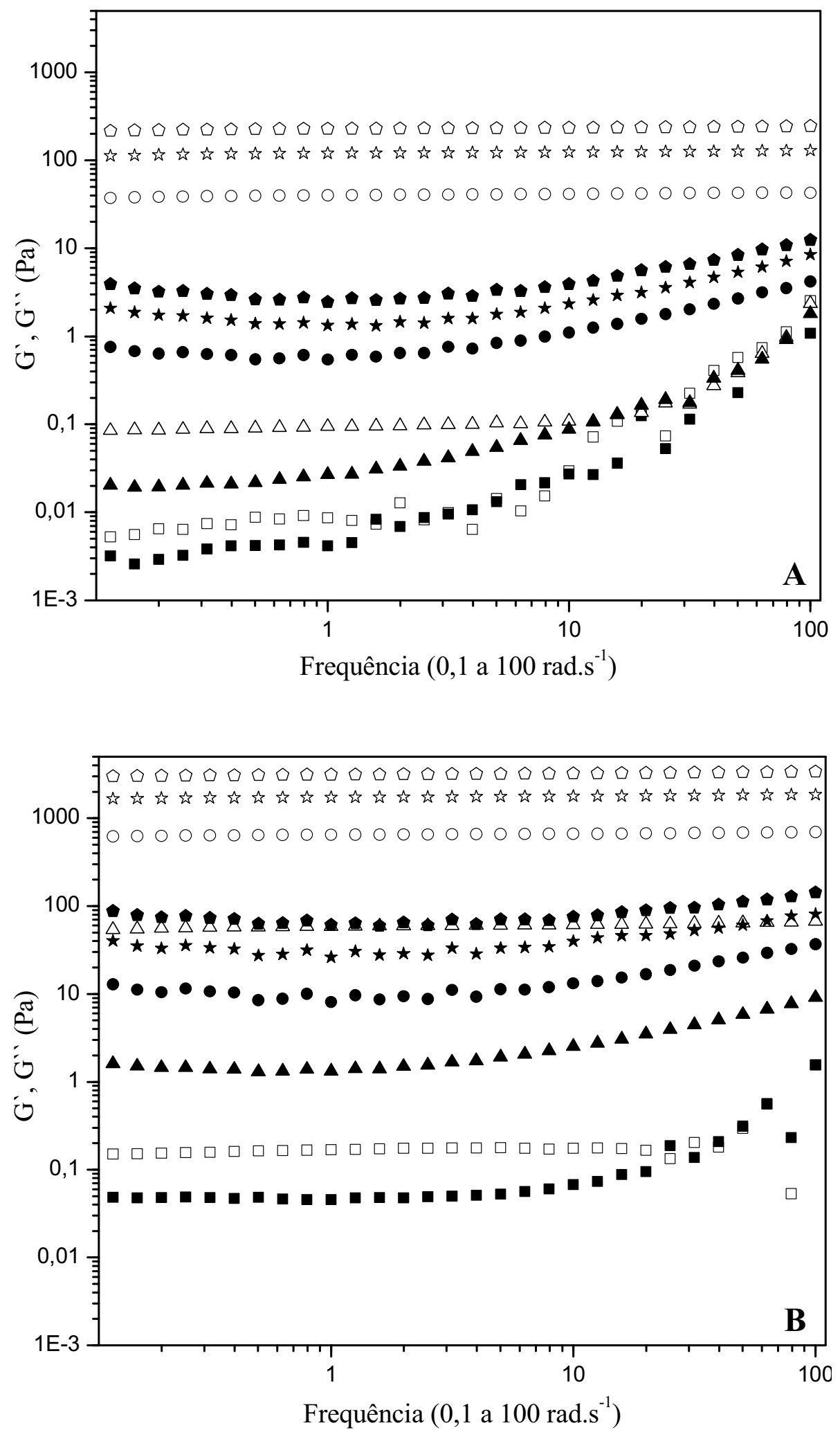

Figura 3.3 - Módulos de armazenamento ( $\left.G^{\prime}\right)$ e dissipação $\left(G^{\prime \prime}\right)$ na faixa de freqüências de 0,1 a 100 rad.s $\mathrm{s}^{-1}$ de soluções aquosas de gelatina e colágeno hidrolisado. (A) 4\% sólidos totais. (B) $10 \%$ sólidos totais. Símbolos abertos $=G^{\prime}$, fechados $=G^{\prime \prime}$. Proporção, $(\%$ em massa $)$, gelatina e colágeno hidrolisado, respectivamente: $\square=0: 100 ; \triangle=25: 75 ; O=50: 50 ; \quad \bar{\zeta}=75: 25 ; \circlearrowleft=100: 0$. 


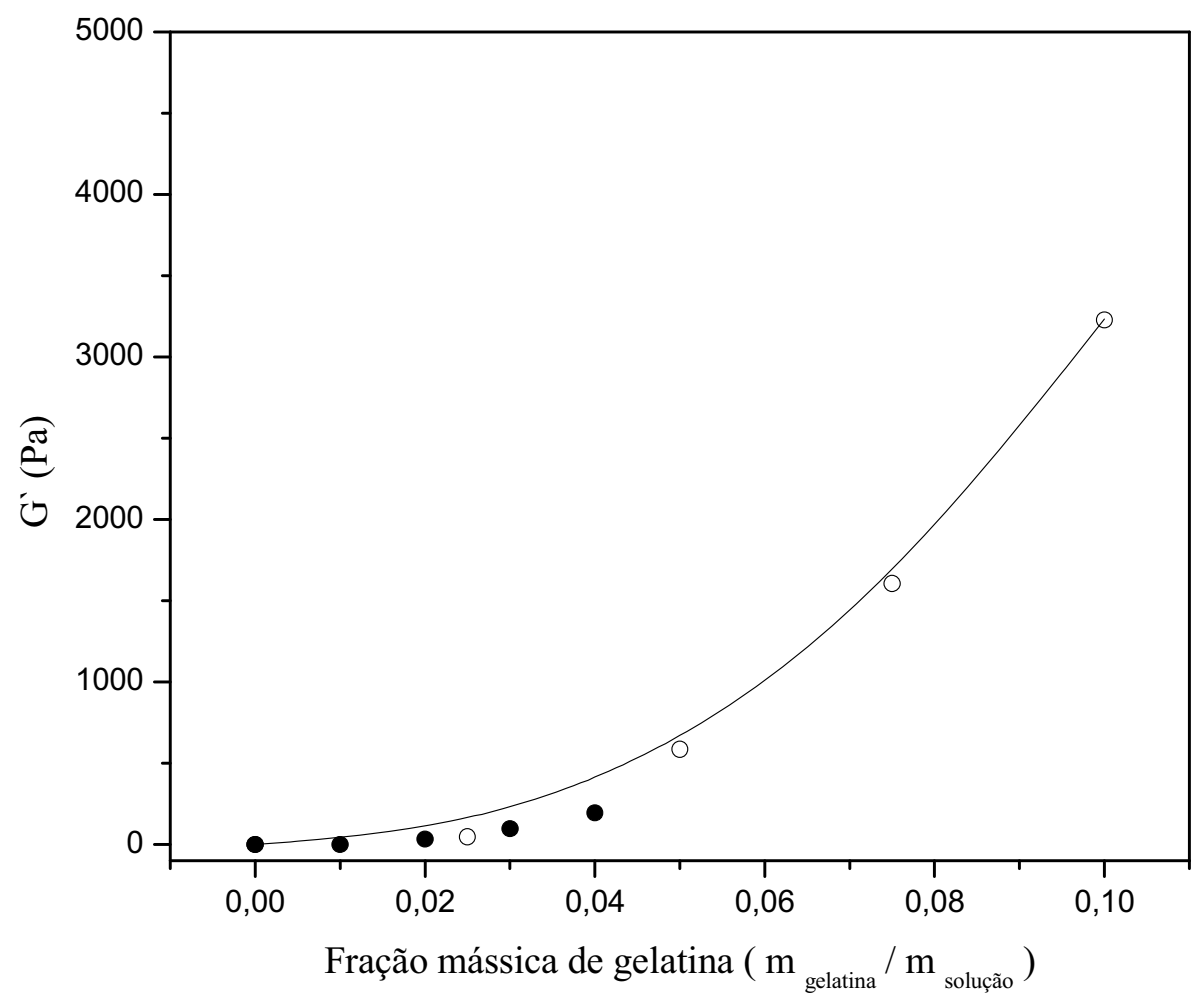

Figura 3.4 - Efeito da concentração de gelatina sobre o módulo de armazenamento $\left(G^{\prime}\right)$ nas soluções contendo gelatina e colágeno hidrolisado. Símbolos abertos $=10 \%$ de sólidos totais. Símbolos fechados $=$ $4 \%$ de sólidos totais.

A Figura 3.5 apresenta o comportamento de $G^{`}$ das soluções de gelatina e colágeno hidrolisado com $10 \%$ de sólidos totais, na região de baixa freqüência angular. $\mathrm{O}$ início do platô varia com a concentração de gelatina, de forma que esse ponto é deslocado para a direita à medida que a concentração de gelatina nas soluções diminui. $\mathrm{O}$ mesmo foi observado por Zandi, Mirzadeh e Mayer (2007). Para soluções contendo somente colágeno hidrolisado, não foi possível observar região de platô, ou seja, esse polímero não possui característica de formação de gel, sendo a gelatina o polímero responsável por essa característica. 


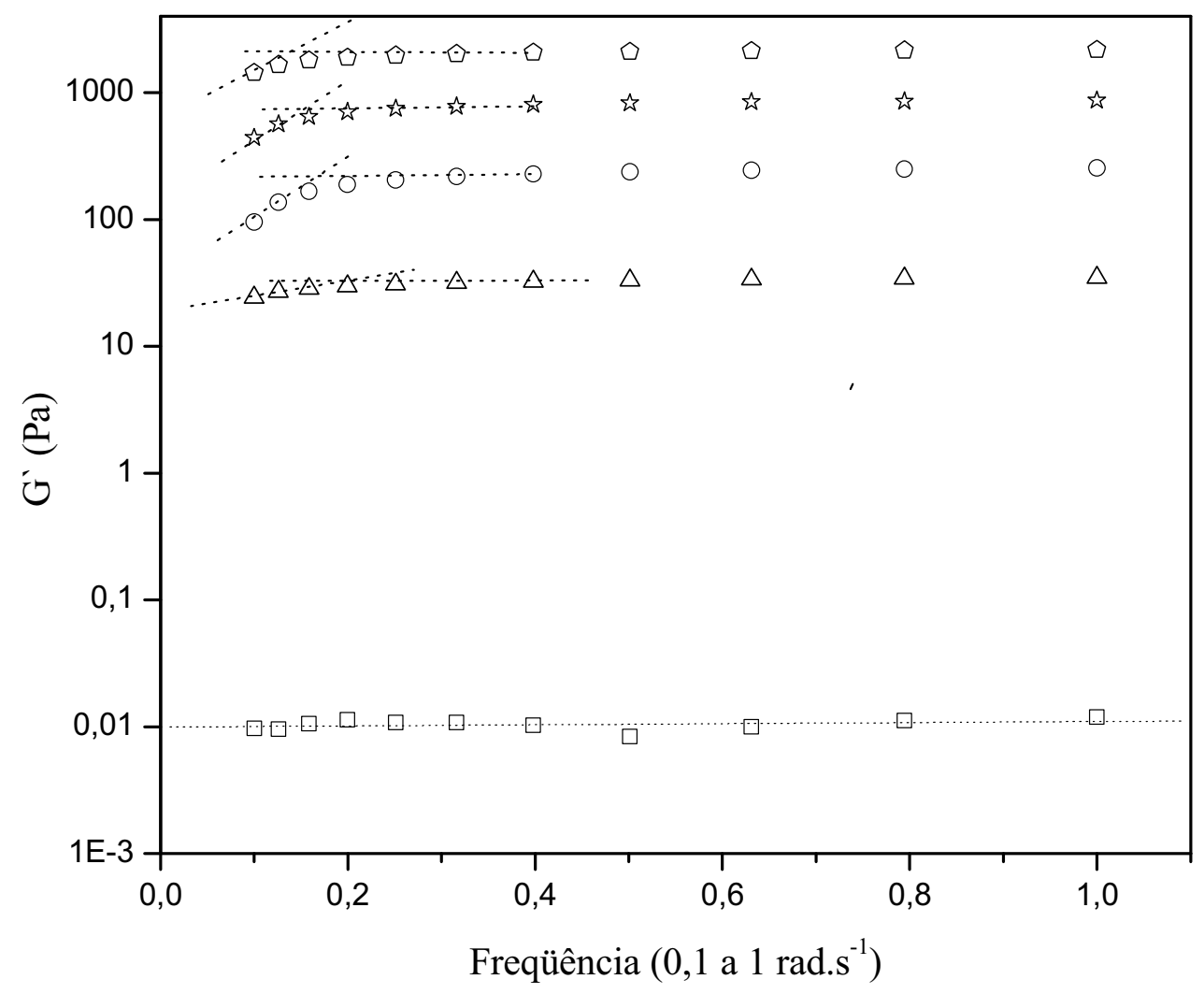

Figura 3.5 - Efeito da concentração de gelatina e colágeno (\% em massa) sobre o módulo de armazenamento $\left(G^{\prime}\right)$ na região de baixa freqüência angular $\left(0,1\right.$ a 1,0 rad.s $\left.{ }^{-1}\right)$ a $20{ }^{\circ} \mathrm{C}$. Sólidos totais $=10 \%$. Proporção, (\% em massa), gelatina e colágeno hidrolisado, respectivamente: $\square=0: 100$; $\triangle=25: 75 ; \bigcirc=50: 50 ; \quad$ 范 $=75: 25 ; \Delta=100: 0$.

\section{- Rampa de Temperatura}

Analisando-se o comportamento do módulo de armazenamento ao longo do tempo, durante as diferentes rampas de aquecimento e resfriamento, observou-se que para todos os ensaios contendo $4 \%$ de sólidos totais e para os ensaios contendo $10 \%$ de sólidos totais nos quais a gelatina representa até $50 \%$ destes sólidos, o ponto de fusão ocorreu em 39,4 $\pm 1,3$ ${ }^{\circ} \mathrm{C}$. Este ponto é obtido observando-se o decréscimo brusco dos valores de G'. Nas amostras de gelatina e colágeno hidrolisado com $10 \%$ de sólidos totais nos quais a gelatina corresponde a $75 \%$ e $100 \%$ da massa de sólidos totais, o ponto de fusão foi de $33,6 \pm 1,1{ }^{\circ} \mathrm{C}$, como pode ser observado nas Figuras 3.6 e 3.7.

Zandi, Mirzadeh e Mayer (2007) estudaram o comportamento de soluções de gelatina tipo A (pele suína) nas concentrações de 1, 3 e $5 \%$ através de reologia por testes oscilatórios, medindo os módulos de armazenamento durante a transição sol-gel em função da temperatura 
e da concentração. Os autores observaram que os géis perdem sua elasticidade quando aquecidos acima do ponto de fusão (entre 25 e $30{ }^{\circ} \mathrm{C}$ para soluções com $1 \%$ de gelatina), e uma solução polimérica viscosa é formada.

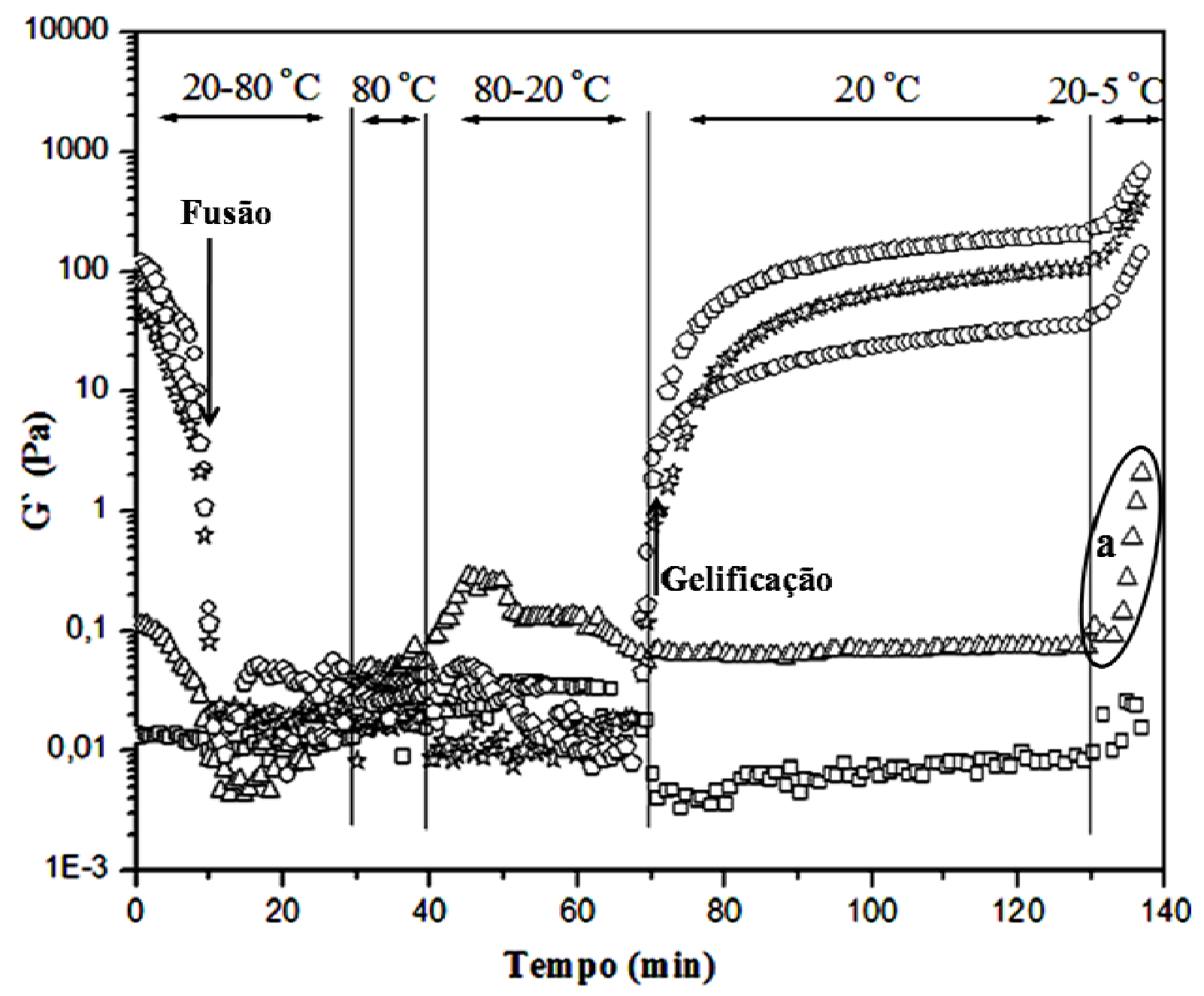

Figura 3.6 - Módulo de armazenamento $\left(G^{`}\right)$ em função do tempo nas rampas de temperatura estudadas para diferentes soluções aquosas de gelatina e colágeno hidrolisado, todas com $4 \%$ de sólidos totais. Proporção, (\% em massa), gelatina e colágeno hidrolisado, respectivamente: $\square=0: 100$; $\triangle=25: 75 ; \bigcirc=50: 50 ;$ 色 $=75: 25 ; \Delta=100: 0$.

Mantendo as amostras a $80{ }^{\circ} \mathrm{C}$ por 10 minutos, observou-se que as soluções aquosas de gelatina com colágeno hidrolisado permaneceram sem elasticidade, prevalecendo apenas as interações intra-moleculares, independente da concentração de gelatina. 


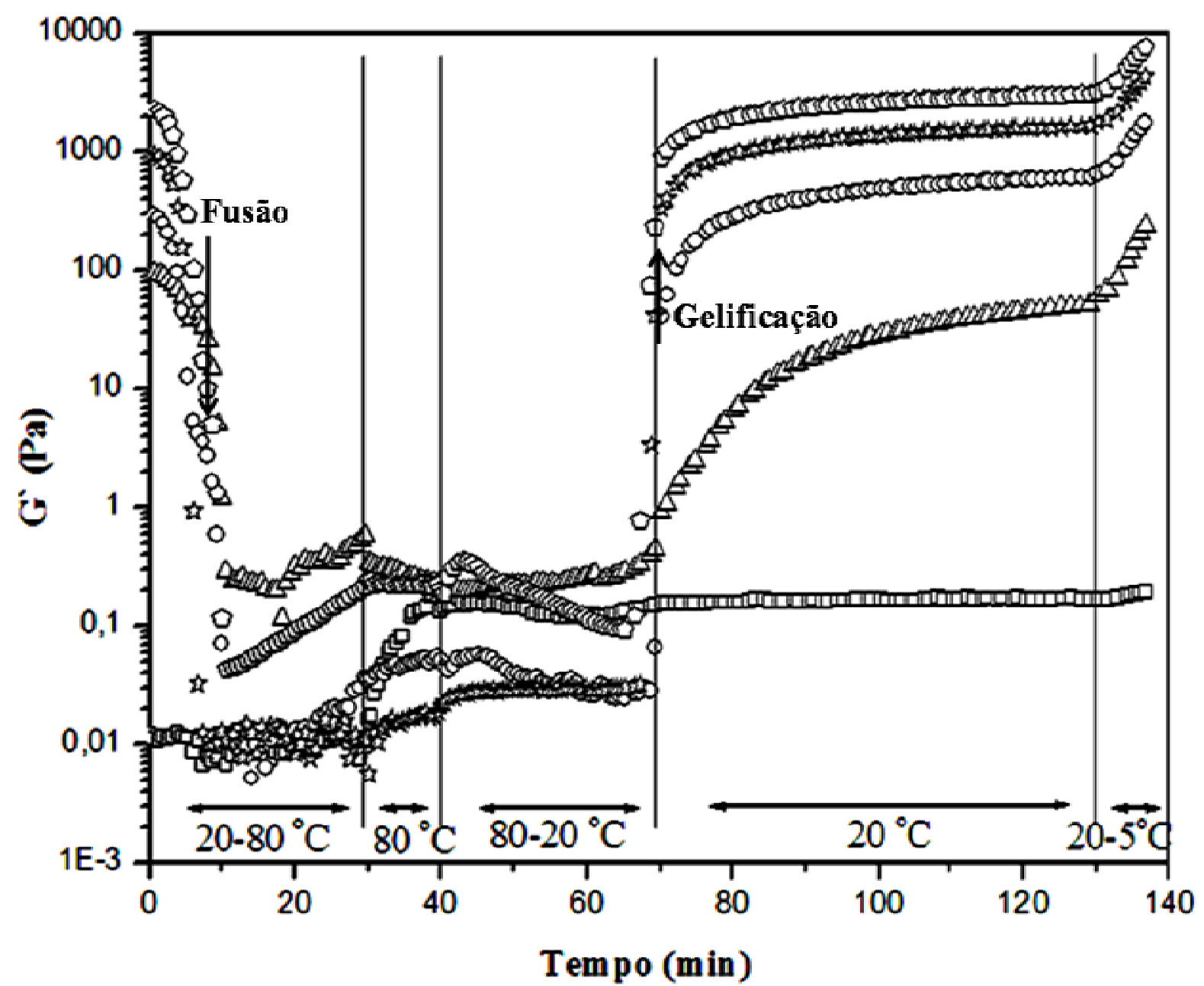

Figura 3.7 - Módulo de armazenamento (G’) em função do tempo nas rampas de temperatura estudadas para diferentes soluções aquosas de gelatina e colágeno hidrolisado, todas com $10 \%$ de sólidos totais. Proporção, (\% em massa), gelatina e colágeno hidrolisado, respectivamente: $\square=0: 100$; $\triangle=25: 75 ; O=50: 50 ; \quad \precsim=75: 25 ; \Delta=100: 0$.

A temperatura de gelificação dos sistemas (Figuras 3.6 e 3.7), ocorreu em torno de 20 ${ }^{\circ} \mathrm{C}$, em todas as concentrações de gelatina, exceto para a solução na qual a gelatina representa apenas $1 \%$ dos sólidos totais. Nesta solução, devido à baixa concentração deste polímero, a gelificação ocorreu a $10{ }^{\circ} \mathrm{C}$ (Figura 3.6, região a). Também se pode observar a ausência da região de elevação de G` na solução contendo apenas colágeno hidrolisado, evidenciando que este componente não possui característica de formação de gel.

Zandi, Mirzadeh e Mayer (2007) observaram a dependência temperatura de gelificação em função da concentração de gelatina através da observação do aumento brusco da viscosidade com a diminuição da temperatura. As soluções gelificaram a $283 \mathrm{~K}\left(10^{\circ} \mathrm{C}\right) \operatorname{com} 1$ \% de concentração, a 293 K com 3 \% e a 297 K com 5 \% de concentração de gelatina. 
Durante a rampa de resfriamento, uma grande quantidade de hélices é formada e o estabelecimento da rede do gel se mostra sensível à concentração de gelatina (DUHAMEL; HELLIO; DJABOUROV, 2002). Ou seja, se continuarmos abaixando a temperatura após atingir o ponto de gel $\left(20\right.$ a $\left.5{ }^{\circ} \mathrm{C}\right)$, observa-se que ligações físicas cruzadas ocorrem, como resultado de interações intermoleculares e como resultado dessas ligações cruzadas, o módulo de armazenamento se desenvolve, como pode ser observado nas Figuras 3.6 e 3.7.

Kim e Uyama (2007) estudaram o comportamento reológico de gelatina obtida da pele de peixes de água fria, observando a influência exercida pela concentração de gelatina e pela adição de enzima microbiana trans-glutaminase. Os autores também observaram que a concentração de gelatina tem uma ação direta no número de ligações cruzadas. Ao analisarem soluções contendo de 10 a 40 \%, em massa, de gelatina observaram que o número de ligações cruzadas aumentou de 5,2 a 28,5 \%. Quando adicionaram a enzima, observaram que esse número de ligações cruzadas aumenta, proporcionalmente ao aumento da concentração de enzima. Isso indica que a enzima utilizada é capaz de viabilizar a reação entre grupos amina disponíveis (como resíduos de glutamina e lysina, por exemplo) e viabilizar um maior número de ligações cruzadas, resultando em géis de gelatina com propriedades mecânicas mais fortes.

Analisando, ainda, o comportamento de $\mathrm{G}^{\prime}$ durante o aquecimento $\left(20\right.$ a $\left.80{ }^{\circ} \mathrm{C}\right)$, observa-se que na região de alta temperatura (Figura 3.8, região b), o módulo de armazenamento diminuiu consideravelmente e que, independente da concentração de gelatina, as curvas apresentaram a mesma característica, ou seja, tenderam a um comportamento constante. Este fato é observado porque, nessa faixa de alta temperatura, apenas as interações intramoleculares ocorrem. Observou-se que a queda brusca nos valores de $\mathrm{G}^{`}$ ocorreu em temperaturas próximas a $40{ }^{\circ} \mathrm{C}$, caracterizando o ponto no qual ocorreu a fusão do gel, como já discutido anteriormente. $\mathrm{Na}$ região de temperaturas mais baixas (Figura 3.8, região a) observa-se o aumento dos valores de G', resultado das interações intermoleculares na formação da rede de gel, sendo que este aumento foi proporcional à concentração de gelatina utilizada em casa solução. 


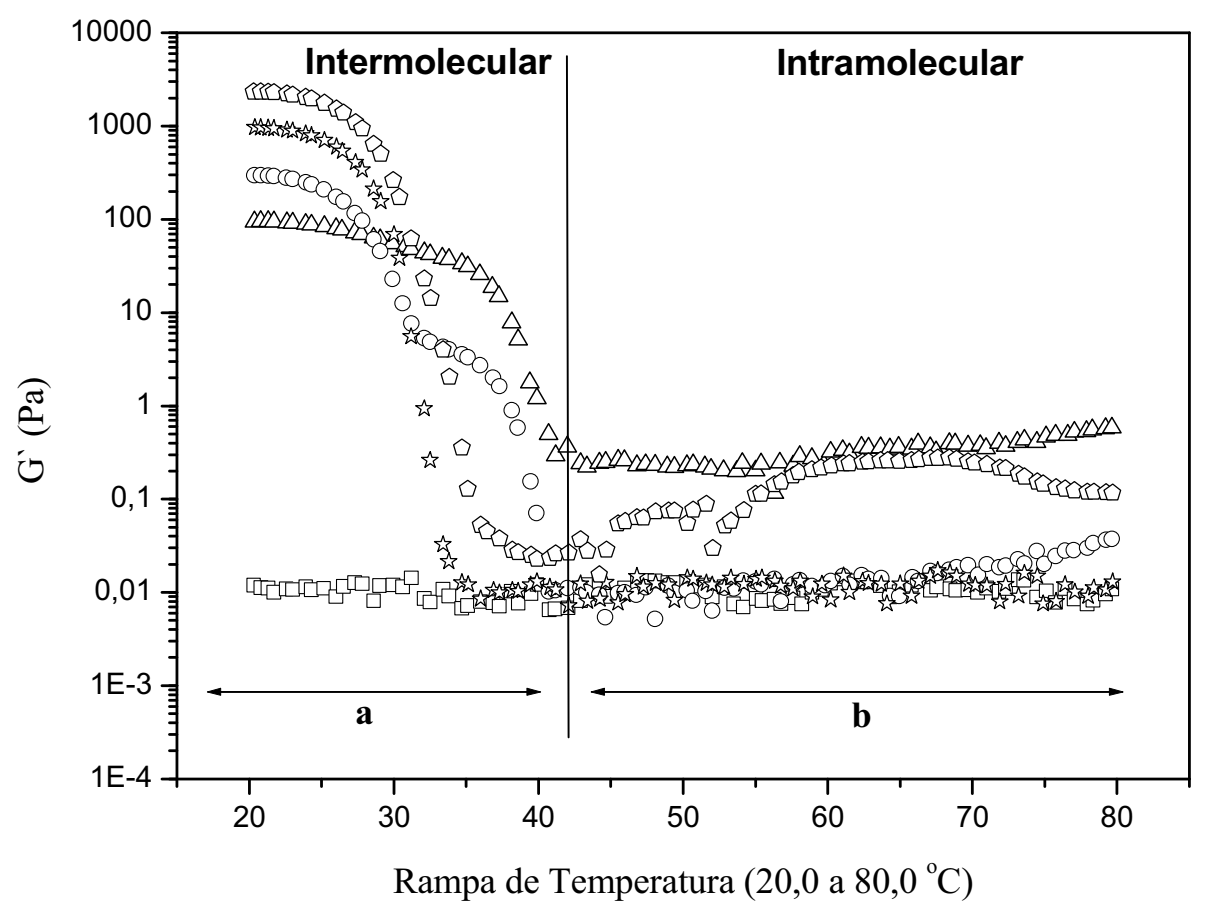

Figura 3.8 - Módulo de armazenamento $\left(G^{`}\right)$ em função de aquecimento de 20 a $80{ }^{\circ} \mathrm{C}$, para diferentes concentrações de gelatina, nos sistemas contendo gelatina e colágeno hidrolisado (10\% de sólidos totais). Proporção, (\% em massa), gelatina e colágeno hidrolisado, respectivamente: $\square=0: 100 ; \triangle=25: 75 ; \bigcirc=50: 50 ;$ 饫 $=75: 25 ; \Delta=100: 0$.

\subsubsection{Gomas de gelatina}

\subsubsection{Estudo reológico por compressão}

Foram obtidos, através dos ensaios reológicos por compressão (TPA), os parâmetros de dureza, fraturabilidade, adesividade, elasticidade, coesividade, gomosidade e mastigabilidade, os quais foram avaliados estatisticamente $(\mathrm{p}<0,05)$ por uma análise de variância (ANOVA). Vale ressaltar que os fatores (variáveis independentes) estudados foram a concentração de gelatina (x) e de colágeno hidrolisado (y).

Observou-se que a concentração dos biopolímeros investigados exerceu sobre os parâmetros de dureza (Figura 3.9), gomosidade e mastigabilidade (Figura 3.10) um efeito significativo apenas de dependência linear, ou seja, não houve efeito significativo da interação entre os fatores. O modelo estatístico do parâmetro dureza é representado pela equação (3.4) 


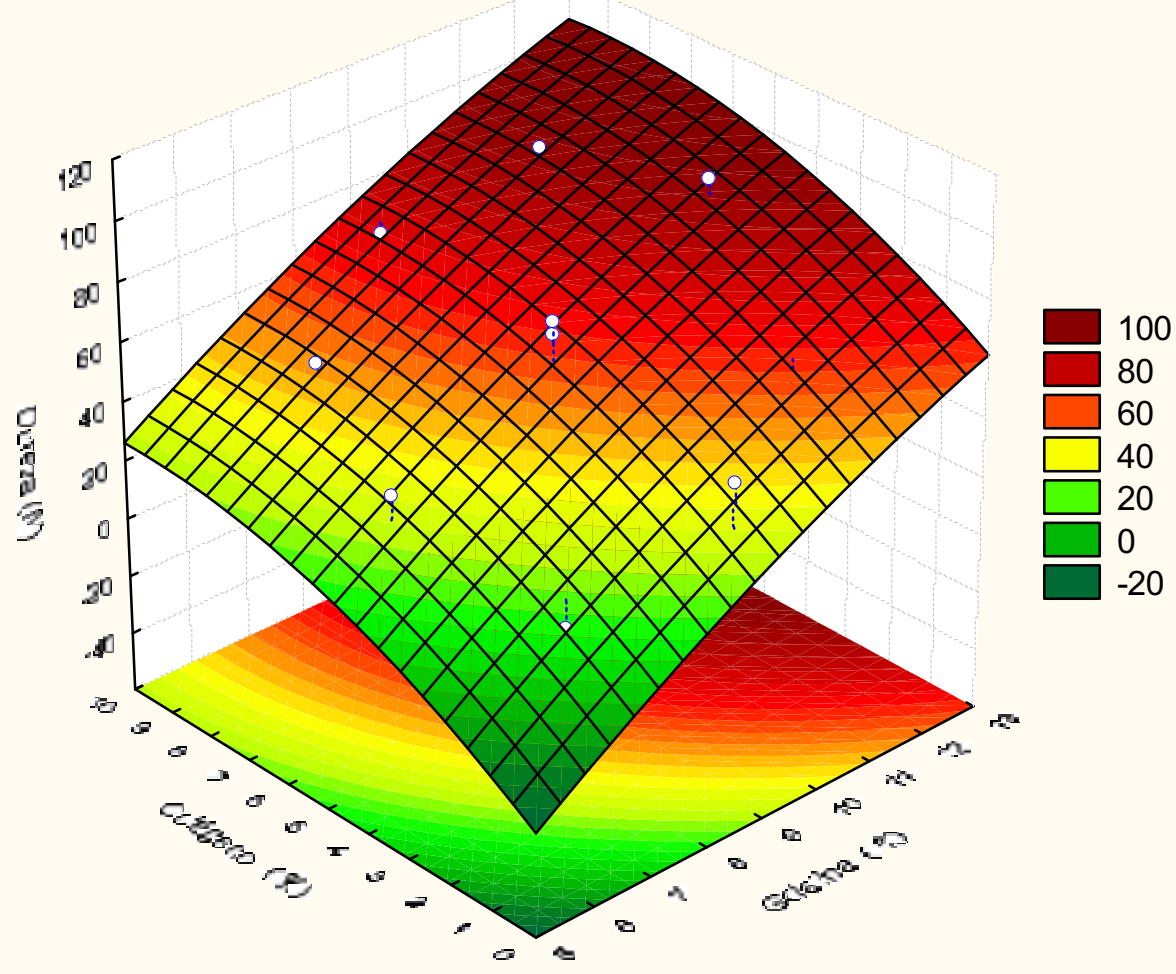

Figura 3.9 - Superfície de resposta do parâmetro dureza, variando-se concentração de gelatina e de colágeno hidrolisado.

$$
Z=62,12+20,83 * x-1,69 * x^{2}+14,44 * y-4,72 * y^{2}-0,39 * x * y+0
$$

onde $\mathrm{Z}$ representa a resposta, no caso a dureza $(\mathrm{N})$ da amostra.

A Figura 3.10 apresenta os gráficos de contorno dos parâmetros gomosidade e mastigabilidade e as equações (3.5) e (3.6) os modelos estatísticos referentes a esses parâmetros, respectivamente.

$$
\begin{aligned}
& Z=39,15+12,44 * x-1,46 * x^{2}+8,97 * y-2,69 * y^{2}-0,02 * x * y \\
& Z=37,35+11,50 * x-1,42 * x^{2}+8,92 * y-2,69 * y^{2}-0,69 * x * y
\end{aligned}
$$



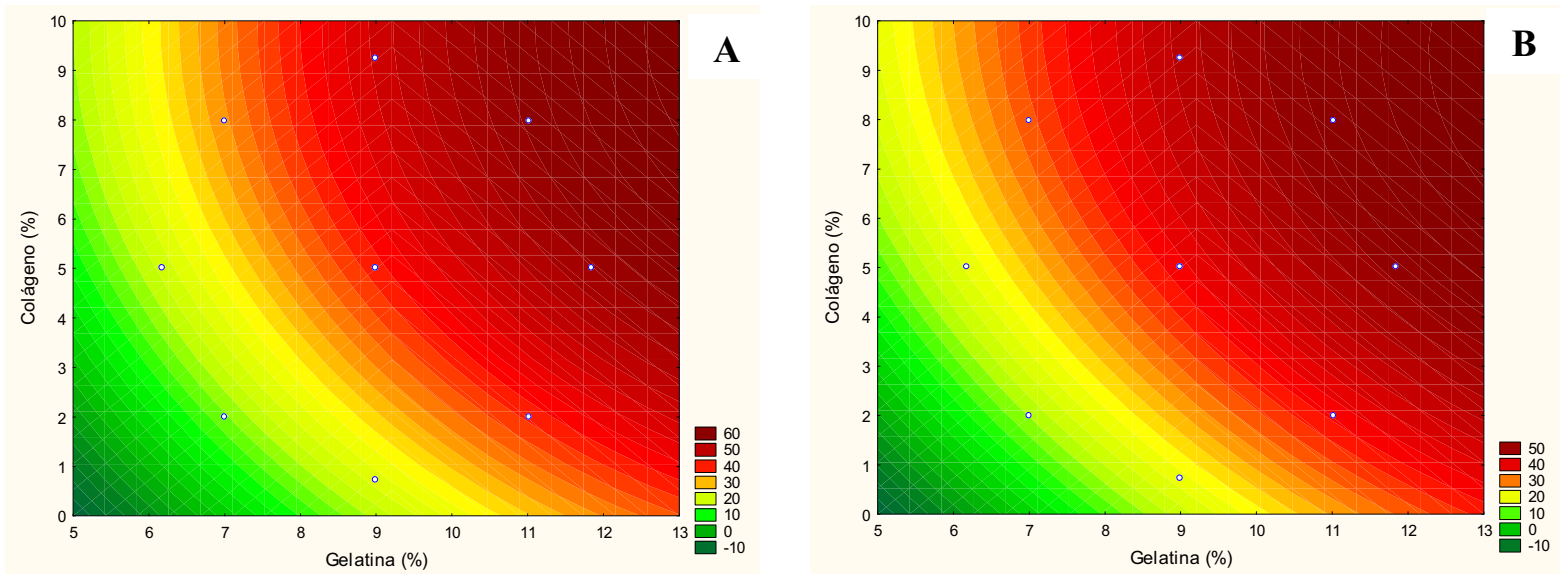

Figura 3.10 - Gráficos de contorno dos parâmetros avaliados no teste TPA, variando-se concentração de gelatina e de colágeno hidrolisado. (A) Gomosidade. (B) Mastigabilidade.

Demars e Ziegler (2001) estudaram géis de gelatina e pectina de alta metoxilação. Esses autores elaboraram gomas contendo níveis de 3,0 a 6,0 \% de gelatina e 0 a $1,5 \%$ de pectina e observaram que a adição de pectina reduziu a força de fratura dos géis de gelatina. Também observaram a dependência da dureza das amostras com relação à concentração de gelatina, de modo que maiores concentrações de gelatina implicaram em gomas com maiores resistências. Dessa forma, concluíram que géis de gelatina e pectina de alta metoxilação possuem propriedades intermediárias, entre géis elásticos de gelatina e géis quebradiços de pectina.

Os parâmetros fraturabilidade, elasticidade e coesividade não foram influenciados significativamente $(\mathrm{p}<0,05)$ por nenhum dos dois fatores estudados. Por fim, observou-se que a concentração de gelatina influenciou de forma significativa no parâmetro adesividade das gomas de gelatina, como pode ser observado na Figura 3.11. O modelo estatístico é representado pela equação (3.7).

Lau, Tang e Paulson (2000) estudaram textura de géis obtidos da mistura de goma gelana e gelatina na presença de diferentes concentrações de íons cálcio. A dureza dos géis obtidos diminuiu à medida que diminuiu a concentração de goma gelana. Por outro lado, a dureza aumentou com o aumento da concentração de íons cálcio até um nível crítico, sendo que após este, a maior concentração de íons cálcio implicou num efeito negativo quanto à dureza. Os parâmetros fraturabilidade, elasticidade e coesividade dos géis foram bastante influenciados pela baixa concentração de íons cálcio $(0-10 \mathrm{mM})$, mas foram menos sensíveis à alta concentração de cálcio do que à proporção de gelatina/gelana utilizada. 
Géis de gelatina são completamente macios e flexíveis, mas requerem uma alta concentração de polímero, tempos longos e baixas temperaturas (WOLF et. al., 1989). A força do gel de gelatina é dependente da concentração, sendo pouco influenciada pela força iônica e pH (PAPAGEORGIOU; KASAPIS; RICHARDSON, 1994; HSU; JAMIESON, 1993).

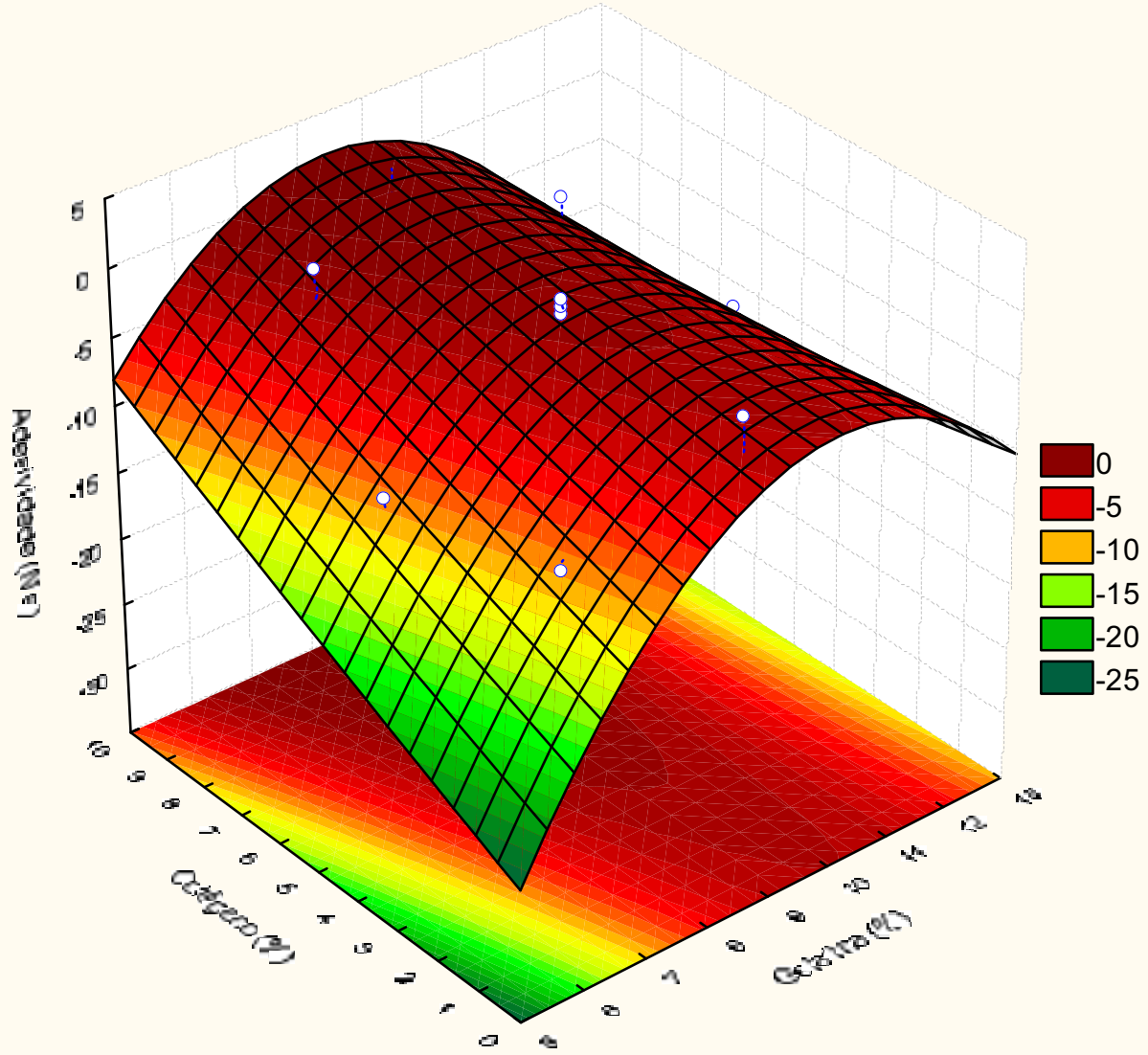

Figura 3.11 - Superfície de resposta do parâmetro adesividade, variando-se concentração de gelatina e de colágeno hidrolisado.

$$
Z=-1,30+0,86 * x-3,44 * x^{2}+1,70 * y+0,07 * y^{2}-1,69 * x * y
$$

Bayarri et al. (2006) estudaram o efeito da adição de sacarose (5 - 25 \%) e aspartame $(0,04-0,16 \%)$ na resistência à compressão de três sistemas de hidrocolóides: k-carragena, goma gelana e k-carragena/goma locusta em três diferentes concentrações $(0,3 ; 0,75$ e 1,2 \%). A adição de sacarose aumentou a força de ruptura nos três sistemas, sendo que este efeito 
apresentou-se mais intenso nos géis de goma gelana. A adição de aspartame não apresentou interferência nos parâmetros de compressão.

\subsubsection{Propriedades ópticas}

Medidas instrumentais de cor foram realizadas com o objetivo de avaliar o efeito do aumento da concentração dos polímeros na opacidade dos géis obtidos. Observou-se que, exceto pelo efeito quadrático da concentração de gelatina, todos os outros efeitos inclusive a interação dos fatores mostraram-se significativos $(\mathrm{p}<0,05)$. O gráfico da superfície de resposta obtido encontra-se na Figura 3.12 e o modelo estatístico de ajuste é apresentado na equação (3.8).

$$
Z=97,57+1,53 * x-0,40 * x^{2}+2,13 * y-0,84 * y^{2}-0,96 * x * y
$$

Barrangou, Daubert e Foegeding (2006) estudaram propriedades de textura de géis de agarose $(0,5-2,5 \%)$ com glicerol $(0-60 \%)$ e observaram que o aumento na concentração de agarose produz aumento na força dos géis e uma rede mais quebradiça, enquanto que o aumento na concentração de glicerol resultou no aumento da força e numa rede mais deformável. Também observaram que à medida que aumentou a concentração de glicerol, aumentou a transparência dos géis, enquanto o aumento na concentração de agarose resultou no aumento da opacidade e da turbidez.

A diferença de cor, $\Delta \mathrm{E}$, foi calculada e expressa em função da soma da massa de gelatina e colágeno hidrolisado utilizada. À medida que esses componentes aumentaram na formulação, a diferença de cor também aumentou de acordo com uma relação linear $\left(\mathrm{R}^{2}>0,98\right)$, como pode ser observado na Figura 3.13. 


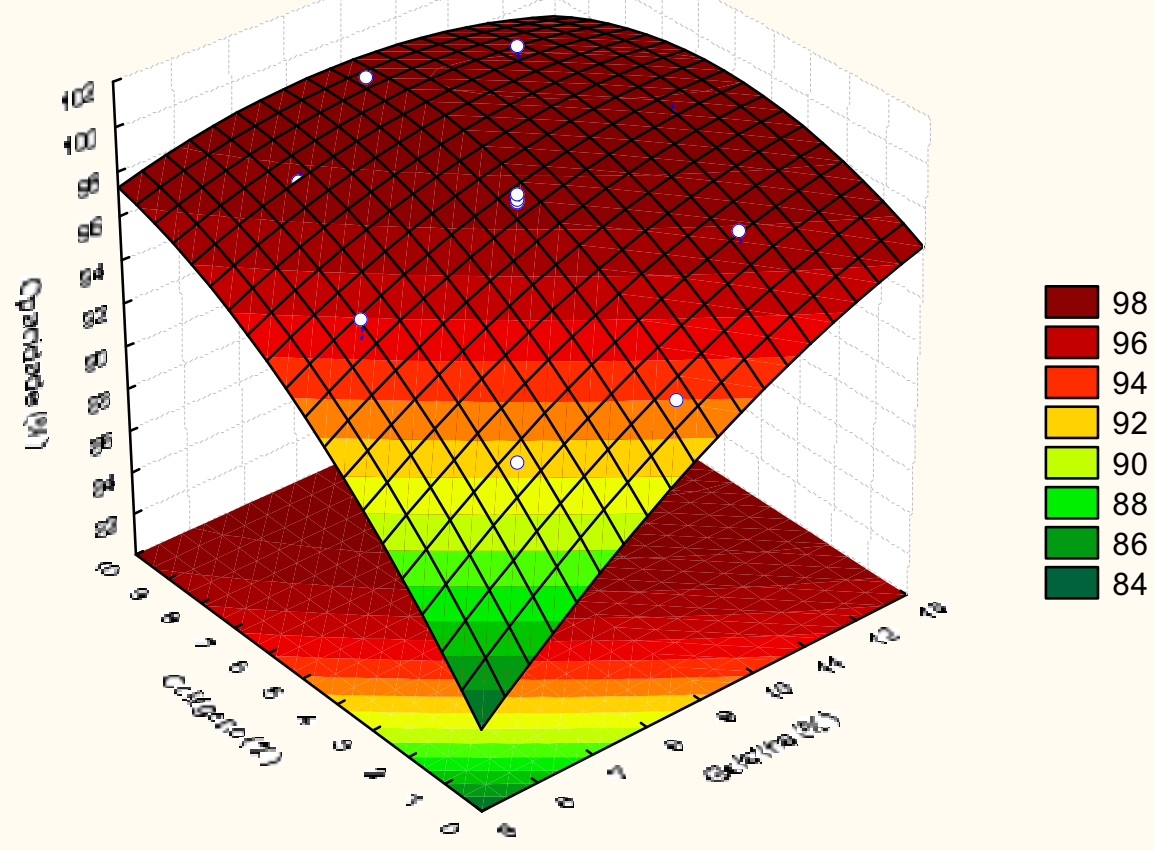

:entração de gelatina e de

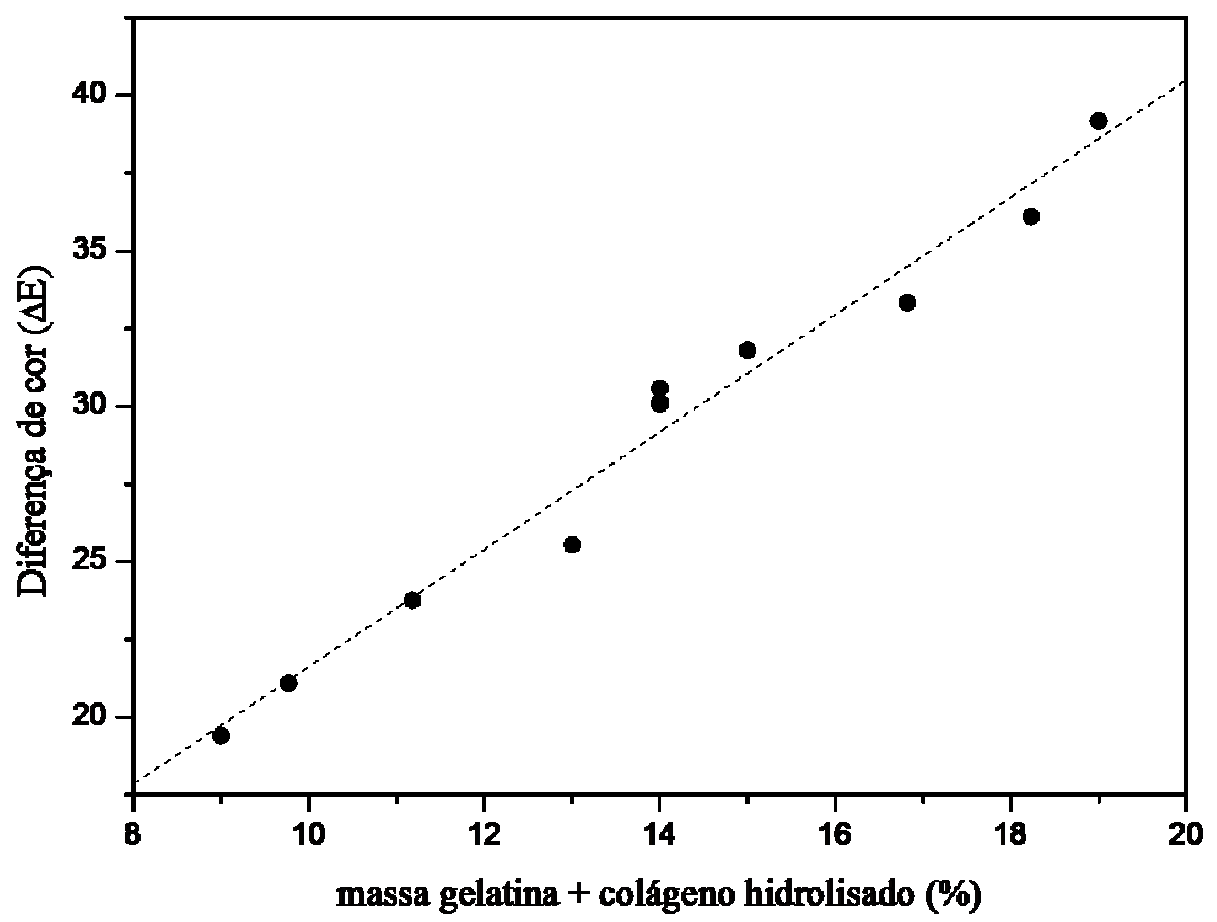

Figura 3.13 - Relação linear da diferença de cor em função da massa de gelatina e colágeno hidrolisado utilizada na elaboração dos géis a base de xarope de maltitol e xilitol. 


\subsubsection{Análise sensorial}

Notas atribuídas acima do ponto da indiferença foram agrupadas e expressas como a porcentagem de aceitação do produto. Observou-se que no grupo infantil, a aceitação do produto final foi de $86,4 \%$ enquanto que dentre os adultos foi de $83,9 \%$.

\subsubsection{Microscopia eletrônica de varredura (MEV)}

A microestrutura da bala utilizada para análise sensorial foi estudada por microscopia eletrônica de varredura (Figura 3.14). Nota-se que a gelatina forma uma rede tri-dimensional consistente e uniforme enquanto que a introdução do colágeno hidrolisado provoca a reestruturação desta rede, resultando em uma malha mais aberta, cujas cavidades são preenchidas por uma fina rede de colágeno hidrolisado.
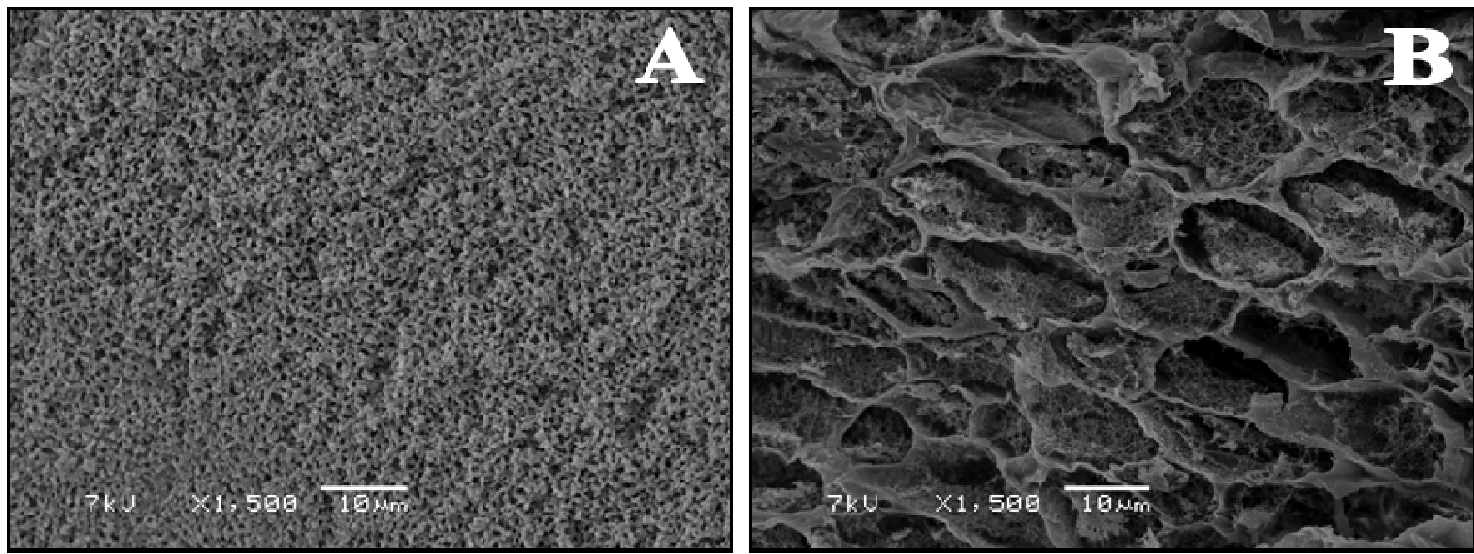

Figura 3.14 - Microscopia eletrônica de varredura (MEV) de uma goma contendo (A) apenas gelatina e (B) gelatina com colágeno hidrolisado (ponto central: $9 \%$ de gelatina e $5 \%$ de colágeno hidrolisado). 


\subsection{CONCLUSÕES}

Os valores de G`e G“ aumentam com a diminuição da temperatura e com o aumento da concentração de gelatina nas soluções. O colágeno hidrolisado não apresenta característica de formação de gel e não foi observado efeito sinergístico quando estudado em conjunto com a gelatina. Exceto para a solução contendo $1 \%$ de gelatina, a temperatura de formação de gel foi de $20{ }^{\circ} \mathrm{C}$.

As concentrações de gelatina e de colágeno hidrolisado nas gomas de gelatina dietéticas exerceram, sobre os parâmetros de dureza, gomosidade e mastigabilidade, um efeito significativo apenas de dependência linear, ou seja, não há efeito significativo da interação entre os fatores. Os parâmetros fraturabilidade, elasticidade e coesividade não foram influenciados significativamente $(\mathrm{p}<0,05)$ por nenhum dos dois fatores estudados. A concentração de gelatina influenciou de forma significativa o parâmetro adesividade das gomas de gelatina.

O aumento nas concentrações de gelatina e de colágeno hidrolisado apresentou efeito significativo sobre a opacidade dos géis obtidos e um aumento crescente na diferença de cor obedeceu a uma relação linear em função da concentração total de biopolímeros na amostra $\left(\mathrm{R}^{2}>0,98\right)$.

Foi possível obter um produto com propriedades mecânicas similares às das tradicionais gomas de gelatina, sendo diferenciado por não utilizar sacarose na formulação e por apresentar maior conteúdo protéico. O produto apresentou boa aceitação tanto pelo público infantil como por adultos.

\section{Agradecimentos}

Os autores agradecem Dr. Paulo Filemon Paolucci Pimenta, chefe do Laboratório de Entomologia Médica (CPqRR/FIOCRUZ) pelo uso do microscópio eletrônico de varredura. Também agradecemos à Gelita pelas amostras de gelatina e colágeno hidrolisado e Tovani pela amostra de xilitol e ao apoio financeiro da CAPES (bolsa de estudos) e FAPESP (processo 2006/56015-2). 


\section{$\underline{\text { REFERÊNCIAS }}$}

BARRANGOU, L. M.; DAUBERT, C. R.; FOEGEDING, E. A. Textural properties of agarose gels. I. Rheological and fracture properties. Food Hydrocolloids, v. 20, p. 184-195, 2006.

BAYARRI, S.; IZQUIERDO, L.; DURÁN, L.; COSTELL, E. Effect of addition of sucrose and aspartame on the compression resistance of hydrocolloids gels. International Journal of Food Science and Technology, v. 41, p. 980-986, 2006.

BINSI, P. K.; SHAMASUNDAR, B. A.; DILEEP, A. O.; BADII, F.; HOWELL, N. K. Rheological and functional properties of gelatin from the skin of Bigeye snapper (Priacanthus hamrur) fish: Influence of gelatin on the gel-forming ability of fish mince. Food Hydrocolloids, v. 23, p. 132-145, 2009.

BOHIDAR, H.; DUBIN, P.; OSADA, Y. Polymer gels fundamentals and applications. Washington, DC: American Chemical Society, 2003.

BUREY, P., BHANDARI, B. R., RUTGERS, R. P. G., HALlEY, P. J.; TORLEY, P. J. Confectionery Gels: A Review on Formulation, Rheological and Structural Aspects. International Journal of Food Properties, v. 12, n.1, p. 176 - 210, 2009.

DEMARS, L. L.; ZIEGLER, G. R. Texture and structure of gelatin/pectin-based gummy confections. Food Hydrocolloids, v. 15, p. 643-653, 2001.

FIGUEIRÓ, S. D.; GÓES, J. C.; MOREIRA, R. A.; SOMBRA, A. S .B. On the physicochemical and dielectric properties of glutaraldehyde crosslinked galactomannan-collagen films. Carbohydrate Polymers, v. 56, p. 313-320, 2004.

GARCIA, T. Analysis of gelatine-based confections. Monofactured Confectionery, Glen Rock, p. 93-101, jun. 2000.

HSU, S.; JAMIESON, A. M. Viscoelastic behavior at the thermal sol-gel transition of gelatin. Polymer, v. 34, p. 2602-2608, 1993.

JACKSON, E. B.; LEES, R. Sugar Confectionary and Chocolate Manufacture. Saint Edmundsbury: Press Limited, 1973, 379 p.

KIM, Y. J.; UYAMA, H. Biocompatible hydrogel formation of gelatin from cold water fish via enzymatic networking. Polymer Journal, v. 39, n. 10, p. 1040-1046, 2007. 
LAU, M. H.; TANG, J.; PAULSON, A. T. Texture profile and turbidity of gellan/gelatin mixed gels. Food Research Internacional, v. 33, p. 665-671, 2000.

NORTON, I. T.; FRITH, W. J. Microstructure design in mixed biopolymer composites. Food Hydrocolloids, v. 15, n. 4-6, p. 543-553, 2001.

PAPAGEORGIOU, M.; KASAPIS, S.; RICHARDSON, R. K. Steric exclusion phenomena in gellan/gelatin systems. I. Physical properties of single and binary gels. Food Hydrocolloids, v. 8, n. 2, p. 97-112, 1994.

PLUCKNETT, K. P.; NORMAND, V.; POMFRET, S. J.; FERDINANDO, D. 'Ductile' mixed biopolymer gel composites. Polymer, v. 41, n. 6, p. 2319-2323, 2000.

QUEIROZ, M. B. São Paulo (Estado). Secretaria de Agricultura e Abastecimento. Centro de Tecnologia de Cereais e Chocolate. Balas de Gomas e Doces Gelificados: Ingredientes e Tecnologia de Fabricação. Manual técnico de tecnologia de fabricação de balas, São Paulo: ITAL, n. 17, p. 39-49, 1999.

RENARD, D.; VAN DE VELDE, F.; VISSCHERS, R.W. The gap between food gel structure, texture and perception. Food Hydrocolloids, v. 20, p. 423-431, 2006.

ROSS-MURPHY, S.B. Structure-property relationships in food biopolymer gels and solutions. Journal of Rheology, v. 39, n. 6, p. 1451-1463, 1998.

STEFFE, F.L. Rheological Methods in Food Process Engineering, Freeman Press, East Lansing, 1996. 418 p.

TOLSTOGUZOV, V. B. Some thermodynamic considerations in food formulation. Food Hydrocolloids, v. 17, n. 1, p. 1-23, 2003.

ZANDI, M; MIRZADEH, H.; MAYER, C. Early stages of gelation in gelatin solution detected by dynamic oscillating rheology and nuclear magnetic spectroscopy. European Polymer Journal, v. 43, p. 1480-1486, 2007.

WESS, T. J.; ORGEL, J. P. Changes in collagen structure: drying, dehydrothermal treatment and relation to long term deterioration. Thermochimica Acta, v. 365, p. 119-128, 2000.

WOLF, C. L.; BEACH, S.; LA VELLE, W. M.; CLARK, R. C. Gellan gum/gelatin blends. US patent 4876105, 1989. 
Estudo reológico e microestrutural de soluções aquosas de gelatina e amido de milho modificado

Artigo será submetido para publicação no periódico Food biophysics 


\title{
Estudo reológico e microestrutural de soluções aquosas de gelatina e amido de milho modificado
}

\author{
MARFIL, P. H. M. ${ }^{1}$; ANHÊ, A. C. B. ${ }^{2}$; TELIS, V. R. N. ${ }^{1}$ \\ ${ }^{1}$ Departamento de Engenharia e Tecnologia de Alimentos, UNESP - Universidade Estadual Paulista, 15054-000. \\ São José do Rio Preto, São Paulo, Brasil; \\ ${ }^{2}$ Centro de Pesquisas René Rachou, FIOCRUZ - Fundação Oswaldo Cruz, 30190-002, Belo Horizonte, Minas \\ Gerais, Brasil.
}

\section{RESUMO}

O comportamento reológico de soluções aquosas de gelatina e amido de milho modificado por ácidos (AMMA) na concentração de $10 \%$ de sólidos totais foi estudado utilizando testes dinâmicos oscilatórios em um reômetro rotacional de tensão controlada com geometria cone e placa $(60 \mathrm{~mm}$, distância de trabalho de $52 \mu \mathrm{m})$. Um sistema Peltier foi utilizado na base da geometria para controle de temperatura. $\mathrm{O}$ pH médio das amostras foi de 5,80 \pm 0,03. Observando o comportamento do módulo de armazenamento $\left(\mathrm{G}^{`}\right)$ no aquecimento, foi observado ponto de fusão da gelatina em $39,4 \pm 1,3{ }^{\circ} \mathrm{C}$ e a temperatura de gelatinização do amido em 65 - $66{ }^{\circ} \mathrm{C}$. Diferentemente da gelatina, o amido não apresenta comportamento reversível, ou seja, depois de gelatinizado os grânulos permanecem intumescidos, o que pode ser observado pelo alto valor de $\mathrm{G}^{\prime}$, que permanece elevado mesmo mantendo a solução a 80 ${ }^{\circ} \mathrm{C}$ e depois resfriando-a a $20{ }^{\circ} \mathrm{C}$. A substituição de $25 \%$ de gelatina por amido de milho modificado resultou em valores de $G^{`}$ similares aos das amostras contendo somente gelatina. A análise da microestrutura de algumas amostras permitiu observar que no sistema contendo $37,5 \%$ de gelatina e $62,5 \%$ de amido, os dois biopolímeros co-existem, sugerindo que não há separação de fases, a nível microestrutural. Os demais sistemas apresentaram, separação de fases, sendo esta mais pronunciada à medida que as amostras foram sendo enriquecidas com gelatina ou amido. A microscopia laser confocal mostrou-se como uma técnica de extrema 
importância para o estudo microestrutural, proporcionando um melhor entendimento sobre o processo de separação de fase entre gelatina e amido.

\begin{abstract}
The rheological behavior of aqueous solutions of gelatin and acid modified corn starch (AMCS) (10 wt \% total solids) was studied using dynamic oscillatory shear tests in a controlled stress rheometer fitted with a cone and plate geometry $(60 \mathrm{~mm}$, gap $52 \mu \mathrm{m})$. A Peltier system in the bottom plate provided the temperature control. $\mathrm{pH}$ values were $5.80 \pm$ 0.03. The storage modulus behavior $\left(\mathrm{G}^{\prime}\right)$ during heating indicated that the gelatin melting point was $39.4 \pm 1.3{ }^{\circ} \mathrm{C}$ and the starch gelatinization temperature was $65-66{ }^{\circ} \mathrm{C}$. Contrary to gelatin, starch does not show reversible behavior, since after gelatinization, granules remained swollen. This behavior can be observed by the $G^{\prime}$ values that remained high even when the solution was heated until $80{ }^{\circ} \mathrm{C}$ and cooled to $20{ }^{\circ} \mathrm{C}$. Substituting $25 \%$ of gelatin by AMCS resulted in $G^{\prime}$ values similar to those of samples containing only gelatin. Microstructural analysis of some systems showed that in samples containing $37.5 \%$ gelatin and $62.5 \%$ AMCS both biopolymers co-existed, with no phase separation. The others systems showed phase separation, which became more pronounced with increasing concentrations of starch or gelatin. Confocal laser scanning microscopy was a very important technique for the microstructural study, providing better understanding of phase separation between gelatin and starch.
\end{abstract}




\subsection{INTRODUCÃ̃}

Há um crescente interesse no mecanismo de separação de fase de misturas de biopolímeros a fim de conhecer as propriedades de textura e estabilidade dos produtos alimentícios. A microestrutura e a distribuição de fases dos sistemas de biopolímeros depende de vários fatores, tais como concentração dos biopolímeros, solvente, $\mathrm{pH}$, conteúdo iônico, força iônica, distribuição do peso molecular, tratamento térmico, pressão, temperatura e propriedades individuais dos biopolímeros (TOLSTOGUZOV, 1991; ZASYPKIN; BRAUDO; TOLSTOGUZOV, 1997).

Estudos sistemáticos de incompatibilidade termodinâmica entre proteínas e polissacarídeos em solução foram desenvolvidos nas décadas de 60 e 70, quando já se tinha uma boa compreensão das relações entre conformação/função de sistemas de um único biopolímero (ANDERSON et al., 1969; GRANT et al., 1973). Hoje, sabe-se que existe uma alta probabilidade de ocorrência de separação de fases, formando duas camadas líquidas imiscíveis, em misturas binárias onde a concentração total de polímeros excede $4 \%$, dependendo, é claro, do pH e da força iônica (ALVES; ANTONOV; GONCALVES, 2000; ZHANG; FOEGEDING, 2003; ANTONOV; GONCALVES, 1999).

Proteínas e polissacarídeos são dois importantes tipos de macromoléculas alimentícias e são os mais importantes ingredientes estruturais e de textura dos alimentos (TOLSTOGUZOV, 1992; DICKINSON, 2003). De fato, complexos proteína/polissacarídeos exibem muitas propriedades funcionais capazes de prover novos padrões de estabilização e texturas em alimentos (SCHMITT et al., 1998).

A separação de fases em géis de proteínas e polissacarídeos perdura como uma ferramenta básica para se obter determinadas propriedades estruturais e de perfil de textura necessárias nas formulações de produtos industrializados. Os industrializados, como sempre, estão diante do desafio da inovação em um crescente e competitivo mercado em termos de custo de ingredientes, produtos de valor agregado e expectativa de um estilo de vida saudável. Entretanto, há uma distância entre o conhecimento fundamental e a aplicação dos conceitos diretamente na produção dos alimentos. Além disso, dentro do contexto de ciência dos materiais, há uma tendência de pesquisas científicas em sistemas com baixo/alto teor de sólidos (KASAPIS, 2008).

Fatores intrínsecos (por exemplo, hidrofobicidade, composição do aminoácido, peso molecular) ou extrínsecos (concentração protéica, $\mathrm{pH}$, força iônica, tipo dos sais presentes, 
pressão, etc.) podem afetar a capacidade de formação de gel de uma proteína, bem como o tipo de gel que será formado, mudando o balanço entre as interações do tipo atração e repulsão, levando a géis "físicos” reversíveis ou interações irreversíveis (ligações covalentes) (DICKINSON, 1997; TOTOSAUS et al., 2002).

Em muitas misturas de biopolímeros, a contribuição entrópica é freqüentemente maior que a contribuição entálpica, de forma que a regra seja geralmente a separação de fases. Neste caso, dois tipos de separação de fases podem ser observados, dependendo da afinidade entre os diferentes biopolímeros e o solvente. Caso exista uma incompatibilidade termodinâmica, as interações entre as moléculas dos biopolímeros distintos serão do tipo repulsivo, favorecendo as interações entre cada biopolímero e o solvente e levando à formação de duas fases, sendo cada uma delas mais rica em determinado biopolímero. Um segundo caso de separação de fases que pode ser observado é conhecido como separação de fases associativa e ocorre quando os dois biopolímeros apresentam cargas opostas. Quando isso ocorre, aparece a complexação entre os polímeros que pode levar ou à formação de complexos solúveis ou a uma separação de fases associativa, onde as duas fases coexistentes apresentam a seguinte composição: uma fase rica em solvente, com uma concentração muito pequena de biopolímeros e uma fase rica em biopolímeros, num fenômeno chamado coacervação (DOUBLIER et al., 2000).

A gelatina apresenta como sua principal propriedade a capacidade de formar géis estáveis em temperaturas menores que $40{ }^{\circ} \mathrm{C}$, desde que a concentração de gelatina na solução seja no mínimo de $1 \%$; em certos casos, essa transição sol-gel é reversível (NEKLYUDOV, 2003). Os géis de gelatina contêm ligações cruzadas ou "zonas de junção" formadas pelo retorno parcial à configuração "ordenada" de tripla hélice similar às seqüências do colágeno original, separadas ao longo do contorno da cadeia por resíduos peptídicos em conformação “desordenada" (ROSS-MURPHY, 1998; RENARD; VAN DE VELDE; VISSCHERS, 2006).

O papel do amido nos confeitos é fornecer a estrutura e as principais características de textura. Amidos modificados por ácidos são obtidos pela adição de uma pequena quantidade de ácido numa suspensão do amido nativo, a qual é aquecida a temperaturas abaixo da temperatura de gelatinização, produzindo amido hidrolisado. Quando o nível desejado de cadeias hidrolisadas é obtido, a mistura é então neutralizada e o amido é filtrado e posteriormente seco. A hidrólise ácida na cadeia do amido resulta numa estrutura mais desintegrada e, conseqüentemente, em cadeias de menor peso molecular. Essa hidrólise ácida implica em grânulos de amido mais facilmente solúveis em água fervente (BELITZ; GROSCH, 1999) que se desintegram quando cozidos, fornecendo uma pasta de baixa 
viscosidade quando aquecida e de elevada viscosidade no gel final em comparação ao amido nativo (RIX, 1990; HERMANSSON; SVEGMARK, 1996).

Segundo Singh et al. (2003), quando as moléculas de amido são aquecidas em excesso de água, a estrutura cristalina é rompida, e as moléculas de água formam pontes de hidrogênio entre a amilose e a amilopectina, expondo seus grupos hidroxila e causando um aumento no poder de inchamento e na solubilidade do grânulo. O poder de inchamento e a solubilidade variam de acordo com a fonte do amido, fornecendo evidências da interação entre as cadeias de amido dentro dos domínios amorfos e cristalinos. A extensão destas interações é influenciada pela proporção amilose: amilopectina e pelas características dessas moléculas (distribuição e peso molecular, grau e comprimento de ramificações e conformação).

Neste trabalho foram realizados estudos reológicos de suspensões com diferentes proporções de gelatina e amido de milho modificado por ácido (AMMA) em solução aquosa, sempre totalizando $10 \%$ de sólidos totais. Microscopia laser confocal foi utilizada para análise da microestrutura dos géis formados. 


\subsection{MATERIAL E MÉTODOS}

\subsubsection{Material}

Para os ensaios reológicos, utilizou-se gelatina extraída de pele bovina, com força de gel de 240 bloom (Gelita, Mococa, Brasil), amido de milho modificado de forma ácida (AMMA) Candymill ${ }^{\circledR}$ (Corn Products, Mogi Guaçu, Brasil) e água destilada.

\subsubsection{Preparo das amostras para ensaios reológicos}

Gelatina e amido de milho modificado foram dispersos em água destilada com auxílio de um bastão de vidro, com diferentes proporções entre os biopolímeros mas de modo que as suspensões finais apresentassem sempre uma concentração total de $10 \%$ (em massa) de sólidos totais. As proporções entre os biopolímeros utilizadas foram as seguintes, sempre em termos de gelatina:amido (\% em massa de sólidos totais): 0:100, 25:75, 50:50, 75:25 e 100:0, Esses materiais foram pesados em balança analítica (MARCONI, JK 200, Piracicaba, Brasil) e o valor de $\mathrm{pH}$ foi obtido com auxílio de um pHmetro digital (TECNAL, Tec-3MP, Piracicaba, Brasil). As suspensões ficaram imersas em banho aquecido a $30{ }^{\circ} \mathrm{C}$ de por 12 horas visando a hidratação dos polímeros, sendo que os ensaios começaram a ser realizados na temperatura de $20^{\circ} \mathrm{C}$.

\subsubsection{Ensaios reológicos}

Testes oscilatórios foram realizados em um reômetro AR-2000ex (TA Instruments, Delaware, USA), utilizando geometria cone e placa ( $2^{\circ} 0$ ' $11^{\prime \prime}$ ') com um espaçamento de 52 $\mu \mathrm{m}$. Amostras de 2,0 mL foram utilizadas, sendo inseridas no reômetro com auxílio de uma pipeta automática. Para cada ensaio reológico foram realizadas as seguintes etapas: 
- Varredura de freqüência $\left(0,1 \mathrm{a} 100 \mathrm{rad} \cdot \mathrm{s}^{-1}\right)$ a $20^{\circ} \mathrm{C}$.

- Rampa de aquecimento até $80^{\circ} \mathrm{C}\left(2{ }^{\circ} \mathrm{C} / \mathrm{min} ; 1 \mathrm{rad} \cdot \mathrm{s}^{-1}\right)$.

- Isotérmico a $80{ }^{\circ} \mathrm{C}$ por 10 minutos $\left(1 \mathrm{rad}^{-1}{ }^{-1}\right)$.

- Resfriamento até $20{ }^{\circ} \mathrm{C}\left(2{ }^{\circ} \mathrm{C} / \mathrm{min} ; 1 \mathrm{rad} . \mathrm{s}^{-1}\right)$.

- Isotérmico a $20^{\circ} \mathrm{C}$ por 1 hora $\left(1 \mathrm{rad} . \mathrm{s}^{-1}\right)$.

- Varredura de freqüência $\left(0,1 \mathrm{a} 100 \mathrm{rad} \cdot \mathrm{s}^{-1}\right)$ a $20{ }^{\circ} \mathrm{C}$.

- Resfriamento até $5{ }^{\circ} \mathrm{C}\left(2{ }^{\circ} \mathrm{C} / \mathrm{min} ; 1 \mathrm{rad} . \mathrm{s}^{-1}\right)$.

Os ensaios foram realizados em duplicata.

\subsubsection{Microscopia Laser Confocal (MLC)}

Amostras dos géis de gelatina e amido de milho modificado foram analisadas em microscopia laser confocal (MLC) utilizando o marcador rhodamina B. Uma solução de rhodamina B 0,05 \% foi preparada e duas gotas desta solução foram adicionadas em $100 \mathrm{~g}$ das suspensões de gelatina e amido de milho modificado antes dos ensaios reológicos. As suspensões continham $10 \%$ de sólidos totais em meio aquoso, de forma que os biopolímeros ficaram disponíveis para uma rápida difusão do marcador. Uma alíquota de 2,0 $\mathrm{mL}$ foi inserida no reômetro. Para o preparo das lâminas de microscopia, uma porção do gel obtido foi retirada do reômetro após a realização da etapa isotérmica a $20{ }^{\circ} \mathrm{C}$ por 1 hora. As lâminas foram cobertas com lamínulas e as laterais foram seladas com esmalte incolor para evitar trocas gasosas e evaporação de água do material. As lâminas foram analisadas em um microscópio laser confocal LSM-510 usando comprimento de onda de $543 \mathrm{~nm}$. 


\subsection{RESULTADOS E DISCUSSÃO}

\subsubsection{Estudo reológico oscilatório}

\section{- Varredura de Freqüência}

Inicialmente, realizou-se um estudo do comportamento do ângulo de fase das suspensões, que combina o comportamento de G`e G”. As curvas obtidas foram comparadas com o comportamento típico de alguns materiais, como sugerido por Steffe (1996). Na Figura 4.1 estão apresentadas curvas do comportamento de gelatina na concentração de 4 e $10 \%$ e de amido de milho modificado na concentração $10 \%$. Foi observado que as suspensões de gelatina, nas duas concentrações estudadas apresentam valores do ângulo de fase $(\delta)$ quase

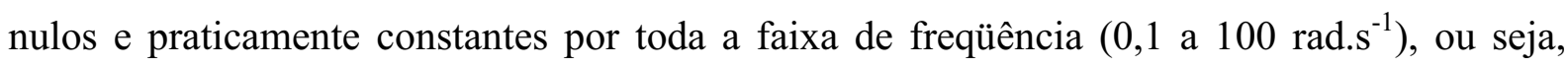
típico comportamento de gel, como era esperado. Quanto ao amido de milho modificado, quando analisamos os valores de $\delta$, este apresenta comportamento similar a uma solução concentrada.

A Figura 4.2 apresenta a varredura de freqüência da solução que contém $10 \%$ de amido, antes e após o aquecimento até $80{ }^{\circ} \mathrm{C}$. Ambas as varreduras foram realizadas a $20{ }^{\circ} \mathrm{C}$. Antes do aquecimento, observa-se o comportamento de uma solução diluída, já que G" é superior a $G^{`}$ em toda amplitude de freqüência estudada. Após o aquecimento, com a nova varredura de freqüência foi possível observar que $G^{`}$ e $G$ “ se interceptam em um determinado valor de freqüência intermediário na faixa estudada, de modo similar ao que ocorre com soluções concentradas, com uma clara tendência ao comportamento mais parecido a um sólido quando analisamos em altas freqüências. $O$ ponto de cruzamento entre $G^{\prime}$ e $G^{\text {" é o }}$ ponto no qual o ângulo de fase equivale a $\pi / 4$. Esse comportamento se justifica pela gelatinização do amido após o aquecimento, aumentando a viscosidade da solução e levando ao comportamento de uma solução concentrada. 


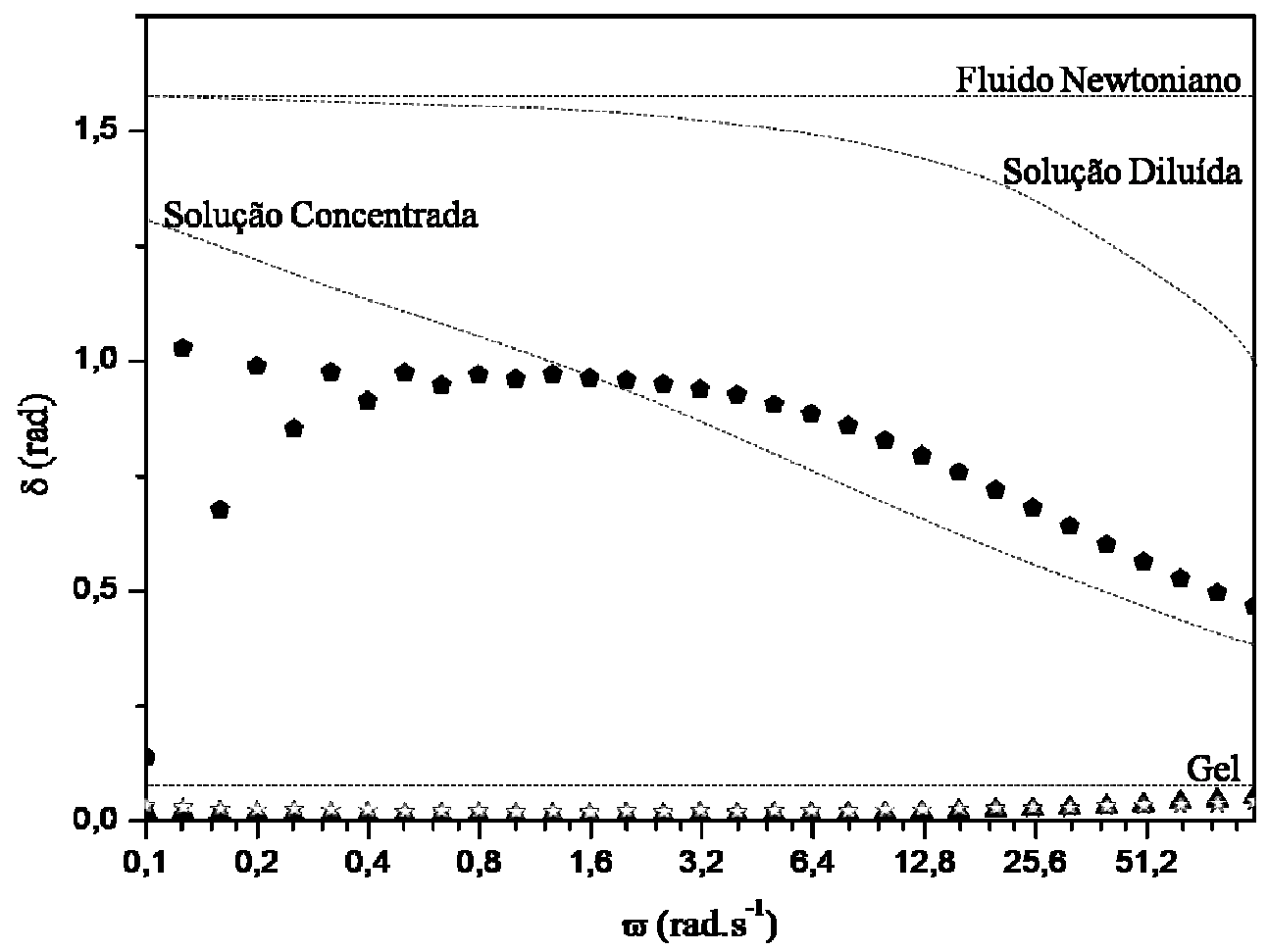

Figura 4.1 - Variação do ângulo de fase $(\delta)$ com a freqüência $(\omega)$ para gelatina nas concentrações de 4 e $10 \%$ e para AMMA na concentração de $10 \%$. ( $\boldsymbol{\Delta}=4 \%$ gelatina; $\hat{\imath}=10 \%$ gelatina; $\boldsymbol{\bullet}=10 \%$ amido).

O comportamento de $G^{`}$ e $G^{\prime \prime}$ das suspensões com diferentes proporções de gelatina e amido, após a etapa isotérmica $\left(20{ }^{\circ} \mathrm{C}\right)$ por uma hora, é apresentado na Figura 4.3. De um modo geral, observa-se o comportamento de gel quando os sistemas apresentam gelatina na composição. É sabido que a existência do platô reflete a estrutura da rede formada por interações intermoleculares não-covalentes em soluções de gelatina (BOHIDAR; DUBIN; OSADA, 2003). Um fato interessante é que nas soluções contendo gelatina com concentração de até $50 \%$ dos sólidos totais, os valores de $\mathrm{G}^{`}$ parecem ser mais influenciados pela quantidade de amido de milho modificado presente do que pela gelatina. Por outro lado, nos sistemas mais ricos em gelatina, há uma tendência de comportamento próximo da gelatina pura, ou seja, menor influência da presença de amido. Ao substituirmos $25 \%$ da gelatina por amido de milho modificado, observou-se comportamento quase que idêntico ao da gelatina pura.

No capítulo 3, ao estudar a reologia de soluções de gelatina e colágeno hidrolisado foi discutida a forte influência que a concentração de gelatina exerceu sobre o módulo de armazenamento $\left(G^{\prime}\right)$, sendo representada por uma equação exponencial. O mesmo fato não foi observado ao analisar as suspensões contendo gelatina e amido de milho modificado (Figura 4.4). 

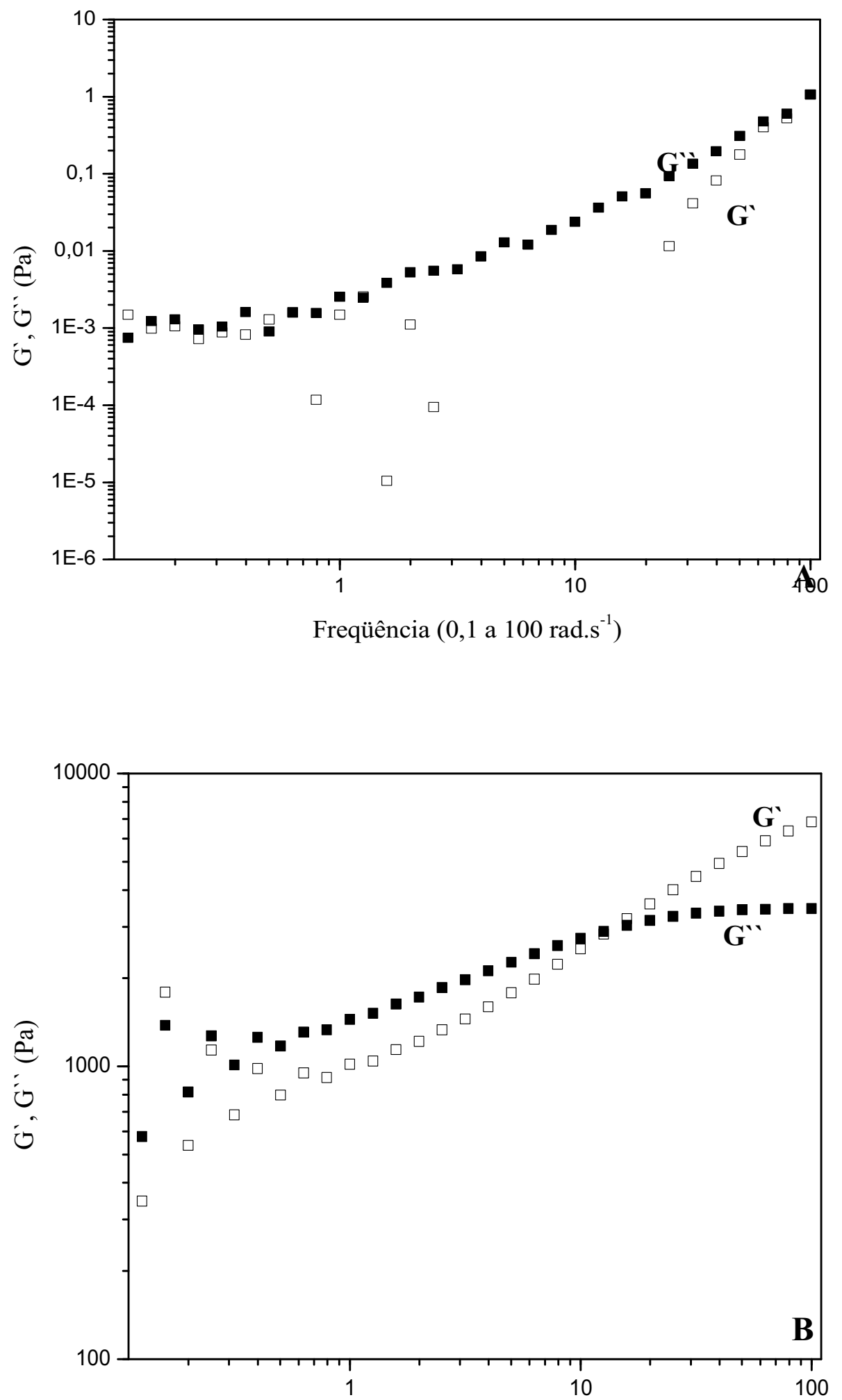

Freqüência $\left(0,1\right.$ a $\left.100 \mathrm{rad} . \mathrm{s}^{-1}\right)$

Figura 4.2 - Módulos de armazenamento $\left(G^{\prime}\right)$ e dissipação $\left(G^{\prime \prime}\right)$ na faixa de freqüências de 0,1 a $100 \mathrm{rad}^{-1} \mathrm{~s}^{-1}$ de solução aquosa de amido de milho modificado $(10 \%)$ a $20{ }^{\circ} \mathrm{C}$. (A) Antes do aquecimento. (B) Depois do aquecimento. Símbolos abertos $=\mathrm{G}^{\prime}$, fechados $=\mathrm{G}^{\prime \prime}$. 


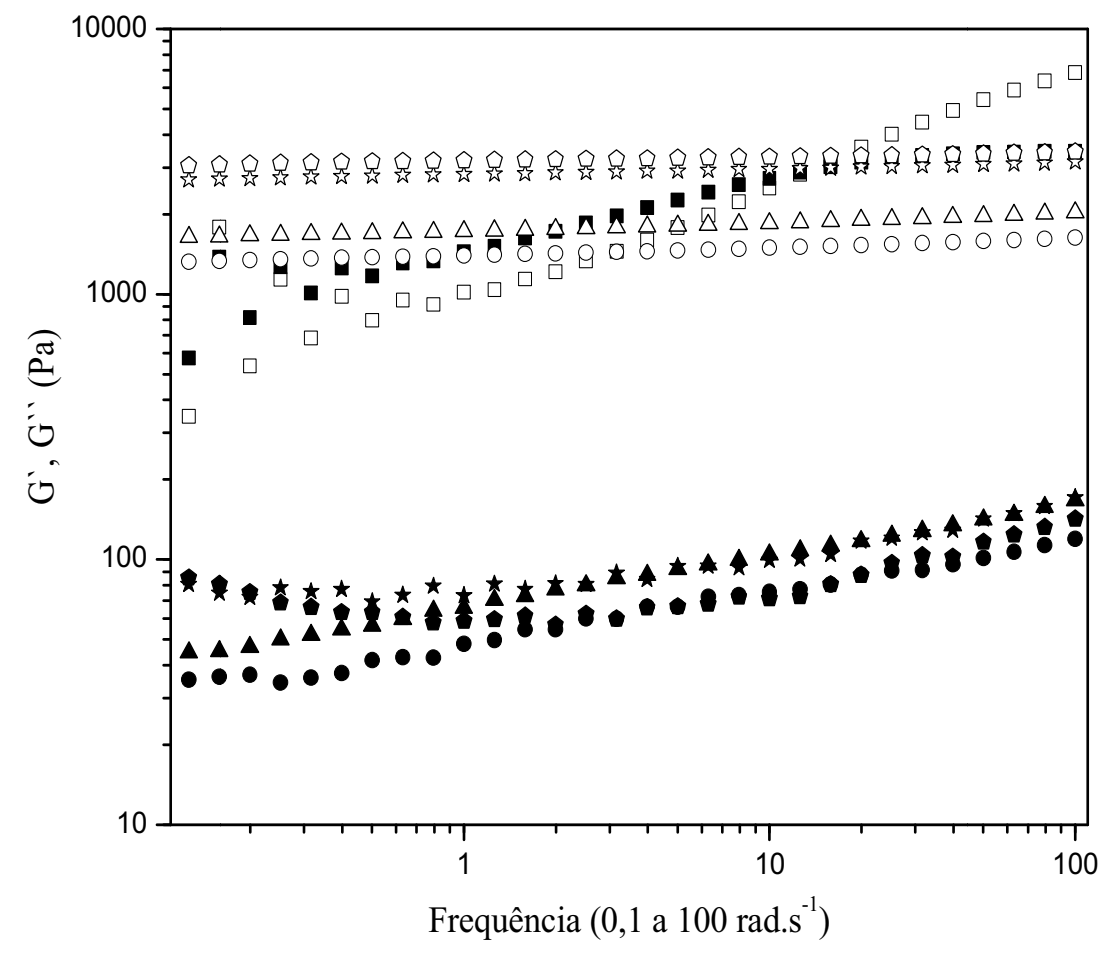

Figura 4.3 - Módulos de armazenamento $\left(G^{`}\right)$ e dissipação $\left(G^{\prime \prime}\right)$ na faixa de freqüências de 0,1 a 100 rad.s $\mathrm{s}^{-1}$ de solução aquosa de gelatina e amido de milho modificado (10\% sólidos totais). Símbolos abertos $=$ G`, fechados = G “. Proporção, (\% em massa), gelatina e amido de milho modificado,

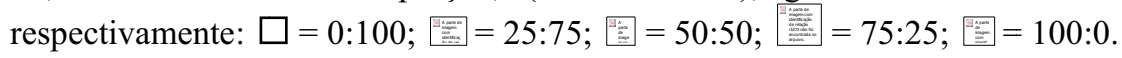

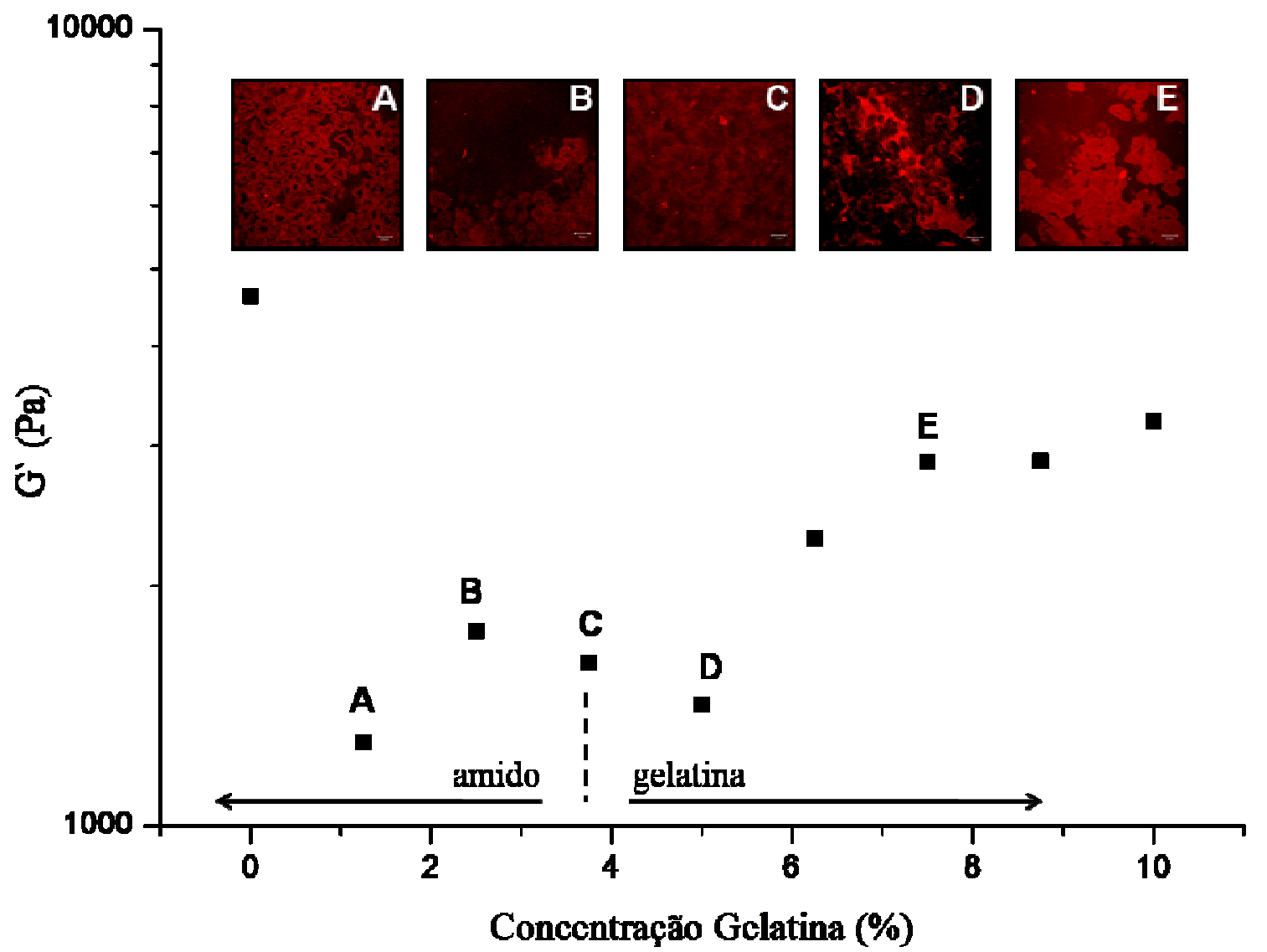

Figura 4.4 - Efeito da concentração de gelatina sobre o módulo de armazenamento ( $G$ ') nas suspensões contendo gelatina e amido de milho modificado de forma ácida ( $10 \%$ de sólidos totais). 
Alevisopoulos, Kasapis e Abeysekera (1996) estudaram a separação de fases em misturas de gelatina ( $5 \%$ ) com crescentes concentrações de maltodextrina (0 até $30 \%$ ) sob condições de resfriamento e aquecimento controlados. Esses autores estudaram o comportamento do módulo de armazenamento $\left(G^{`}\right)$ em função da concentração de maltodextrina como forma de explicar a separação de fases entre a proteína e o polissacarídeo. Alevisopoulos e Kasapis (1999) atribuíram a separação à taxa de resfriamento utilizado, porém, este não é o único parâmetro que pode controlar o comportamento das fases, ou seja, concluíram que frações poliméricas de diferentes massas molares podem reduzir a um terço a concentração de maltodextrina necessária para observação da inversão de fases na presença de gelatina.

Na Figura 4.4 é possível observar que a amostra que contém apenas amido modificado apresentou o maior valor de G` quando comparada a todas as demais. Esse valor de G` decresceu com a adição de gelatina, atingindo um mínimo para a solução contendo $50 \%$ de gelatina e $50 \%$ de AMMA (amostra D). A análise da microestrutura de alguns sistemas permitiu observar que a concentração na qual os dois biopolímeros co-existem corresponde à amostra $\mathrm{C}$, isto é, $37,5 \%$ de gelatina e 62,5 de AMMA (em relação ao total de sólidos). Este ponto é caracterizado como o ponto de inversão de fase, ou seja, ponto no qual a proteína e o amido co-existem numa única fase (Figura 4.5). A partir deste ponto, observa-se uma leve diminuição no valor de $\mathrm{G}^{\prime}$ (amostra D) seguido por um súbito aumento, até atingir o valor correspondente à amostra E. A partir daí observa-se uma região na qual $G$ ' tem valores próximos aos de suspensões de gelatina pura, indicando uma imediata separação de fases nos sistemas. Este fato sugere que ocorra uma gelificação separada dos dois biopolímeros quando utilizados nessas concentrações em baixas temperaturas (KASAPIS, 1999).

Em baixas concentrações de polissacarídeos, a separação de fase segregativa pode também originar um aumento da concentração de proteínas, aumentando a resposta elástica se a conectividade entre os agregados da proteína não for afetada. Deste modo o efeito do polissacarídeo na gelificação da proteína depende da natureza do polissacarídeo, do $\mathrm{pH}$, da força iônica, da temperatura do tratamento e da concentração utilizada (OLSSON; LANGTON; HERMANSSON, 2002).

Ainda na Figura 4.4 é possível analisar a região rica em amido, ou seja, baixas concentrações de gelatina, na qual, observa-se novamente separação de fases com predomínio do comportamento do amido. Um fato interessante é observado na amostra A, que contém a mínima concentração de gelatina (87,5 \% amido e $12,5 \%$ de gelatina dos $10 \%$ de sólidos totais), na qual o comportamento esperado seria um valor de $G^{`}$ maior que o observado. No 


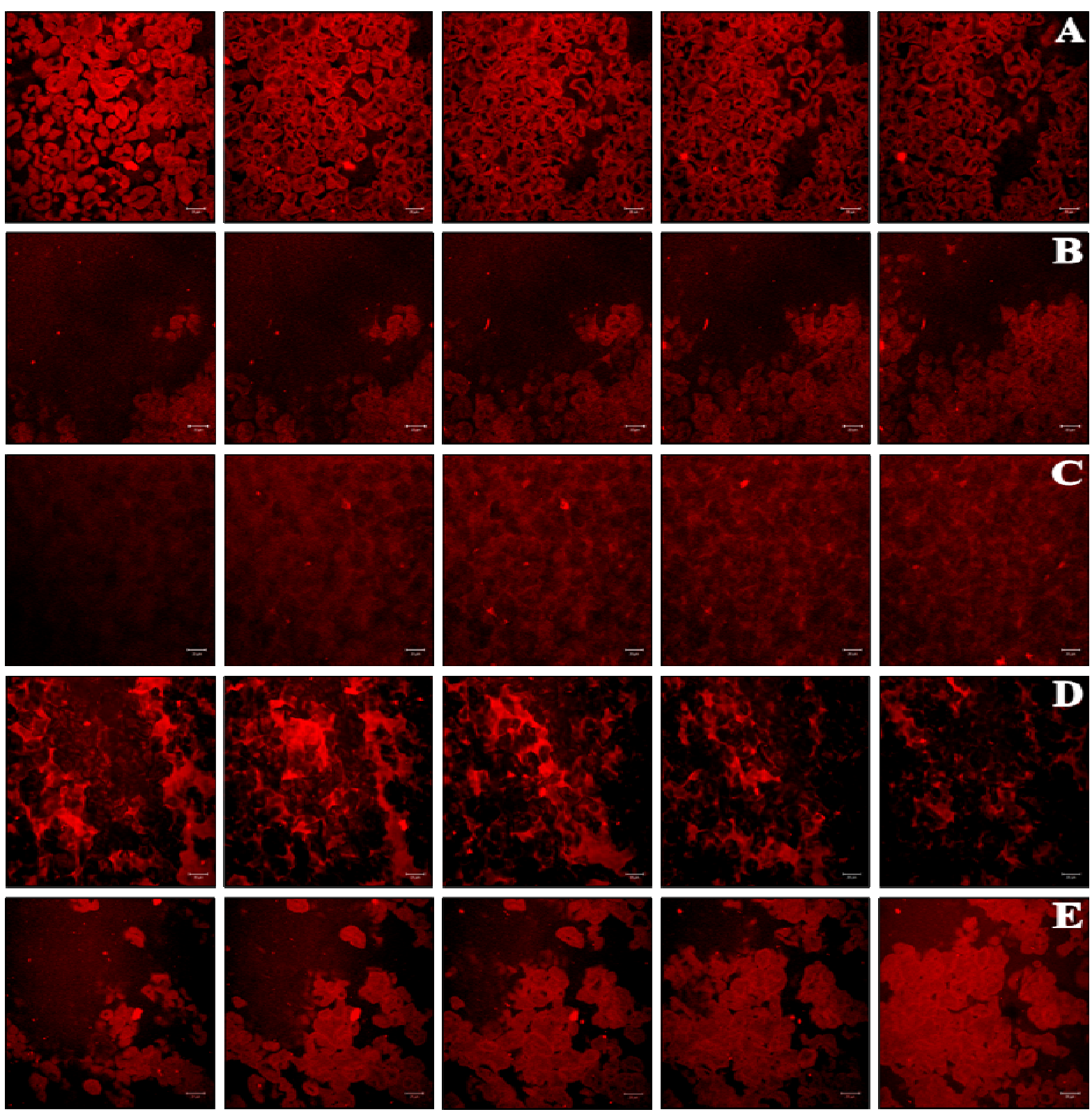

Figura 4.5: Imagens seriadas obtidas no microscópio laser confocal de géis de gelatina $(\mathrm{G}) /$ amido modificado (A) (distância entre os cortes seriados de $3 \mu \mathrm{m}$ ). A) 12,5:87,5; B) 25:75; C) 37,5:62,5; D) 50:50; E) 75:25. 
entanto, o comportamento de $G^{`}$ e a análise microestrutural sugerem que a substituição de parte do amido por gelatina fez com que a quantidade de amido fosse insuficiente para manter o alto valor de G’ observado na amostra de amido puro, ao mesmo tempo em que a quantidade de gelatina não foi suficiente para formar uma rede contínua ao longo do sistema, ficando a gelatina distribuída de forma heterogênea, em regiões isoladas devido à presença do amido gelatinizado (Figuras 4.4 e $4.5 \mathrm{~A}$ ).

O processo de aquecimento implica no inchamento dos grânulos e conseqüentemente na diminuição de líquido disponível, o que acaba aumentando a concentração de hidrocolóides, quando estes são adicionados simultaneamente aos amidos. Alguns autores observaram que a adição de hidrocolóides pode aumentar o poder de intumescimento dos grânulos de amido (ALLONCE et al., 1989; TECANTE; DOUBLIER, 1999).

\section{- Rampa de Temperatura}

Analisando o comportamento de $G^{`}$ durante as rampas de aquecimento e resfriamento, observou-se que nos sistemas contendo gelatina, o ponto de fusão ocorreu em $39,4 \pm 1,3{ }^{\circ} \mathrm{C}$. Este ponto é obtido observando-se a súbita diminuição dos valores de $\mathrm{G}^{\prime}$.

A Figura 4.6 ilustra o comportamento de $G^{\prime}$ quando o amido modificado é aquecido. A brusca elevação do módulo de armazenamento ocorre entre $65-66{ }^{\circ} \mathrm{C}$ e corresponde à temperatura de gelatinização do amido. Diferentemente da gelatina, o amido não apresenta comportamento reversível, ou seja, depois de gelatinizados os grânulos permanecem intumescidos, o que pode ser observado pelo alto valor de $\mathrm{G}^{`}$ que permanece elevado mesmo mantendo a solução a $80{ }^{\circ} \mathrm{C}$ e depois resfriando-a a $20{ }^{\circ} \mathrm{C}$.

Géis são comumente classificados como químicos ou físicos, sendo que a grande diferença entre esses grupos refere-se ao tipo de ligações estabelecidas entre as moléculas dos polímeros. De acordo com Bohidar, Dubin e Osada (2003), se um gel é formado através de uma reação química, as ligações estabelecidas são covalentes e o gel formado é irreversível. Entretanto, os géis físicos atingem estabilidade nas soluções através da formação de possíveis forças secundárias, como pontes de hidrogênio, forças de Van der Waals, interações bipolares, hidrofóbicas, etc. (BURCHARD; ROSS-MURPHY, 1990). Esses géis, formados por interações físicas, são reversíveis quando parâmetros termodinâmicos como $\mathrm{pH}$, força iônica e/ou temperatura são modificados. 
Quando avaliamos o comportamento de $G^{`}$ nos sistemas que possuem gelatina e amido modificado de forma combinada (Figura 4.6) observa-se que, tanto o amido modificado quanto a gelatina, mantêm inalteradas suas temperaturas de formação de gel. Este fato fica claro quando se analisa o comportamento de $G^{`}$ na solução em que a gelatina representa $25 \%$ dos sólidos totais e o amido modificado, $75 \%$ dos mesmos.

Durante a rampa de resfriamento, uma grande quantidade de hélices é formada e o estabelecimento da rede do gel se mostra sensível à concentração de gelatina (DUHAMEL; HELLIO; DJABOUROV, 2002). Ou seja, se continuarmos abaixando a temperatura após atingir o ponto de gel $\left(20\right.$ a $\left.5{ }^{\circ} \mathrm{C}\right)$, observa-se que ligações físicas cruzadas ocorrem, como resultado de interações intermoleculares e como resultado dessas ligações cruzadas, o módulo de armazenamento se desenvolve, como pode ser observado na Figura 4.6. Nesta região, as propriedades reológicas das soluções de gelatina mudam de ligações não-covalentes entre aminoácidos para desdobramento da cadeia e formação de hélice (ZANDI; MIRZADEH; MAYER, 2007).

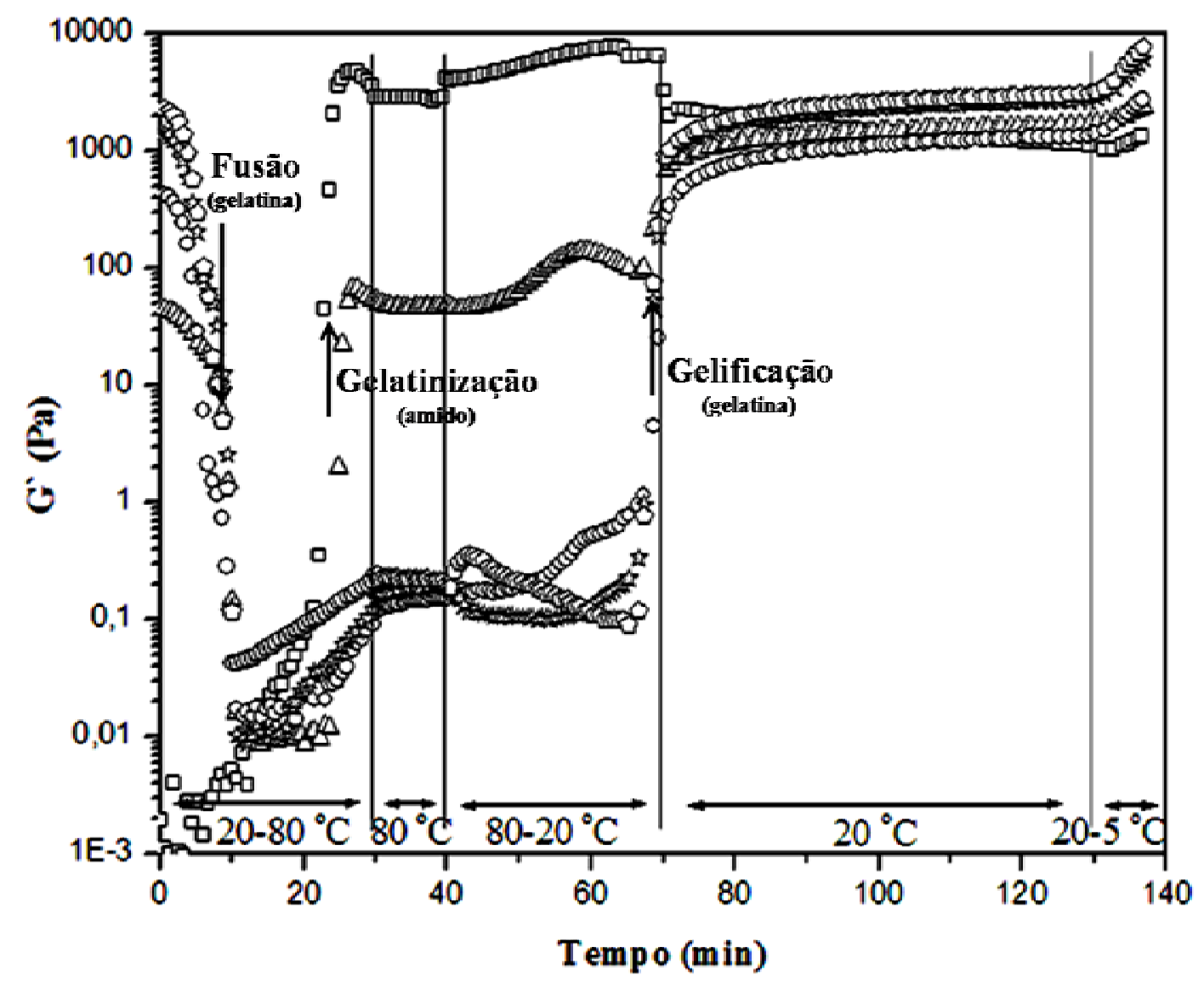

Figura4.6 - Módulo de armazenamento $\left(\mathrm{G}^{\prime}\right)$ em função do tempo nas rampas de temperatura estudadas para diferentes suspensões aquosas de gelatina e amido de milho modificado, todas com $10 \%$ de sólidos totais. Proporção, (\% em massa), gelatina e amido modificado, respectivamente: $=0: 100 ; \triangle=25: 75 ; \bigcirc=50: 50 ; \Sigma=75: 25 ; \Delta=100: 0$. 
Se analisarmos, para todas as concentrações estudadas, os valores de G` no início dos ensaios $\left(20^{\circ} \mathrm{C}\right)$ e, após o aquecimento $\left(80{ }^{\circ} \mathrm{C}\right)$ seguido novamente do resfriamento a $20{ }^{\circ} \mathrm{C}$, é possível observar o comportamento reversível característico da gelatina. Na Figura 4.6 fica claro o comportamento reversível da gelatina e não-reversível do amido. Panouillé e LarretaGarde (2009) estudaram o comportamento reológico de misturas de gelatina e alginato. Esses autores aqueceram e resfriaram a gelatina repetidas vezes e o comportamento do módulo de armazenamento é praticamente o mesmo, ou seja, observaram também o comportamento reversível da gelatina e irreversível do alginato.

Firoozmand, Murray e Dickinson (2009) estudaram o comportamento reológico e a microestrutura da separação de fases de géis de gelatina e amido de batata oxidado misturados com xarope de sacarose e glicose. Foram preparadas soluções com 7 \% de gelatina, 25,5 \% xarope de sacarose, $31,4 \%$ de xarope de glicose e amido variando de 0 (controle) até $6 \%$. As amostras foram submetidas a tratamentos térmicos de 24 a $60{ }^{\circ} \mathrm{C}$ e por tempos de 20 segundos a 30 minutos. Os autores observaram que, em sistemas contendo $7 \%$ de gelatina e $5 \%$ de amido, à medida que a temperatura dos géis aumenta de 40 a $60{ }^{\circ} \mathrm{C}$ há uma redução da magnitude do desenvolvimento de G' e também um aumento da extensão de separação de fases, observada por microscopia. De modo similar, quando as amostras foram expostas a 40 ${ }^{\circ} \mathrm{C}$, variando-se o tempo de 12 a 30 minutos, houve uma redução na magnitude do desenvolvimento de G`e um aumento da separação de fases em tempos maiores.

Analisando ainda o comportamento de G` (Figura 4.7) durante o aquecimento (20 a 80 ${ }^{\circ} \mathrm{C}$ ), na amostra contendo somente amido, observa-se a crescente elevação de G’ até o seu aumento brusco (temperatura de gelatinização). As demais amostras, na temperatura de $20{ }^{\circ} \mathrm{C}$ apresentam valores de $\mathrm{G}^{`}$ elevados, devido à presença de gelatina. Uma queda no módulo de $\mathrm{G}^{\prime}$ ocorre em torno de $40{ }^{\circ} \mathrm{C}$, como resultado da fusão de gelatina. Na amostra em que a gelatina representa $75 \%$ dos sólidos totais, o comportamento de G’ em altas temperaturas é semelhante ao que ocorre com gelatina pura, como se a presença de amido de milho modificado não fosse expressiva. Por outro lado, nas amostras em que o amido representa 75 \% dos sólidos, o comportamento do módulo de armazenamento tem um comportamento híbrido: apresenta altos valores de G`em baixas temperaturas, devido à presença da gelatina, mas também mostra o aumento súbito desse módulo em temperaturas mais altas, acima da temperatura de gelatinização do amido, de modo similar à solução contendo apenas amido. 


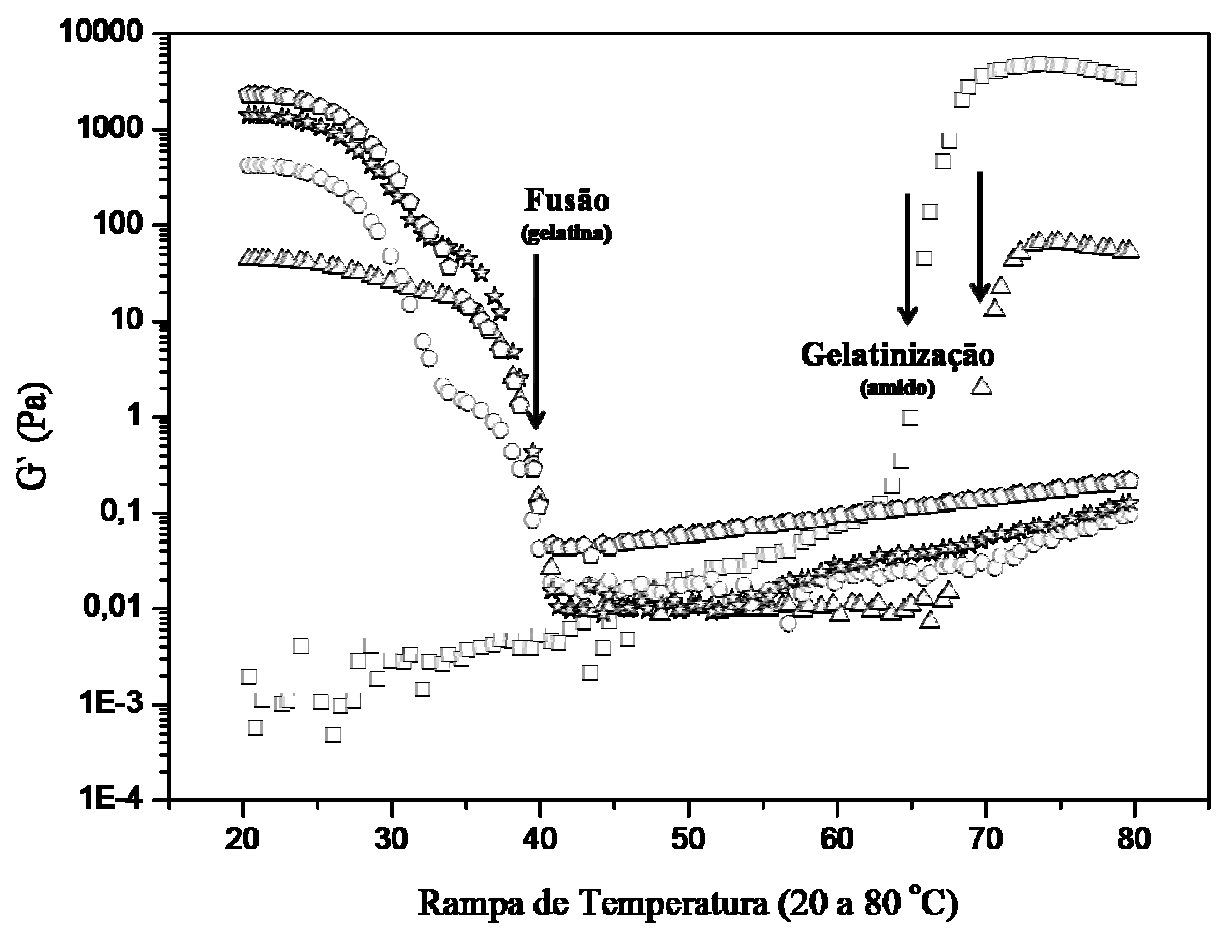

Figura 4.7 - Módulo de armazenamento $\left(G^{`}\right)$ em função de aquecimento de 20 a $80{ }^{\circ} \mathrm{C}$, para diferentes concentrações de gelatina, nos sistemas contendo gelatina e amido de milho modificado (10\% de sólidos totais). Proporção, (\% em massa), gelatina e amido modificado, respectivamente:

$=0: 100 ; \quad=25: 75 ; \quad=50: 50 ; \quad=75: 25 ; \quad=100: 0$.

\subsubsection{Estudo microestrutural}

A Figura 4.5 mostra imagens seriadas dos géis gelatina/amido modificado marcadas com rhodamina B e obtidas ao microscópio laser confocal LSM-510. A Figura 4.5C representa a amostra 37,5:62,5 (37,5\% de gelatina e 62,5\% de amido com relação aos $10 \%$ de sólidos totais), onde se observa a presença de um sistema homogêneo e com ausência de separação de fases. Na amostra seguinte 50:50 (Figura 4.5D) observa-se o início de um processo de segregação entre os biopolímeros. A gelatina se apresenta fortemente corada e o amido é observado como estruturas negras. Isso acontece pelo fato de que a rhodamina, na presença de elevadas concentrações de proteína, não se liga aos grânulos de amido, que aparecem como buracos negros em meio à fase protéica fortemente corada pelo marcador fluorescente (VAN DE VELDE; RIEL; TROMP, 2002). A separação de fases foi claramente observada nas concentrações 25:75 (Figura 4.5B) e 75:25 (Figura 4.5E). Os resultados mostram aglomerados de grânulos de amido intumescidos, envolvidos por gelatina dissolvida. 
De todos os sistemas mistos, a amostra com maior concentração de amido (12,5:87,5 Figura 4.5A) mostrou uma grande quantidade de grânulos de amido pouco intumescidos e fortemente marcados. Essa intensa fluorescência observada se justifica pelo fato de que, na ausência ou em baixas concentrações de proteína (gelatina), a rhodamina se liga aos grânulos de amido (VAN DE VELDE; RIEL; TROMP, 2002). A amostra também apresentou uma leve segregação entre os biopolímeros, com predomínio de regiões ricas em amido, como foi confirmado pelo comportamento de $\mathrm{G}^{`}$ (Figura 4.4).

De modo geral, com a diminuição da concentração de amido, o grânulo apresentou maior expansão devido à maior disponibilidade de água. A expansão aconteceu em todos os as direções (WILLIAMS; BOWLER, 1982; VAN DE VELDE; RIEL; TROMP, 2002).

A separação de fases em misturas de proteínas e polissacarídeos pode levar à formação de estruturas esféricas na fase dispersa. Seu tamanho pode variar, mas comumente se encontra entre 2 a $20 \mu \mathrm{m}$. Formações de inclusões esféricas observadas sugerem a existência de um nível significativo de energia na interface líquido-líquido desses sistemas (RENARD; VAN DE VELDE; VISSCHERS, 2006). Norton e Frith (2001) observaram que, em misturas de gelatina e maltodextrina, a separação de fases freqüentemente leva ao aprisionamento de gotas no interior de outras gotas.

Misturas de proteínas e polissacarídeos que, sob determinadas condições, resultam em separação de fases são interessantes para a criação de novas estruturas porque a adição de polissacarídeos, mesmo em baixas concentrações, pode criar grandes diferenças na estrutura e nas propriedades reológicas, além da possibilidade de indução de grandes diferenças na consistência ou textura com apenas pequenos efeitos em outras propriedades organolépticas (RENARD; VAN DE VELDE; VISSCHERS, 2006). 


\subsection{CONCLUSÕES}

Observando o comportamento de $G^{`}$ no aquecimento, o ponto de fusão da gelatina foi determinado como sendo igual a $39,4 \pm 1,3{ }^{\circ} \mathrm{C}$, enquanto a temperatura de gelatinização do amido ficou no intervalo de 65 a $66{ }^{\circ} \mathrm{C}$.

Diferentemente da gelatina, o amido não apresenta comportamento reversível, ou seja, depois de gelatinizado os grânulos permanecem intumescidos, o que pode ser observado pelo alto valor de $G^{\prime}$ que permanece elevado mesmo mantendo a solução a $80{ }^{\circ} \mathrm{C}$ e depois resfriando-a a $20{ }^{\circ} \mathrm{C}$.

A substituição de $25 \%$ de gelatina por amido de milho modificado resultou em valores de G`similares aos das amostras contendo somente gelatina.

A análise da microestrutura de alguns sistemas permitiu observar que a concentração na qual os dois biopolímeros co-existem, sem separação de fases correspondeu à amostra 37,5:62,5. Os demais sistemas apresentaram separação de fases, sendo esta mais pronunciada à medida que as amostras foram ficando enriquecidas com gelatina ou amido, exceto na amostra 12,5:87,5, na qual o comportamento esperado seria valor de $G^{\prime}$ maior que o observado. Sugere-se que a quantidade de amido seja insuficiente para manter o alto valor de G' observado na amostra de amido puro, ao mesmo tempo em que a quantidade de gelatina não foi suficiente para formar uma rede contínua ao longo do sistema, ficando a gelatina distribuída de forma heterogênea.

A microscopia laser confocal mostrou-se como uma técnica de extrema importância para o estudo microestrutural, proporcionando um melhor entendimento sobre o processo de separação de fase entre gelatina e amido.

\section{Agradecimentos}

Os autores agradecem ao Dr. Paulo Filemon Paolucci Pimenta e Fernanda Gambogi Oliveira, chefe e técnica, respectivamente, do Laboratório de Entomologia Médica (CPqRR/FIOCRUZ) pela análise do material ao microscópio laser confocal. Os autores também agradecem à Gelita e Corn Products, e Dra. Rosiane Lopes da Cunha (FEA/UNICAMP) pela doação de amostras de materiais. Também agradecemos o apoio financeiro da CAPES (bolsa de estudos) e FAPESP (2006/56015-2). 


\section{$\underline{\text { REFERÊNCIAS }}$}

ALEVISOPOULOS, S.; KASAPIS, S.; ABEYSEKERA, R. Formation of kinetically trapped gels in the maltodextrin-gelatin system. Carbohydrate Research, v. 293, p. 79-99, 1996.

ALEVISOPOULOS, S.; KASAPIS, S. Molecular weight effects on the gelatin/ maltodextrin gel. Carbohydrate Polymers, v. 40, p. 83-87, 1999.

ALLONCE, M.; LEFEBVRE, J.; LLAMAS, G.; DOUBLIER, J. L. A rheological characterization of cereal starch-galactomannan mixtures. Cereal Chemistry, v. 66, n. 2, p. 90-93, 1989.

ALVES, M. M., ANTONOV, Yu. A.; GONCALVES, M. P. Phase equilibria and mechanical properties of gel-like water-gelatin-locust bean gum systems. International Journal of Biological Macromolecules, v. 27, p. 41-47, 2000.

ANDERSON, N. S.; GAMPBELL, J. W.; HARDING, M. M.; REES, D. A.; SAMUEL, J. W. B. X-ray diffraction studies of polysaccharide sulphates: Double helix models for $\kappa$ - and $l$ carrageenans. Journal of Molecular Biology, v. 45, p. 85-99, 1969.

ANTONOV, Yu. A., GONCALVES, M. P. Phase separation in aqueous gelatin- $\kappa$ carrageenan systems. Food Hydrocolloids, v. 13, p. 517-524, 1999.

BELITZ, H.-D.; GROSCH, W. Food Chemistry; Springer Verlag: Berlin, New York, 1999; 774 pp. In: BUREY, P.; BHANDARI, B. R.; RUTGERS, R. P. G.; HALLEY, P. J.; TORLEY, P. J. Confectionary gels: a review on formulation, rheological and structural aspects. International Journal of Food Properties, v. 12, n. 1, p. 176-210, 2009.

BOHIDAR, H.; DUBIN, P.; OSADA, Y. Polymer gels fundamentals and applications. Washington, DC: American Chemical Society, 2003.

BURCHARD, W.; ROSS-MURPhY, S. B. Physical Networks, Polymers and Gels. Elsevier, New York, 1990.

DICKINSON, E. Enzymic crosslinking as a tool for food colloid rheology control and interfacial stabilization. Trends in Food Science \& Technology, v. 8, n. 10, p. 334-339, 1997.

DICKINSON, E. Hydrocolloids at interfaces and the influence on the properties of dispersed systems. Food Hydrocolloids, v. 17, p. 25-39, 2003. 
DOUBLIER, J.L.; GARNIER, C.; RENARD, D.; SANCHEZ, C. Protein-polyssacharide interactions. Current Opinion in Colloid \& Interface Science, v. 5, p. 202-214, 2000.

DUHAMEL, C. J.; HELLIO, D.; DJABOUROV, M. All gelatin networks: I. Biodiversity and physical chemistry. Langmuir, v. 18, p. 7208-7217, 2002.

FIROOZMAND, H.; MURRAY, B. S.; DICKINSON, E. Microstructure and rheology of phase-separated gels of gelatin + oxidized starch. Food Hydrocolloids, v. 23, p. 1081-1088, 2009.

GRANT, G. T.; MORRIS, E. R.; REES, D. A.; SMITH, P. J. C.; THOM, D. Biological interactions between polysaccharides and divalent cations: The egg-box model. Federation of European Biochemical Societies Letters, v. 32, p. 195-198, 1973.

HERMANSSON, A.-M.; SVEGMARK, K. Developments in the understanding of starch functionality. Trends in Food Science \& Technology, v. 7, n. 11, p. 343-353, 1996.

HIGGINS, J. S.; TAMBASCO, M.; LIPSON, J. E. G. Polymer blends; stretching what we can learn through the combination of experiment and theory. Progress in Polymer Science, v. 30, p. 832-843, 2005.

KASAPIS, S. The elastic moduli of the microcrystalline cellulose-gelatin blends. Food Hydrocolloids, v. 13, p. 543-546, 1999.

KASAPIS, S. Phase Separation in Biopolymer Gels: A low- to high-solid exploration of structural morphology and functionality. Critical Reviews in Food Science and Nutrition, v. 48, p. 341-359, 2008.

NEKLYUDOV, A. D. Nutritive fibers of animal origin: collagen and its fractions as essential components of new and useful food products. Applied Biochemistry and Microbiology, v. 39, n. 3, p. 229-238, 2003.

NORTON, I. T.; FRITH, W. J. Microstructure design in mixed biopolymer composites. Food Hydrocolloid, v. 15, p. 543-553, 2001.

OLSSON, C.; LANGTON, M.; HERMANSSON, A. M. Dynamic measurements of betalactoglobulin structures during aggregation, gel formation and gel breakup in mixed biopolymer systems. Food Hydrocolloids, v.16, n. 5, p. 477-488, 2002.

PANOUILLÉ, M.; LARRETA-GARDE, V. Gelation behaviour of gelatin and alginate mixtures. Food Hydrocolloids, v. 23, p. 1074-1080, 2009. 
RENARD, D., VAN DE VELDE, F., VISSCHERS, R.W. The gap between food gel structure, texture and perception. Food Hydrocolloids, v. 20, p. 423-431, 2006.

RIX, A. Gelling and Whipping Agents. In: JACKSON, E. B. Sugar Confectionery Manufacture. Van Nostrand Reinhold, Glasgow, p. 57-76, 1990.

ROSS-MURPHY, S. B. Structure-property relationships in food biopolymer gels and solutions. Journal of Rheology, v. 39, n. 6, p. 1451-1463, 1998.

SCHMITT, C.; SANCHEZ, C.; DESOBRY-BANON, S.; HARDY, J. Structure and technofunctional properties of protein-polysaccharide complexes: a review. Critical Reviews in Food Science and Nutrition, v. 38, n. 8, p. 689-753, 1998.

SINGH, N.; SINGH, J.; KAUR, L.; SODHI, N. S.; GILL, B. S. Morphological, thermal and rheological properties of starches from different botanical sources. Food Chemistry, v.81, p. 219-231, 2003.

STEFFE, F.L. Rheological Methods in Food Process Engineering, Freeman Press: East Lansing, 1996; 418 p.

TECANTE, A.; DOUBLIER, J. L. Steady flow and viscoelastic behavior of crosslinked waxy corn starch-kappa-carrageenan pastes and gels. Carbohydrate Polymers, v. 40, n. 3, p. 221 $231,1999$.

TOLSTOGUZOV, V. B. Functional properties of food proteins and role of proteinpolysaccharide interaction. Food Hydrocolloids, v. 4, p. 429-468, 1991.

TOLSTOGUZOV, V. The functional properties of food proteins. In PHILIPS, G. O.; WILLIAMS, P. A.; WEDLOCK, D. J. (Eds.). Gums and stabilizers for the food industry, vol. 6 (pp. 241-266). Oxford: IRL Press, 1992.

TOTOSAUS, A.; MONTEJANO, J. G.; SALAZAR, J. A.; GUERRERO, I. A review of physical and chemical protein-gel induction. International Journal of Food Science and Technology, v. 37, n. 6, p. 589-601, 2002.

VAN DE VELDE, F.; RIEL, J. V.; TROMP, R. H. Visualization of starch granule morphologies using confocal scanning laser microscopy (CSLM). Journal of the Science of Food and Agriculture, v. 82, p. 1528-1536, 2002. 
ZANDI, M; MIRZADEH, H.; MAYER, C. Early stages of gelation in gelatin solution detected by dynamic oscillating rheology and nuclear magnetic spectroscopy. European Polymer Journal, v. 43, p. 1480-1486, 2007.

ZASYPKIN, D. V.; BRAUDO, E. E.; TOLSTOGUZOV, V. B. Multicomponent biopolymer gels. Food Hydrocolloids, v. 11, n. 2, p. 159-170, 1997.

ZHANG, G.; FOEGEDING, E. A. Heat-induced phase behavior of $\beta$ lactoglobulin/polysaccharide mixtures. Food Hydrocolloids, v. 17, p. 785-792, 2003.

WILLIAMS, M. R.; BOWLER, P. Starch gelatinization: a morphological study of triticeae and other starches. Starch, v. 34, p. 221-223, 1982. 


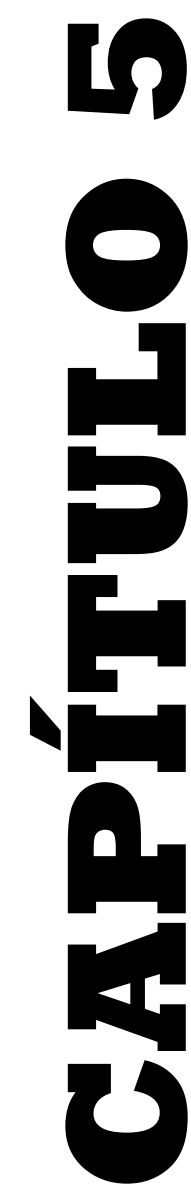

\section{Texture and microstructure of} gelatin/corn starch-based gummy confections

Food Hydrocolloids

Enviado em março / 2010 


\title{
Texture and microstructure of gelatin / corn starch-based gummy confections
}

\author{
MARFIL, P. H. M. ${ }^{1}$; ANHÊ, A. C. B. ${ }^{2}$; TELIS, V. R. N. ${ }^{1, *}$ \\ ${ }^{1}$ Departamento de Engenharia e Tecnologia de Alimentos, UNESP - Universidade Estadual Paulista, 15054-000. \\ São José do Rio Preto, São Paulo, Brazil \\ ${ }^{2}$ Centro de Pesquisas René Rachou, FIOCRUZ - Fundação Oswaldo Cruz, 30190-002, Belo Horizonte, Minas \\ Gerais, Brazil \\ * Corresponding author. \\ E-mail address: vanianic@ibilce.unesp.br \\ Telephone number: 551732212255 \\ Fax number: 551732212299
}

\section{ABSTRACT}

The texture of gummy gels prepared with gelatin and acid modified corn starch (AMCS) was quantified by instrumental techniques and their microstructure was examined by confocal laser scanning microscopy (CLSM) and scanning electron microscopy (SEM). Gelatin:AMCS gummy gels were divided into two groups: the first group (Group 1) consisted of gels containing different gelatin (0-10 wt\%) and AMCS (0-10 wt\%) concentrations, totalizing $10 \mathrm{wt} \%$ solids; the second group (Group 2) was made up of gels prepared with a fixed gelatin concentration $(8 \mathrm{wt} \%)$ and varying AMCS concentrations (0 - $5 \mathrm{wt} \%)$. The gummy gels were formulated with Lycasin ${ }^{\circledR}$ (maltitol syrup) and xylitol, shaped in cylindrical molds and submitted to texture profile analysis (TPA) and colorimetric analysis. Pure starch gels presented higher stringiness and adhesiveness. When AMCS was introduced into gelatin gels, a dramatically change in the gel structure was observed. The addition of $1 \mathrm{wt} \%$ AMCS formed a thermodynamically stable gel. However, increasingly AMCS concentration leaded to a thermodynamic incompatibility, exposed by a higher number of hollow zones and unswollen starch granules. In samples formulated with a fixed gelatin content $(8 \mathrm{wt} \%)$, an 
increase in hardness and opacity and a decrease in stringiness and adhesiveness were observed with increasing AMCS content (2 - $5 \mathrm{wt} \%)$. It could be concluded that the presence of gelatinized starch significantly affected the morphology of the gelatin network, but preserved the mechanical properties of gels when a suitable balance between gelatin and AMCS contents was attained. Based on these considerations, the addition of AMCS in gelatin gels can be an alternative in the formulation of gummy confections.

Keywords: acid modified corn starch, TPA, scanning electron microscopy, confocal laser scanning microscopy, gels.

\subsection{Introduction}

Proteins are often used for products formulation, such as coatings, capsules in pharmaceutical and food industries, adhesives, surfactants and plastic items. Nevertheless, the higher price of proteins and proteinaceous materials, when compared with other biopolymers, especially starch and cellulose, has limited research on their technical applications (Chiellini, Cinelli, Fernandes, Kenawy \& Lazzeri, 2001).

Gelatin is the biopolymer obtained by hydrolytic degradation of the most abundant mammalian protein, collagen. It has wide-ranging industrial applications, especially in the food industry (Ward \& Courts, 1977). The native conformation of collagen is a triple helix held together by interchain hydrogen bonding. In dilute aqueous solutions above $37{ }^{\circ} \mathrm{C}$ the gelatin molecules exist as separate disordered chains (coils). On cooling, regions of the molecules start to revert to ordered helical collagen-like sequences ("frustrated renaturation"). When a solution containing around $1 \mathrm{wt} \%$ gelatin is cooled to room temperature, the gelatin molecules form an infinite network cross-linked by hydrogen bonding, i.e., a thermoreversible gel. The role of the coil-helix transition in this mechanism has been thoroughly investigated (Ferry \& Eldridge, 1949; Flory \& Weaver, 1960; Guo, Colby, Lusignan \& Whitesides, 2003). The gel strength of gelatin gels is dependent on the gelatin concentration, with little effect of ionic strength and pH (Papageorgiou, Kasapis \& Richardson, 1994; Hsu \& Jamieson, 1993).

The behavior of mixtures of gelatin and various polysaccharides as alginate (Panouillé \& Larreta-Garde, 2009), pectin (DeMars \& Ziegler, 2001) and starch (Firoozmand, Murray \& Dickinson, 2009; Firoozmand, Murray \& Dickinson, 2007; Tromp, Velde, Riel \& Paques, 2001) has been widely studied. The knowledge of protein-polysaccharide interactions is 
important for food formulations since these mixtures generally lead to phase separation. This phase separation occurs due to thermodynamic incompatibility or complex coacervation, depending on the affinity between the different biopolymers and the solvent (Doublier, Garnier, Renard, \& Sanchez, 2000).

In addition to its role in plant physiology, starch is the most important carbohydrate source in human nutrition (Veiga, Ryan, Sourty, Llanes \& Marchessault, 2000). It is also widely used, alone or with other gelling agents, to provide a wide range of jelly and gum products. Native and modified starches are important ingredients of many formulated foods (Abd Karim, Norziah \& Seow, 2000).

The role of starch in gummy confections is to provide their base structure and many of their textural characteristics. Acid modified starches are formed by adding a small amount of acid to a starch suspension and heating to a temperature below the starch gelatinization temperature producing hydrolyzed starch (Lees, 1980). When the required degree of chain concision is achieved, the mix is neutralized and the starch filtered off and dried. The acid hydrolyses some bonds within the starch granule, leading to a less linked structure and a reduction in molecular weight of some chains. This causes the starch granules to be readily soluble in boiling water (Belitz \& Grosch, 1999) and disintegrate when cooked to give a lower hot paste viscosity and higher gel viscosity than native starches (Rix, 1990; Hermansson \& Svegmark, 1996).

In many food products, such as processed meats, cheese, yogurt and confectionary products, texture is primarily dependent upon formation of a gel network, which can be strongly affected by the nature of the biopolymers present in the formulation. The use of gelatin in gummy confection is indicated because the final product shows good hardness and transparence, two characteristics that are desirable by consumers.

A gummy confection consists of high proportions of sucrose and glucose syrup, combined with gelling components such as starch, gelatin, or pectin, along with food acid, flavourings and colourings. Common confectionery gels products form a portion of the lucrative confectionery market and there are continual consumer demands for more interesting and innovative products that have new and exciting textures, flavors and appearances. Improving or modifying confectionery gels textures can meet these demands, but first an understanding of how the behavior and structure of the gel is developed must be achieved (Burey, Bhandari, Rutgers, Halley \& Torley, 2009). In addition, an increase in the demand for low-sugar products has been observed in recent years, in such a way that a gummy confection without sucrose and glucose syrup could be a new and attractive alternative to consumers. 
The aim of this study was to investigate the influence of acid modified corn starch (AMCS) addition in gelatin based gummy confections, analyzing their mechanical and optical properties (by TPA tests and colorimetric analysis) and microstructure (by SEM and CLSM) in order to contribute to the knowledge on structure development in blended biopolymer systems.

\subsection{Material and methods}

\subsubsection{Material}

The gummy gels were formulated using gelatin, AMCS, maltose syrup (Lycasin ${ }^{\circledR}$ ), xylitol and distillated water. The food-grade, type B, bloom number 240 gelatin, extracted from bovine hides by alkaline treatment (Appendix B) was supplied from Gelita (Mococa, Brazil). Commercial food-grade corn starch, acid modified (Appendix B), Candymil ${ }^{\circledR}$ (moisture content $12.2 \mathrm{wt} \%$, ash content $<2 \mathrm{wt} \%, \mathrm{pH} 5.4$ ) was provided from Corn Products (Mogi Guaçu, Brazil). Maltose syrup (Lycasin ${ }^{\circledR}$ ) and xylitol were supplied, respectively, from Roquette (Lestrem, France) and Tovani Benzaquen (São Paulo, Brazil). These materials were used without any chemical treatment.

\subsubsection{Preparation of gelatin/corn starch gels}

The gelatin/corn starch gels were prepared in two sample groups. In the first group (Group 1), the samples contained different proportions of gelatin:AMCS, always totalizing 10 $\mathrm{wt} \%$ gelling agents in the final formulation. The adopted levels of gelling agents were: 10:0; $9: 1 ; 8: 2 ; 7: 3 ; 0: 10$, respectively, gelatin and AMCS wt $\%$. These formulations were completed with $60 \mathrm{wt} \%$ Lycasin $^{\circledR}, 10 \mathrm{wt} \%$ xylitol, and $20 \mathrm{wt} \%$ distilled water.

In the second group (Group 2), the samples contained a fixed amount of gelatin (8 $\mathrm{wt} \%$ of the final formulation) and different proportions of AMCS, varying form 0 to $5 \mathrm{wt} \%$ of the final formulation. In order to kept constant the proportion between the additional formulation ingredients, the following procedure was adopted: the amount of gelling agents was subtracted from a total of $100 \mathrm{wt} \%$ and the remaining amount was divided into nine 
portions, which were composed by six portions of Lycasin ${ }^{\circledR}$, one portion of xylitol and two portions of distilled water, according to Table 5.1.

Table 5.1

Formulations of gelatin and AMCS gels of groups 1 and 2.

\begin{tabular}{|c|c|c|c|c|c|c|}
\hline & Sample & $\begin{array}{l}\text { Gelatin } \\
(w t \%)\end{array}$ & $\begin{array}{l}\text { AMCS } \\
(w t \%)\end{array}$ & $\begin{array}{l}\text { Lycasin }^{\circledR} \\
(\mathbf{w t} \%)\end{array}$ & $\begin{array}{l}\text { Xylitol } \\
(w t \%)\end{array}$ & $\begin{array}{l}\text { Water } \\
(\mathbf{w t} \%)\end{array}$ \\
\hline \multirow{5}{*}{ Group 1} & $7 \mathrm{G} 3 \mathrm{~S}$ & 7.00 & 3.00 & 60.00 & 10.00 & 20.00 \\
\hline & $8 \mathrm{G} 2 \mathrm{~S}$ & 8.00 & 2.00 & 60.00 & 10.00 & 20.00 \\
\hline & $9 \mathrm{G} 1 \mathrm{~S}$ & 9.00 & 1.00 & 60.00 & 10.00 & 20.00 \\
\hline & 10G0S & 10.00 & - & 60.00 & 10.00 & 20.00 \\
\hline & 0G10S & - & 10.00 & 60.00 & 10.00 & 20.00 \\
\hline \multirow{6}{*}{ Group 2} & $8 \mathrm{G} 0 \mathrm{~S}$ & 8.00 & 0.00 & 61.34 & 10.22 & 20.44 \\
\hline & $8 \mathrm{G} 1 \mathrm{~S}$ & 8.00 & 1.00 & 60.67 & 10.11 & 20.22 \\
\hline & $8 \mathrm{G} 2 \mathrm{~S}$ & 8.00 & 2.00 & 60.0 & 10.00 & 20.00 \\
\hline & $8 \mathrm{G} 3 \mathrm{~S}$ & 8.00 & 3.00 & 59.33 & 9.89 & 19.78 \\
\hline & $8 \mathrm{G} 4 \mathrm{~S}$ & 8.00 & 4.00 & 58.67 & 9.78 & 19.55 \\
\hline & $8 \mathrm{G} 5 \mathrm{~S}$ & 8.00 & 5.00 & 58.00 & 9.67 & 19.33 \\
\hline
\end{tabular}

The aqueous gelatin solution was prepared by dissolving gelatin granules in distilled water $\left(80-90{ }^{\circ} \mathrm{C}\right)$. In order to fully dissolve all granules, the gelatin solution was kept for 30 minutes in a water bath at $60{ }^{\circ} \mathrm{C}$, with regular manual stirring. A similar procedure was used to prepare the starch solution, but in this case the water bath was kept at $90{ }^{\circ} \mathrm{C}$, with manual stirring for 9 minutes (until the starch suspension became transparent).

Lycasin ${ }^{\circledR}$ and xylitol were mixed and heated over a metal sheet at $125{ }^{\circ} \mathrm{C}$ and cold at $90{ }^{\circ} \mathrm{C}$. This syrup and the gelatin solution were then added to the starch solution, under manual stirring for 1 minute in a water bath at $90{ }^{\circ} \mathrm{C}$ (Figure 5.1). The final formulation was subjected to $\mathrm{pH}$ measurement, which resulted in values varying in the range of 5.9 to 6.2. A portion of the final formulation was placed into cylindrical silicon molds for texture and color analysis (items 2.3 and 2.4), whereas the remaining material was processed for microstructure analysis (items 2.5 and 2.6).

\subsubsection{Mechanical properties}

The mechanical properties of the gels were determined by compression using a TAXT2i Texture Analyzer (Stable Microsystems Ltd., Godalming, UK) with an acrylic cylindrical plate probe $(49,2 \mathrm{~mm}$ of diameter) lubricated with canola oil. 


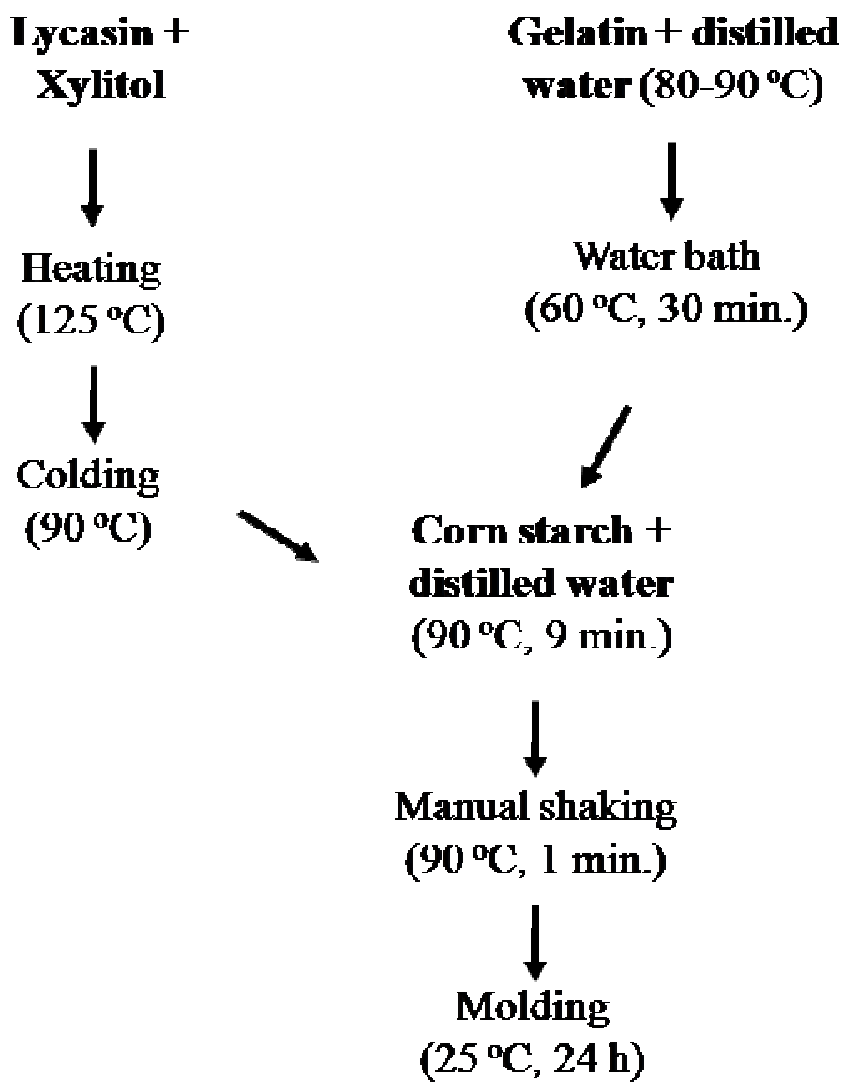

Figure 5.1. Schematic diagram showing processing steps used to prepare gelatin and AMCS gel samples.

The cylindrical-shaped gels $(20 \mathrm{~mm}$ length and $31 \mathrm{~mm}$ diameter $)$ were kept at ambient temperature $\left(25^{\circ} \mathrm{C}\right)$ for 24 hours and then were subjected to the instrumental texture profile analysis (TPA) tests. The samples were compressed twice at $1 \mathrm{~mm} / \mathrm{s}$ to $40 \%$ of their original height and the measurements were performed in triplicate. The textural parameters recorded during the analysis were hardness, fracturability stringiness, adhesiveness and springiness, defined according to Steffe (1996) and calculated by the Texture Expert software (Stable Microsystems Ltd., Godalming, UK).

\subsubsection{Opacity}

The opacity (Y) was measured in a colorimeter (Hunterlab / Colorflex, Reston, USA). The Y value was calculated by the Universal software 3.2 (Hunter Lab Associates Laboratory, Reston, USA, 1997), according to Equation (1). 
$\mathrm{Y}=\left(\mathrm{Y}_{\mathrm{B}} / \mathrm{Y}_{\mathrm{W}}\right) \cdot 100$

where $Y_{B}$ and $Y_{w}$ are the opacity under black and white standard, respectively. The opacity values were obtained in an arbitrary scale (0 to $100 \%)$.

\subsubsection{Scanning electronic microscopy (SEM)}

For scanning electron microscopy (SEM), samples were fixed in a $2.5 \%$ glutaraldehyde solution overnight, dehydrated in a graded ethanol solution series and dried by the critical point method using liquid $\mathrm{CO}_{2}$ and acetone. The gels were fractured, mounted on stubs using double-sided stick tape and coated with gold. Samples were analyzed in the Scanning Electron Microscope (Scanning Electron Microscope JEOL JSM 5600, JEOL, Tokyo, Japan).

\subsubsection{Confocal laser scanning microscopy (CLSM)}

For Confocal Laser Scanning Microscopy (CLSM), the fluorescent marker Rhodamine B was used for non-covalent labeling. Two drops of an aqueous, $0.05 \%$ Rhodamine B solution was added to $100 \mathrm{~g}$ of sample at $70{ }^{\circ} \mathrm{C}$. At this temperature the samples were in a liquid state. In these circumstances, all sites in the sample were accessible for the Rhodamine, and diffusion were fast. Samples were mounted in microscope slides, covered with glass cover slips and sealed with nail polish to prevent evaporation. Slides were analyzed in a confocal laser scanning microscopy (Zeiss Laser Scanning Microscope 510, Carl Zeiss, Konigsallee, Gottingen, Germany) using the wavelength of $543 \mathrm{~nm}$.

\subsection{Results and discussion}

\subsubsection{Mechanical properties}


The TPA analysis showed that gelatin has an important role in all textural parameters studied. Considering the samples of Group 1, 10G0S and 9G1S gels did not show significant difference $(\mathrm{p}<0.05)$ in hardness and fracturability (Table 5.2). On the other hand, these parameters decreased with the increasing AMCS proportion (8G2S, 7G3S, 0G10S), mainly in the case of hardness. Similar results were observed by DeMars and Ziegler (2001) in gelatin/pectin-based gummy confections when pectin concentration increased. Gelatin also showed a high influence in stringiness and adhesiveness, since the decrease in gelatin concentration resulted in stringy and adhesive gels, as can be observed in Figure 5.2. In this figure, the negative area that appears in the detailed area indicates the adhesiveness, while the horizontal and vertical arrows represent, respectively, stringiness and adhesive force (maximum negative force). Taking into account the springiness, there were no significant differences between samples of Group 1, although a trend of maximum springiness had been observed for the sample $7 \mathrm{G} 3 \mathrm{~S}$.

Table 5.2

Hardness, fracturability, stringiness, adhesiveness, springiness and opacity values of gelatin and AMCS gels (Group 1).

\begin{tabular}{cccccccc}
\hline $\begin{array}{c}\text { Gelatin } \\
(\mathbf{w t} \%)\end{array}$ & $\begin{array}{c}\text { AMCS } \\
(\mathbf{w t} \%)\end{array}$ & $\begin{array}{c}\text { Hardness } \\
(\mathbf{N})\end{array}$ & $\begin{array}{c}\text { Fracturability } \\
(\mathbf{N})\end{array}$ & $\begin{array}{c}\text { Stringiness } \\
(-)\end{array}$ & $\begin{array}{c}\text { Adhesiveness } \\
(\mathbf{N} . \mathbf{s})\end{array}$ & $\begin{array}{c}\text { Springiness } \\
(\%)\end{array}$ & $\begin{array}{c}\text { Opacity } \\
(\%)\end{array}$ \\
\hline 10.0 & - & $40.08 \pm 2.10^{\mathrm{a}}$ & $0.200 \pm 0.001^{\mathrm{a}}$ & $0.86 \pm 0.14^{\mathrm{a}}$ & $-0.35 \pm 0.13^{\mathrm{a}}$ & $95.5 \pm 0.3^{\mathrm{a}}$ & $90.03 \pm 0.34^{\mathrm{a}}$ \\
9.0 & 1.0 & $42.69 \pm 1.19^{\mathrm{a}}$ & $0.200 \pm 0.001^{\mathrm{a}}$ & $0.96 \pm 0.11^{\mathrm{a}}$ & $-0.55 \pm 0.05^{\mathrm{a}}$ & $94.6 \pm 4.2^{\mathrm{a}}$ & $96.24 \pm 0.44^{\mathrm{b}}$ \\
8.0 & 2.0 & $33.89 \pm 1.71^{\mathrm{b}}$ & $0.177 \pm 0.005^{\mathrm{b}}$ & $1.12 \pm 0.15^{\mathrm{a}}$ & $-0.68 \pm 0.18^{\mathrm{a}}$ & $96.5 \pm 3.0^{\mathrm{a}}$ & $97.76 \pm 0.29^{\mathrm{c}}$ \\
7.0 & 3.0 & $18.26 \pm 0.07^{\mathrm{c}}$ & $0.180 \pm 0.005^{\mathrm{b}}$ & $1.98 \pm 0.25^{\mathrm{b}}$ & $-1.10 \pm 0.14^{\mathrm{b}}$ & $97.5 \pm 2.5^{\mathrm{a}}$ & $98.02 \pm 0.21^{\mathrm{c}}$ \\
- & 10.0 & $1.10 \pm 0.08^{\mathrm{d}}$ & $0.134 \pm 0.004^{\mathrm{c}}$ & $3.82 \pm 0.21^{\mathrm{c}}$ & $-2.08 \pm 0.19^{\mathrm{c}}$ & $95.4 \pm 0.9^{\mathrm{a}}$ & $*$ \\
\hline
\end{tabular}

${ }^{\mathrm{abc}}$ Means \pm standard error, values with different letters in same column are significantly different, $\mathrm{P}<0.05$.

* the consistence of the obtained gel did not permit evaluate opacity.

Gels containing only AMCS as the gelling agent (0G10S) showed the lower ability of gel formation presented by this biopolymer when compared to gelatin, even in the presence of maltitol syrup that behaves as a body agent, and xylitol that is an edulcorant. Nevertheless, when starch is used blended with gelatin, it can present a synergistic effect, enhancing the mechanical properties of the final product.

In order to study the influence of AMCS on the texture of gelatin gels, some experiments were carried out in samples with a fixed gelatin concentration ( $8 \mathrm{wt} \%$ of the final formulation) and different proportions of AMCS, varying form 0 to $5 \mathrm{wt} \%$ of the final formulation, corresponding to samples of Group 2 (Table 5.1). The results of TPA tests applied in these samples are presented in Table 5.3. 


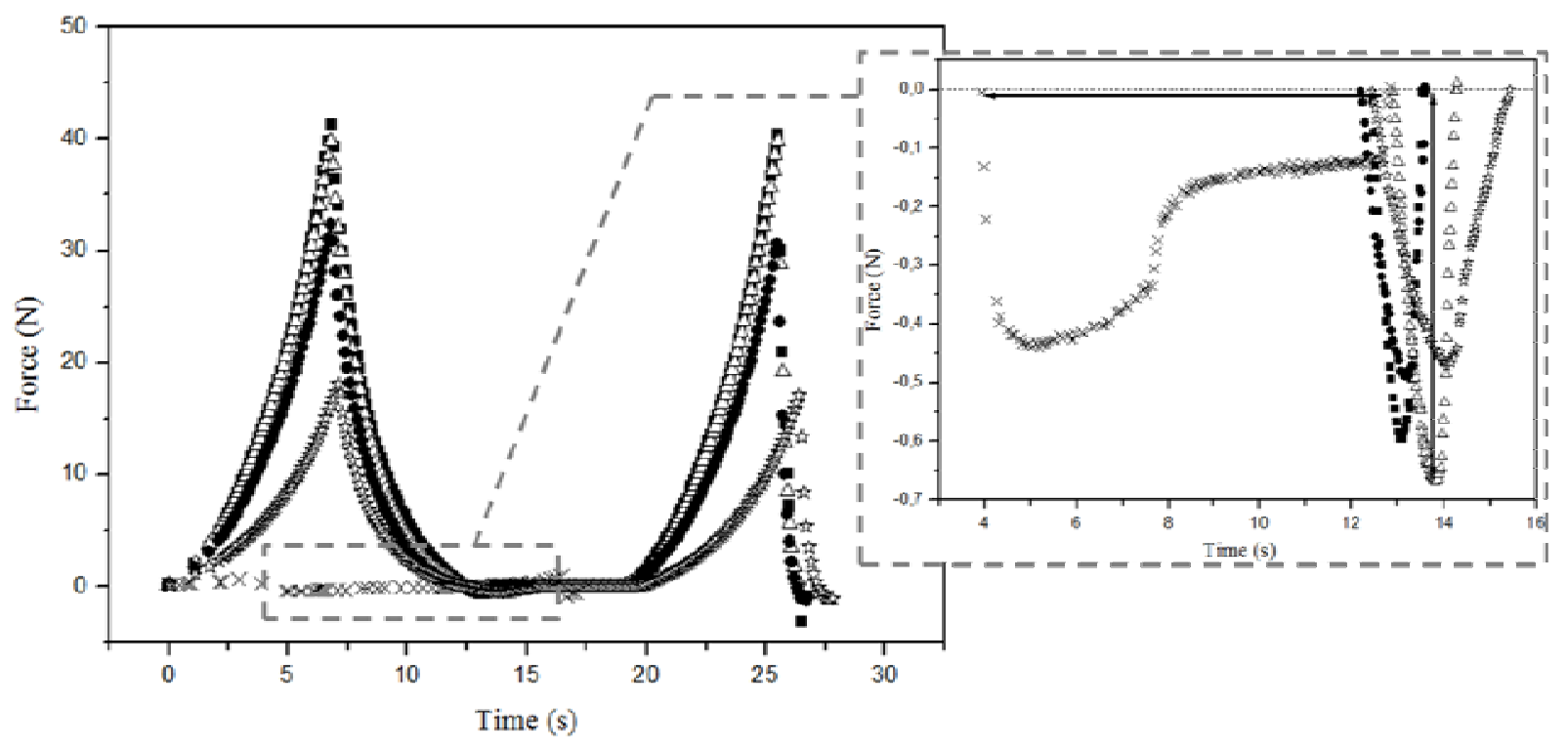

Figure 5.2. Texture profile analysis of gelatin:AMCS gels (10 wt $\%$ solids) in different proportions, respectively: 10:0 (closed squares); 9:1 (open triangles); 8:2 (closed circles); 7:3 (open stars); 0:10 (cross).

The highest hardness values were observed in samples 8G4S (51.67 N) and 8G5S $(53.63 \mathrm{~N})$, which were higher than those that would be obtained by summation of hardness values of samples prepared with the individual biopolymers as, for instance, in samples 10G0S $(40.08 \mathrm{~N})$ and $0 \mathrm{G} 10 \mathrm{~S}(1.10 \mathrm{~N})$. This could suggest that there is a synergistic effect between the two biopolymers, which would cause an increase in hardness of blended gels. On the other hand, it should be pointed out that the total gelling agents' concentration in samples $8 \mathrm{G} 4 \mathrm{~S}$ and $8 \mathrm{G} 5 \mathrm{~S}$ were higher than in samples $10 \mathrm{G} 0 \mathrm{~S}$ and $0 \mathrm{G} 10 \mathrm{~S}$. Taking into account sample $8 \mathrm{G} 2 \mathrm{~S}$ that was prepared with a total of $10 \mathrm{wt} \%$ gelling agents, the resulting hardness $(35.06$ N) was lower than for the sample containing only gelatin.

Table 5.3

Hardness, fracturability, stringiness, adhesiveness, springiness and opacity values of gelatin and AMCS gels containing $8 \mathrm{wt} \%$ gelatin and $0-5 \mathrm{wt} \%$ AMCS (Group 2).

\begin{tabular}{ccccccc}
\hline $\begin{array}{c}\text { Corn Starch } \\
(\mathbf{w t} \%)\end{array}$ & $\begin{array}{c}\text { Hardness } \\
(\mathbf{N})\end{array}$ & $\begin{array}{c}\text { Fracturability } \\
(\mathbf{N})\end{array}$ & $\begin{array}{c}\text { Stringiness } \\
(-)\end{array}$ & $\begin{array}{c}\text { Adhesiveness } \\
(\mathbf{N} . \mathbf{s})\end{array}$ & $\begin{array}{c}\text { Springiness } \\
(\%)\end{array}$ & Opacity (\%) \\
\hline- & $31.94 \pm 1.23^{\mathrm{a}}$ & $0.195 \pm 0.001^{\mathrm{a}}$ & $2.10 \pm 0.03^{\mathrm{a}}$ & $-2.97 \pm 0.52^{\mathrm{a}}$ & $92.3 \pm 3.3^{\mathrm{ab}}$ & $81.33 \pm 0.59^{\mathrm{a}}$ \\
1.00 & $33.30 \pm 0.23^{\mathrm{a}}$ & $0.195 \pm 0.005^{\mathrm{a}}$ & $1.36 \pm 0.22^{\mathrm{bcd}}$ & $-0.70 \pm 0.41^{\mathrm{b}}$ & $96.5 \pm 0.4^{\mathrm{ab}}$ & $89.93 \pm 0.54^{\mathrm{b}}$ \\
2.00 & $35.06 \pm 3.11^{\mathrm{a}}$ & $0.178 \pm 0.004^{\mathrm{b}}$ & $1.48 \pm 0.01^{\mathrm{b}}$ & $-1.24 \pm 0.20^{\mathrm{bc}}$ & $90.0 \pm 0.9^{\mathrm{a}}$ & $97.28 \pm 0.68^{\mathrm{c}}$ \\
3.00 & $35.87 \pm 2.77^{\mathrm{a}}$ & $0.178 \pm 0.004^{\mathrm{b}}$ & $1.22 \pm 0.02^{\mathrm{c}}$ & $-0.56 \pm 0.25^{\mathrm{bd}}$ & $90.6 \pm 3.3^{\mathrm{a}}$ & $97.57 \pm 0.20^{\mathrm{cd}}$ \\
4.00 & $51.67 \pm 1.62^{\mathrm{b}}$ & $0.188 \pm 0.010^{\mathrm{a}}$ & $0.91^{\mathrm{c}} \pm 0.25^{\mathrm{cd}}$ & $-0.47 \pm 0.46^{\mathrm{bcd}}$ & $90.5 \pm 1.5^{\mathrm{a}}$ & $97.64 \pm 0.23^{\mathrm{cd}}$ \\
5.00 & $53.63 \pm 0.50^{\mathrm{b}}$ & $0.186 \pm 0.009^{\mathrm{a}}$ & $1.05 \pm 0.01^{\mathrm{d}}$ & $-0.58 \pm 0.10^{\mathrm{bd}}$ & $92.8 \pm 2.1^{\mathrm{a}}$ & $96.04 \pm 0.37^{\mathrm{c}}$ \\
\hline
\end{tabular}

Contrary to the observed above for samples of Group 1, samples of Group 2 showed a trend of less stringy and adhesive gels with increasing starch concentration (Table 5.3 and 
Figure 5.3). Nevertheless, this result could be reflecting the increase in the total content of gelling agents.

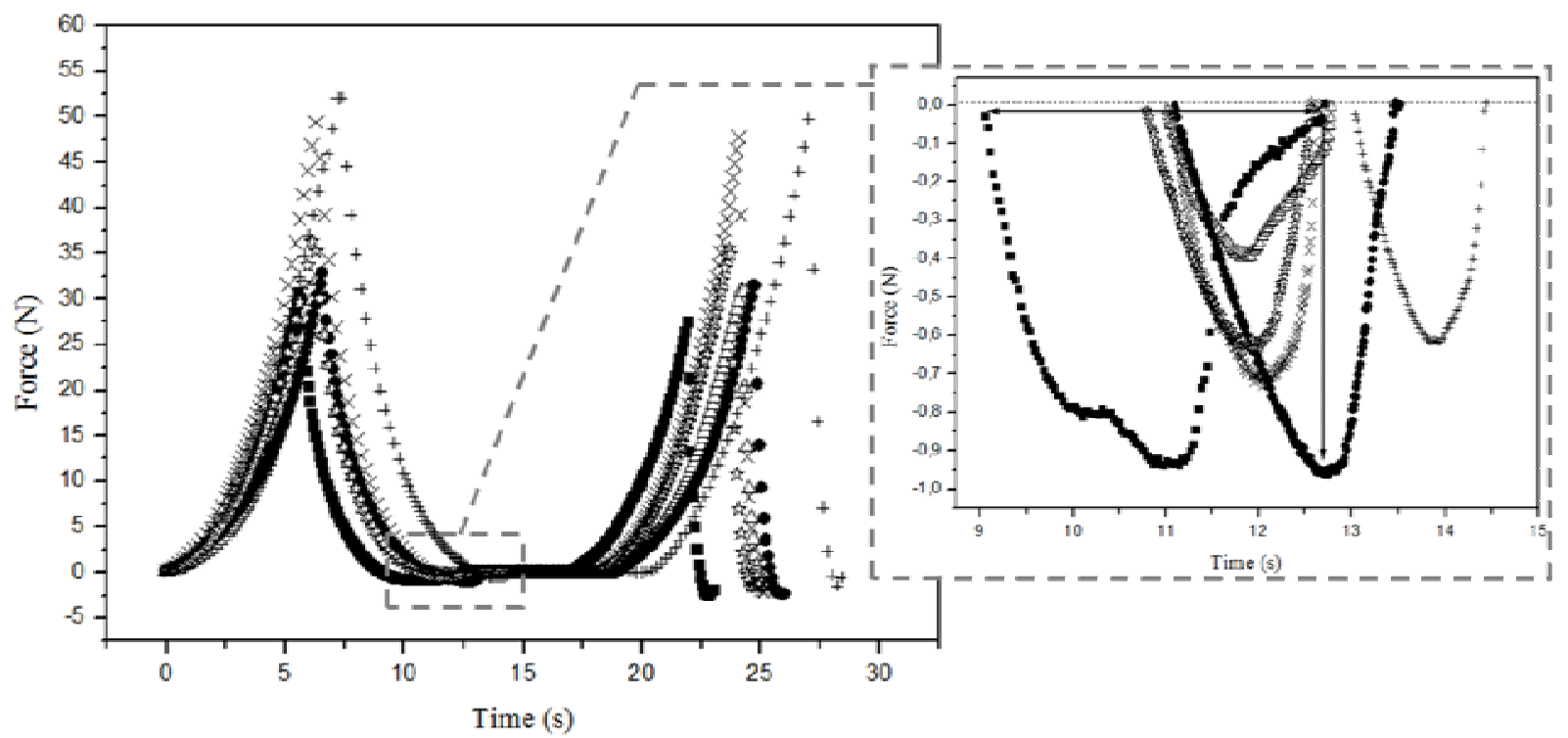

Figure 5.3. Texture profile analysis of gelatin:AMCS gels containing $8 \mathrm{wt} \%$ gelatin and different AMCS contents: $0 \%$ (closed squares); $1 \%$ (open triangles); $2 \%$ (closed circles); $3 \%$ (open stars); $4 \%$ (cross); $5 \%$ (plus signs).

\subsubsection{Opacity}

In general, gelatin gels were very transparent. This transparence decreased with the increase in gelatin concentration, as can be concluded by comparison of samples 10G0S (Table 5.2) and 8G0S (Table 5.3).

Table 5.2 shows that addition of a small concentration of AMCS $(1 \mathrm{wt} \%)$ decreased transparence, but resulted in a gel with mechanical proprieties similar to pure gelatin gels. In Table 5.3, the influence of AMCS in gel opacity can be clearer observed, since in these samples, gelatin concentration was kept constant (8 wt \%): the AMCS increasing caused transparence decreasing. For instance, the initial opacity value of $81.33 \%(8 \mathrm{G} 0 \mathrm{~S})$ increased to $97.28 \%(8 \mathrm{G} 2 \mathrm{~S})$ with the addition of only $2 \mathrm{wt} \%$ starch.

\subsubsection{Microscopy structure}


In order to relate the mechanical properties and microstructure of gels, the samples were subjected to analysis by SEM (Figure 5.4) and CLSM (Figures 5.5 and 5.6). For CLSM, as Rhodamine B is a protein specific dye, gelatin appears grayish or reddish in the fotographs, while the darker areas indicate the absence of protein.

SEM (Figure 5.4) permitted the visualization of the three-dimensional structure of the mixed systems. CSLM (Figures 5.5 and 5.6) corroborated the results, confirming that the grayish or reddish network observed was formed by gelatin, since it was stained by Rhodamine.

In the absence of AMCS, gelatin showed a thin spongy and regular aspect (Figures $5.4 \mathrm{~A}$ and $5.5 \mathrm{~A}$ ). The addition of $1 \mathrm{wt} \%$ of AMCS changed dramatically the morphology of the gel, since the gelatin formed fibrillar framework containing some swollen AMCS (Figures 5.4B and 5.5B). These fibers were randomly distributed and connected with one another and the swollen AMCS granules appear to be embraced by the gelatin network. Heating of AMCS suspensions leads to swelling and finally disruption of the AMCS granules, the so-called gelatinization process. Therefore, it could be deduced that the presence of gelatinized starch would affect significantly the morphology of gelatin network. In many applications and in almost all food applications, starch granules are heated before use.

The addition of 2 to $5 \mathrm{wt} \%$ AMCS (Figures 5.4C-D and 5.5C-F) resulted in a polygonal network of gelatin with many hollow zones where the starch granules were localized, but contrary to what was observed in Figure 5.4B, the swollen AMCS granules appear to be disconnected from the network. The increasing of AMCS concentration in the mixed systems showed a more compact appearance, that was related to the higher hardness found on the TPA tests. The network was predominantly composed by gelatin, which explained the self-supported structure of the systems. In addition, the increasing of AMCS concentration also showed a higher number hollow zones and unswollen starch granules.

When two biopolymers (proteins and/or polysaccharides) are mixed together, we can observe a single phase or a phase separation (associative or segregative) (Piculell, Bergfeldt \& Nilsson, 1995; Doublier, Garnier, Renard \& Sanchez, 2000; de Kruif \& Tuinier, 2001; Turgeon, Beaulieu, Schmitt \& Sanchez, 2003). The behavior of a single phase occurs in some rare cases or for low polymer concentrations, when the biopolymers are miscible and co-exist. This situation was identified in the sample $8 \mathrm{G} 1 \mathrm{~S}$ (Figures 5.6A-C), where the biopolymers co-existed because of the low starch concentration. This gel was considered thermodynamically stable, according to the definitions of Tolstoguzov (1992). 

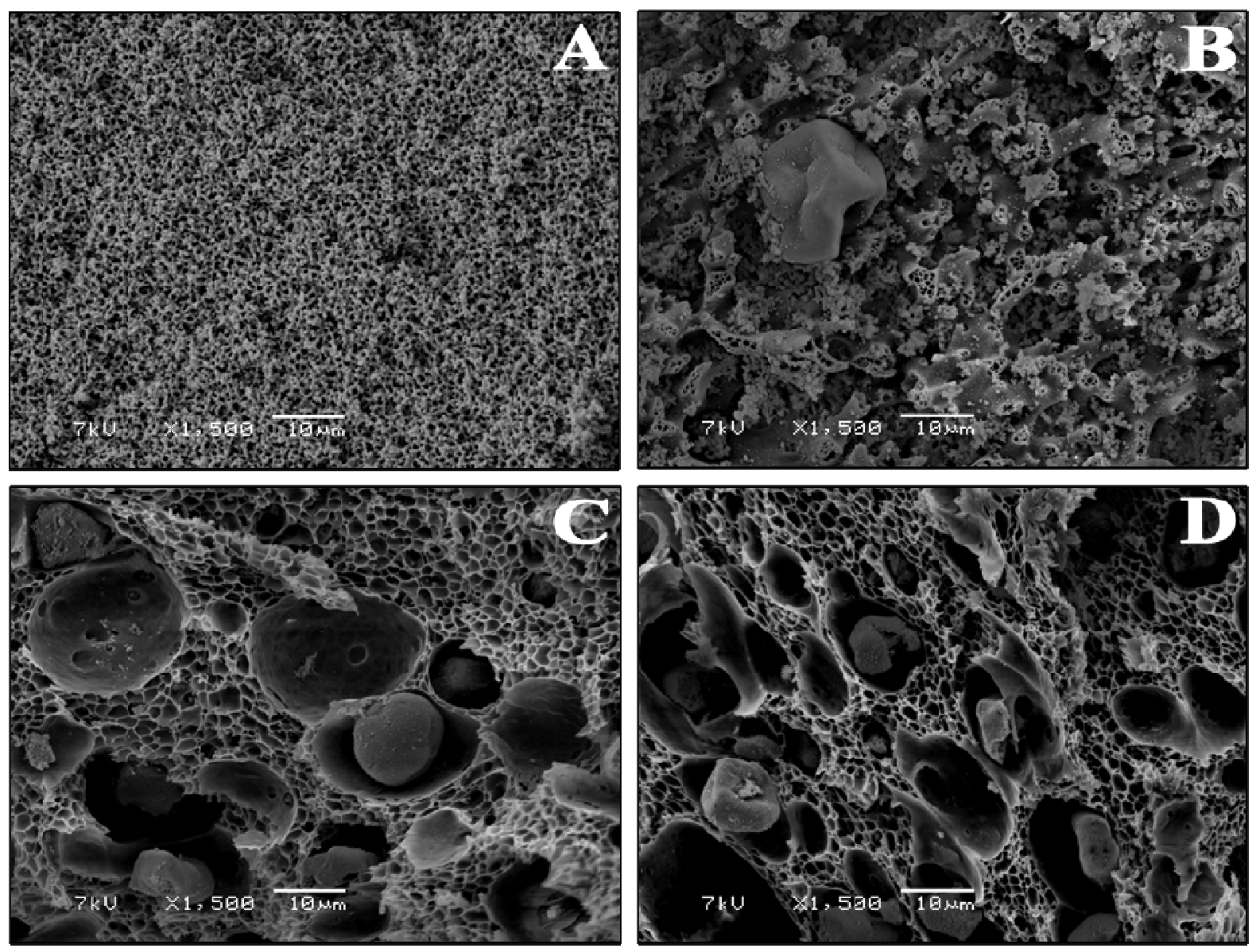

Figure 5.4. SEM images of blended systems containing $8 \mathrm{wt} \%$ gelatin and zero (A), $1 \mathrm{wt} \%$ (B), $3 \mathrm{wt} \%$ (C) and 5 wt $\%$ (D) AMCS. 


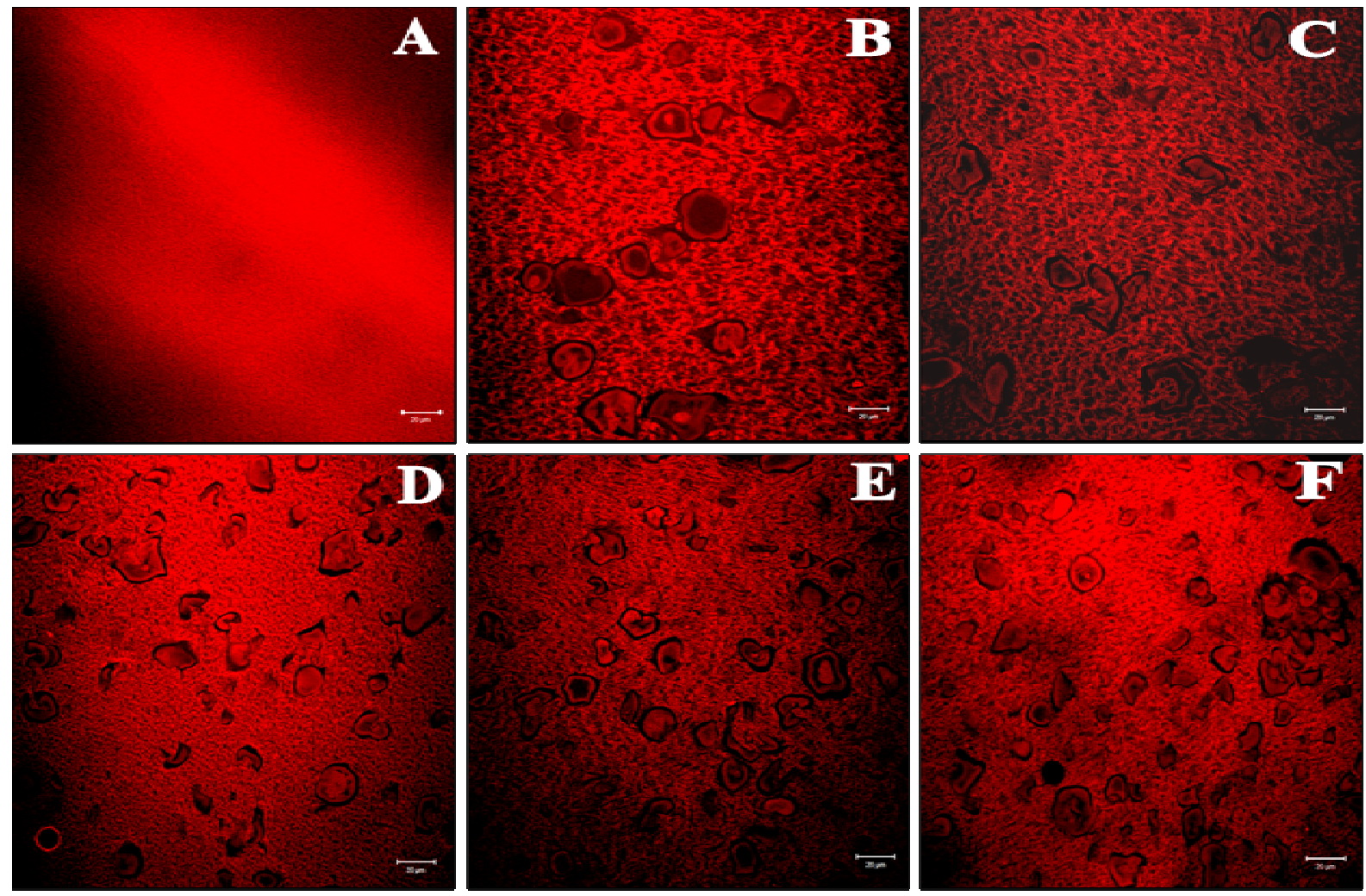

Figure 5.5. CSLM images of blended systems containing zero (A), 1 wt $\%$ (B), 2 wt $\%$ (C), 3 wt $\%$ (D), 4 wt $\%$ (E) and $5 \mathrm{wt} \%$ (F) AMCS. Grayish (or reddish) regions are rich in gelatin.
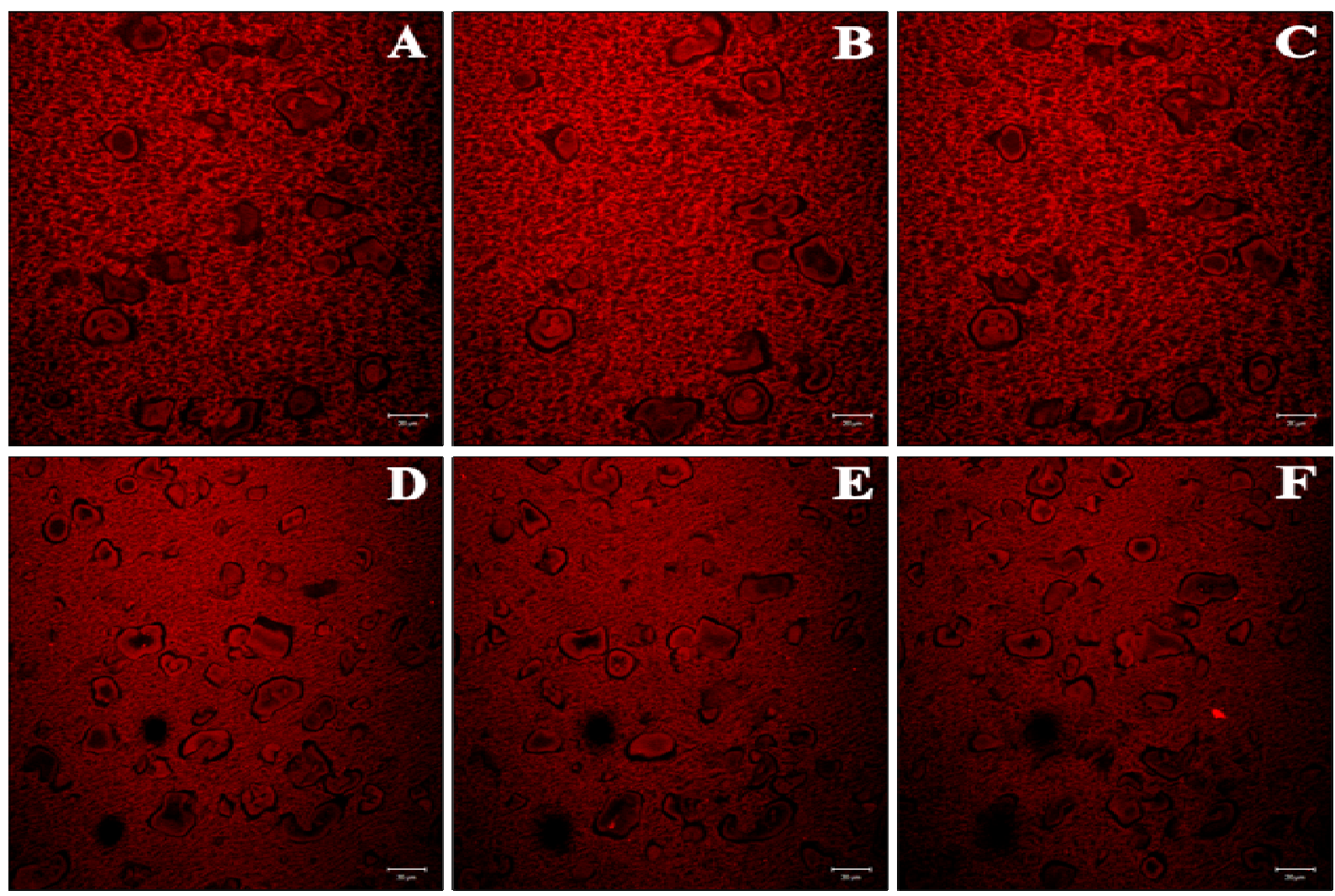

Figure 5.6. CSLM images of cross-sections of $8 \mathrm{G} 1 \mathrm{~S}$ (A, B, C) and $8 \mathrm{G} 5 \mathrm{~S}$ (D, E, F) samples showing some AMCS in the gelatin network (distance between cross-sections: $2 \mu \mathrm{m}$ ). 
Nevertheless, the increasing of AMCS concentration modified the structure of the gels, showing a thermodynamic incompatibility. This behavior became evident by the hollow zones that segregated starch granules from the gelatin. The network was more compact, whereas gelatin was repulsed by the starch.

A thermodynamic unstable system is the most frequent and is mainly due to excluded volume effects and repulsion between the two biopolymers (Tolstoguzov, 1992; Doublier, Garnier, Renard, \& Sanchez, 2000). This behavior is also called segregative phase separation and occurs when each phase is enriched with one of the two biopolymers. In the systems studied in the present work, although the progressively increase in the AMCS concentration, phase separation did not occur probably due to the increasingly viscosity of the suspension caused by the starch gelatinisation. Figure 5.6 shows cross-sections of $8 \mathrm{G} 1 \mathrm{~S}$ (Figure 5.6A-C) and 8G5S (Figure 5.6D-F), revealing the absence of phase separation. The key feature of CLSM is the imaging of a single focal plane in the sample. This enables the visualization of cross-sections of the blended systems without the need for sectioning techniques. Crosssections were taken at $2 \mu \mathrm{m}$ intervals.

In mixed biopolymer systems phase separation is governed by critical polymer concentration, polymer shape, and compatibility of the biopolymers present. The extent of mixing is governed by the "Flory-Huggins interaction parameter," which is dependent on solvent quality and volume as well as polymer concentration and size (Clark, 1995; Danner, 1993). Altering the quality of the solvent (e.g., adding sugar to water), results in changes to the extent of mixing in the blended biopolymer system. This leads to mixed biopolymer systems that contain sugars to present a different morphology than those formed in an aqueous environment (Kasapis, Mitchell, Abeysekera \& MacNaughtan, 2004). The morphology of the systems studied in the present work must have been affected by the presence of maltitol and xilytol.

Studies of single biopolymer systems containing sugar have shown that in polysaccharides, such as starch, in which sugar concentration approaches levels found in confectionery gels, chain-chain associations are reduced. This leads to a less aggregated structure than in the case of the aqueous system, meaning that must be increased as the sugar inhibits the gel network aggregation. Gelatin gels behave quite differently from starch gel systems, with chain association being increased in the presence of sugar, rather than reduced. Sugars tend to destabilize polysaccharide gel networks at levels of 40-60\% sugars, but increase gelatin gel networks at these levels of sugar (Kasapis, Mitchell, Abeysekera \& MacNaughtan, 2004). 
In aqueous systems, gelatin gels appear as continuous systems, but upon addition of sugar they separate into sugar-rich and gelatin-rich phases, showing high biopolymer aggregation. In aqueous systems, polysaccharides show fibrillar network structures, but upon addition of sugar some of these features are lost. This is due to the threshold of thermodynamic stability of structure formation for polysaccharides being exceeded at these levels, and considerable parts of the network "dissolving" in the saturated sugar environment. Thermodynamic stability of gelatin gel network formation is increased at 40-60\% sugar and continues to increase at levels above this (Kasapis, Al-Marhoobi, Deszczynski, Mitchell \& Abeysekera, 2003).

The photographies (Figure 5.4C-D) showed some unswollen AMCS granules in the gelatin network. Several theories suggest that sugar can affect starch gelatinization. One theory is that sugar molecules interact with starch granule amorphous regions and increases the gelatinization temperature $\left(\mathrm{T}_{\text {gel }}\right)$ of the starch. In limited water $(<30 \%)$, starch $\mathrm{T}_{\text {gel }}$ increases with decreasing moisture content. When sugar is dissolved in the water being used for gelatinization, part of the water is bound by the sugar, effectively decreasing the moisture content, leading to an increased starch $\mathrm{T}_{\text {gel }}$ (Beleia \& Miller, 1996; Perry \& Donald, 2002). Another theory is that sugar displaces water inside the starch granules, therefore inhibiting one of the promoters of starch gelatinization. Sugars are also thought to stabilize crystalline regions in the starch and hence immobilize water molecules, hindering starch gelatinization (Beleia \& Miller, 1996).

\subsection{Conclusions}

The results presented in this paper showed that starch gels are more stringiness and adhesiveness than those of gelatin. When AMCS was introduced in gelatin gels, it dramatically changed the structure. The addition of $1 \mathrm{wt} \%$ AMCS formed a thermodynamically stable gel. However, the increasing of AMCS concentration modified the structure of gelatin network, showing a thermodynamic incompatibility, a higher number of hollow zones and unswollen starch granules. In addition, an increasing of hardness and opacity and a decreasing of stringiness and adhesiveness was observed. It could be deduced that the presence of gelatinized starch would affect significantly the morphology of gelatin network. Finally, the addition of AMCS to gelatin gels resulted in more opaque gels, although the mechanical properties were preserved when a suitable balance between gelatin and AMCS 
contents was attained, as in the case of samples containing 9:1, 8:4 and 8:5 wt $\%$ of gelatin:AMCS. Based on these considerations, the addition of AMCS in gelatin gels can be an alternative in the formulation of gummy confections.

\section{Acknowledgements}

The authors thank Dr. Paulo Filemon Paolucci Pimenta and Fernanda Gambogi Oliveira, director and technician, respectively, from the Medical Entomology Laboratory from CPqRR/FIOCRUZ, for enabling microscopic analysis. The authors also thank Gelita, Corn Products and Tovani Benzaquen, and Dr. Rosiane Lopes da Cunha from FEA/UNICAMP, for providing sample materials. The financial support of CAPES (scholarship) and FAPESP (Process 2006/56015-2) are gratefully acknowledged. 


\section{References}

Abd Karim, A.; Norziah, M.H. \& Seow, C.C. (2000). Methods for the study of starch retrogradation. Food Chemistry, 71(1), 9-36.

Beleia, A. \& Miller, R.A. (1996). Starch gelatinization in sugar solutions. Starch, 48(7-8), 259-262.

Belitz, H.-D. \& Grosch, W. (1999). Food Chemistry, New York: Springer Verlag, 774pp.

Burey, P., Bhandari, B. R., Rutgers, R. P. G., Halley, P. J. \& Torley, P. J. (2009). Confectionery gels: a review on formulation, rheological and structural aspects. International Journal of Food Properties, 12(1), 176-210.

Chiellini, E.; Cinelli, P.; Fernandes, E. G.; Kenawy, E-R, S. \& Lazzeri, A. (2001). Gelatinbased blends and composites, morphological and thermal mechanical characterization. Biomacromolecules, 2, 806-811.

Clark, A. (1995). Kinetics of demixing. In Harding, S.; Hill, S. \& Mitchell, J. (Eds.); Biopolymer Mixtures (pp. 37-64). Nottingham: Nottingham University Press.

Danner, R. (1993). Handbook of polymer solution thermodynamics. New York: American Institute of Chemical Engineers.

DeMars, L. L. \& Ziegler, G. R. (2001). Texture and structure of gelatin/pectin-based gummy confections. Food Hydrocolloids, 15, 643-653.

Doublier, J. -L., Garnier, C., Renard, D., \& Sanchez, C. (2000). Protein-polysaccharide interactions. Current Opinion in Colloid and Interface Science, 5(3-4), 202-214.

Ferry, J. D. \& Eldridge, J. E. (1949). The cross-linking process in gelatin gels I. Journal of Physical and Colloid Chemistry, 53, 184-196.

Firoozmand, H.; Murray, B. S. \& Dickinson, E. (2009). Microstructure and rheology of phase-separated gels of gelatin + oxidized starch. Food Hydrocolloids, 23, 1081-1088. 
Firoozmand, H.; Murray, B. S. \& Dickinson, E. (2007). Fractal-type particle gel formed from gelatin + starch solution. Langmuir, 23, 4646-50.

Flory, P. J. \& Weaver, E. S. (1960). Helix coil transitions in dilute aqueous collagen solutions. Journal of the American Chemical Society, 82, 4518-25.

Guo, L.; Colby, R. H.; Lusignan, C. P. \& Whitesides, T. H. (2003). Kinetics of triple helix formation in semidilute gelatin solutions. Macromolecules, 36(26), 9999-10008.

Hermansson, A.-M. \& Svegmark, K. (1996). Developments in the understanding of starch functionality. Trends in Food Science \& Technology, 7(11), 343-353.

Hsu, S. \& Jamieson, A. M. (1993). Viscoelastic behavior at the thermal sol-gel transition of gelatin. Polymer, 34, 2602-2608.

Kasapis, S.; Al-Marhoobi, I. M.; Deszczynski, M.; Mitchell, J.R. \& Abeysekera, R. (2003). Gelatin vs polysaccharide in mixture with sugar. Biomacromolecules, 4(1), 1142-1149.

Kasapis, S.; Mitchell, J.; Abeysekera, R. \& MacNaughtan, W. (2004). Rubber-to-glass transitions in high sugar-biopolymer mixtures. Trends in Food Science \& Technology, 15(6), 293-304.

de Kruif, C. G. \& Tuinier, R. (2001). Polysaccharide protein interactions. Food Hydrocolloids, 15(4-6), 555-563.

Lees, R. (1980). Faults, causes and remedies: in sweet and chocolate manufacture. England: Specialised Publications: Surbiton.

Panouillé, M. \& Larreta-Garde, V. (2009). Gelation behaviour of gelatin and alginate mixtures. Food Hydrocolloids, 23, 1074-1080.

Papageorgiou, M.; Kasapis, S. \& Richardson, R. K. (1994). Steric exclusion phenomena in gellan/gelatin systems. I. Physical properties of single and binary gels. Food Hydrocolloids, $8(2), 97-112$. 
Perry, P.A. \& Donald, A.M. (2002). The effect of sugars on the gelatinisation of starch. Carbohydrate Polymers, 49(2), 155-165.

Piculell, L., Bergfeldt, K., \& Nilsson, S. (1995). Factors determining phase behavior of multi component polymer systems. In Harding, S. E.; Hill, S. E. \& Mitchell, J. R. (Eds.), Biopolymer mixtures (pp. 13-35). Nottingham: University Press.

Rix, A. (1990). Gelling and whipping agents. In Jackson, E. B. Sugar Confectionery Manufacture. New York: Van Nostrand Reinhold, Glasgow; Blackie.

Steffe, F.L. (1996). Rheological methods in food process engineering, East Lansing: Freeman Press, 418 pp.

Tolstoguzov, V. B. (1992). In: Philips, G.; Williams, P. \& Wedlock, D. (Eds.), Interactions of gelatin with polysaccharides. Gums and stabilisers in the food industry, (Vol. 6) (pp. 241266). Oxford: IRL Press.

Tromp, R. H.; Velde, F. V.; Riel, J. V. \& Paques, M. (2001). Confocal scanning light microscopy (CSLM) on mixtures of gelatine and polysaccharides. Food Research International, 34, 931-938.

Turgeon, S. L., Beaulieu, M., Schmitt, C., \& Sanchez, C. (2003). Protein-polysaccharide interactions: phase-ordering kinetics, thermodynamic and structural aspects. Current Opinion in Colloid \& Interface Science, 8(4-5), 401-414.

Veiga, V.; Ryan, D. H.; Sourty, E.; Llanes, F. \& Marchessault, R. H. (2000). Formation and characterization of superparamagnetic cross-linked high amylose starch. Carbohydrate Polymers, 42(4), 353-357.

Ward, A. G. \& Courts, A., Eds. (1977). The Science and Technology of Gelatin; Academic Press: London. 


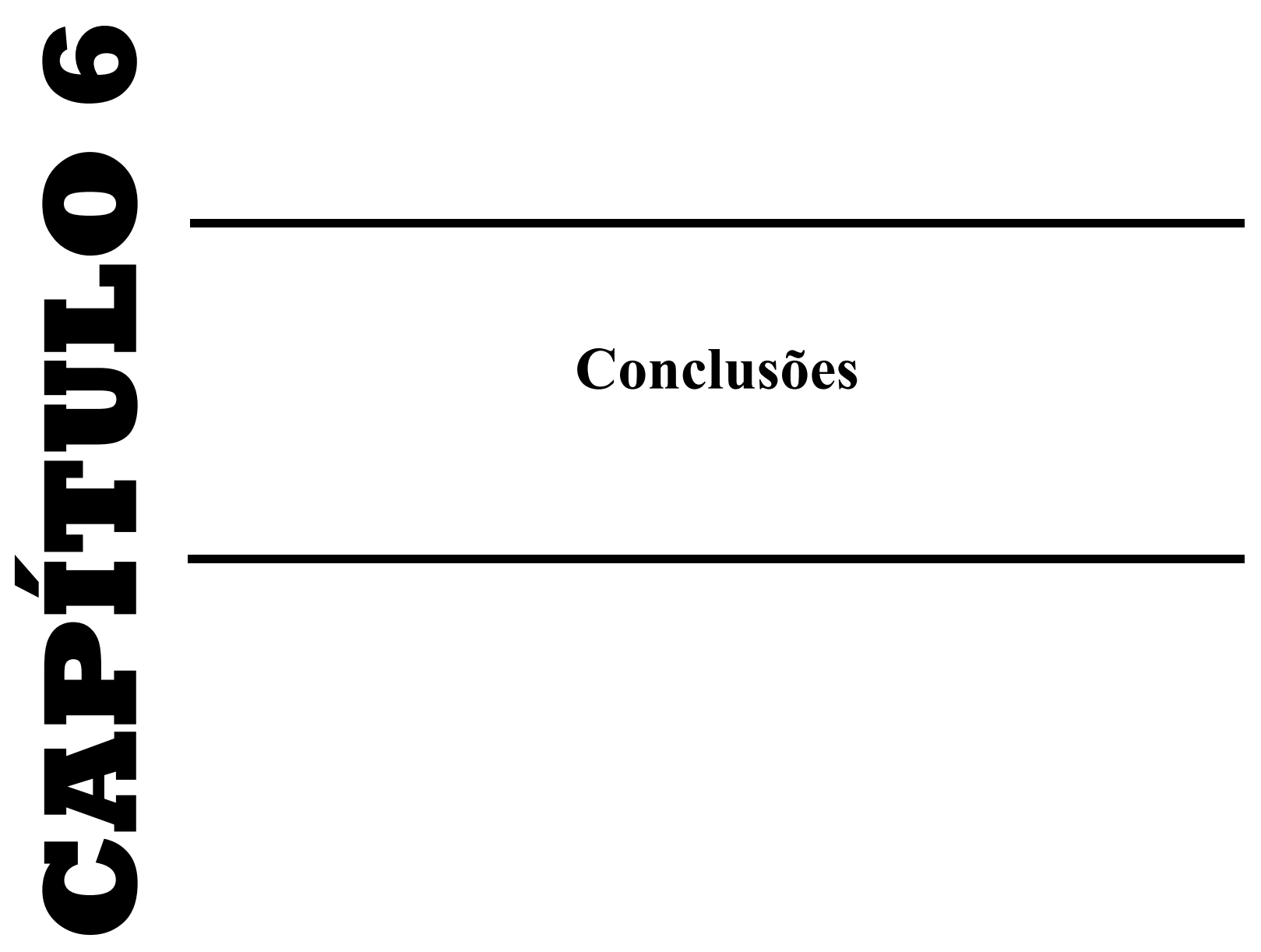




\section{CONCLUSÕES}

- Em todas as amostras analisadas, os valores de G`e G“ aumentaram com a diminuição da temperatura e com o aumento da concentração de gelatina nas soluções. O colágeno hidrolisado não apresenta característica de formação de gel e não foi observado efeito sinergístico quando estudado em conjunto com a gelatina. Exceto para a solução contendo $1 \%$ de gelatina, a temperatura de formação de gel foi de $20{ }^{\circ} \mathrm{C}$, enquanto que a temperatura de fusão da gelatina foi de $39,4 \pm 1,3{ }^{\circ} \mathrm{C}$.

- O valor do módulo de armazenamento $\left(G^{`}\right)$ correspondente ao platô viscoelástico (varredura de freqüência) aumentou com o aumento da concentração de gelatina e, comparando-se soluções com mesma concentração de gelatina, as amostras com amido possuem altura de platôs maiores do que as que contêm colágeno hidrolisado nas mesmas concentrações.

- As concentrações de gelatina e de colágeno hidrolisado nas gomas de gelatina dietéticas exerceram, sobre os parâmetros de dureza, gomosidade e mastigabilidade, um efeito significativo apenas de dependência linear, ou seja, não há efeito significativo da interação entre os fatores. A concentração de gelatina e colágeno hidrolisado não influenciou os parâmetros fraturabilidade, elasticidade e coesividade significativamente $(p<0,05)$ sendo que a concentração de gelatina influenciou de forma significativa o parâmetro adesividade das gomas de gelatina.

- Ainda sobre gomas dietéticas de gelatina, o aumento nas concentrações de gelatina e de colágeno hidrolisado apresentou efeito significativo sobre a opacidade dos géis obtidos e um aumento crescente na diferença de cor que obedeceu a uma relação linear em função da concentração total de biopolímeros na amostra $\left(\mathrm{R}^{2}>0,98\right)$. Foi possível obter um produto com propriedades mecânicas similares às das tradicionais gomas de gelatina, sendo diferenciado por não utilizar sacarose na formulação e por apresentar maior conteúdo protéico. O produto apresentou boa aceitação tanto pelo público infantil como por adultos.

- O amido de milho modificado de forma ácida (AMMA) apresentou temperatura de gelatinização no intervalo de 65 a $66{ }^{\circ} \mathrm{C}$. Diferentemente da gelatina, o amido não apresenta comportamento reversível, ou seja, depois de gelatinizado os grânulos permanecem intumescidos, o que pode ser observado pelo alto valor de $G^{\prime}$ que permaneceu elevado mesmo mantendo a solução a $80{ }^{\circ} \mathrm{C}$ e depois resfriando-a a $20{ }^{\circ} \mathrm{C}$. A substituição 
de $25 \%$ de gelatina por amido de milho modificado resultou em valores de G’ similares aos das amostras contendo somente gelatina.

- A análise da microestrutura de suspensões aquosas de gelatina e AMMA permitiu observar que a concentração na qual os dois biopolímeros co-existem, sem separação de fases correspondeu à amostra contendo uma relação de concentrações de gelatina:AMMA igual a 37,5:62,5. Os demais sistemas apresentaram separação de fases, sendo esta mais pronunciada à medida que as amostras foram ficando enriquecidas com gelatina ou amido, exceto na amostra 12,5:87,5.

- Géis de gelatina e AMMA formulados com uma base de xarope de maltitol e xilitol apresentaram uma grande mudança da estrutura devido à presença de AMMA. A adição de $1 \%$ de AMMA resultou num gel termodinamicamente estável sendo que, em maiores concentrações de amido o resultado é uma incompatibilidade termodinâmica, evidenciada pelo maior número de espaços vazios e grânulos não entumescidos. Por outro lado, houve um aumento da dureza e opacidade e uma diminuição da pegajosidade e adesividade.

- A adição de AMMA em géis de gelatina resultou em géis mais opacos, contudo as propriedades mecânicas foram preservadas quando um adequado balanço entre gelatina e AMMA foi atingido, como no caso das amostras 9:1, 8:4 e 8:5 \% em massa de gelatina:AMMA. Assim, a adição de AMMA em géis de gelatina pode ser uma alternativa na formulação de confeitos. 


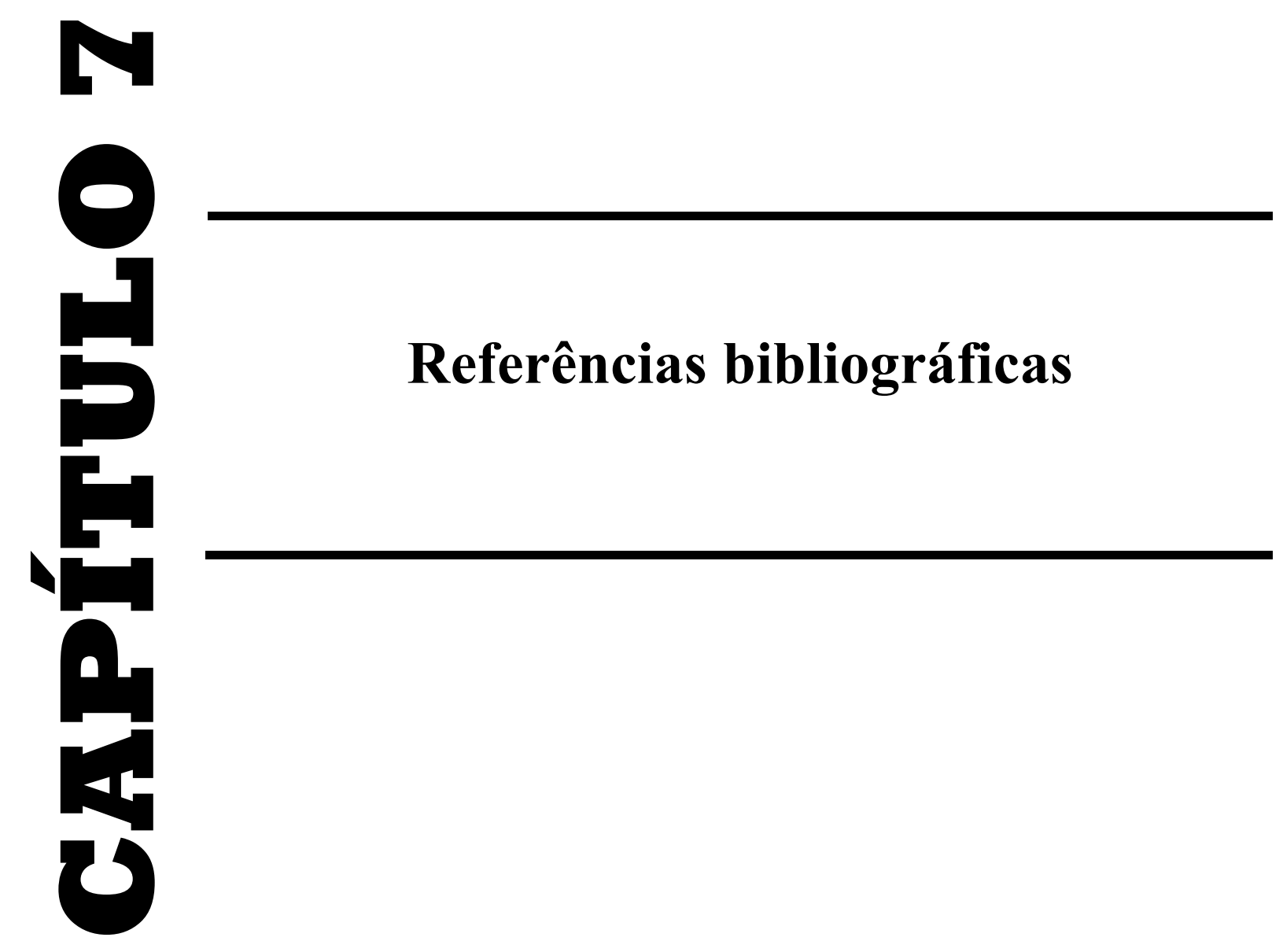




\section{REFERÊNCIAS BIBLIOGRÁFICAS}

ABD KARIM, A.; NORZIAH, M. H.; SEOW, C. C. Methods for the study of starch retrogradation. Food Chemistry, v. 71, n. 1, p. 9-36, 2000.

AGUILERA, J. M. Microstructure and Food Product Engineering. Food Technology. v. 54, n. 11, p. 56-65, 2000.

BRASIL. Agência Nacional de Vigilância Sanitária. Resolução - CNNPA nº 12, de 1978. Disponível em: <http://www.anvisa.gov.br/legis/resol_bloqueado/12_78_balas.htm $>$. Acesso em: 13 fev. 2009.

BRASIL. Agência Nacional de Vigilância Sanitária. Portaria no 503, de 22 de junho de 1998. Disponível em: <http://www.anvisa.gov.br/legis/portarias_bloqueado/503_98.htm>. Acesso em: 13 fev. 2009.

BARNES, H. A.; HUTTON, J. F.; WALTERS, K. An Introduction to Rheology. Elsevier, p. 37-54, 1989.

BELITZ, H.-D.; GROSCH, W. Food Chemistry, New York: Springer Verlag, 774pp, 1999.

BINSI, P. K.; SHAMASUNDAR, B. A.; DILEEP, A. O.; BADII, F.; HOWELL, N. K. Rheological and functional properties of gelatin from the skin of Bigeye snapper (Priacanthus hamrur) fish: Influence of gelatin on the gel-forming ability of fish mince. Food Hydrocolloids, v. 23, p. 132-145, 2009.

BOURNE, M. C. Texture profile analysis. Food Technology. v. 32, n. 7, p. 62-66, 1978.

BOURNE, M. C; KENNY, J.F; BARNARD, J. Computer-assisted readout of data from texture profile analysis curves. Journal Texture Studies, v. 9, p. 481-494, 1978.

BOURNE, M. C. Food texture and viscosity: concept and measurement. New York: Academic Press, p. 44-177, 1982.

BUREY, P.; BHANDARI, B. R.; HOWES, T.; GIDLEY, M. J. Hydrocolloid gel particles: formation, characterization, and application. Critical Reviews in Food Science and Nutrition. v. 48, n. 5, p. 361-377, 2008. 
BUREY, P.; BHANDARI, B. R.; RUTGERS, R. P. G.; HALlEY, P. J.; TORLEY, P. J. Confectionery gels: a review on formulation, rheological and structural aspects. International Journal of Food Properties, v. 12, p. 176-210, 2009.

CLARK, A. H.; ROSS-MURPHY, S. B.; NISHINARI, K.; WATASE, M. Shear ModulusConcentration Relationships for Biopolymer Gels. Comparison of Independent and Cooperative Crosslink Descriptions. In: BURCHARD, W.; ROSS-MURPHY, S. B, Editors, Physical Networks: Polymers and Gels, Elsevier Applied Science. p. 209-219, 1990.

DEMARS, L. L.; ZIEGLER, G. R. Texture and structure of gelatin/pectin-based gummy confections. Food Hydrocolloids, v. 15, p. 643-653, 2001.

DICKINSON, E. Hydrocolloids at interfaces and the influence on the properties of dispersed systems. Food Hydrocolloids, v. 17, p. 25-39, 2003.

DOUBLIER, J.L.; GARNIER, C.; RENARD, D.; SANCHEZ, C. Protein-polyssacharide interactions. Current Opinion in Colloid \& Interface Science, v. 5, p. 202-214, 2000.

EDWARDS, W. P. The Science of Sugar Confectionery. The Royal Society of Chemistry: Cambridge, 2000. 166p.

ELEYA OULD, M. M.; LENG, X. J.; TURGEON, S. L. Shear effects on the rheology of $\beta$ lactoglobulin/ $\beta$-carrageenan mixed gels. Food Hydrocolloids, v. 20, p. 946-951, 2006.

ELIASSON, A. C. Starch in food - Structure, function and applications. New York: Boca Raton, CRC Press; 2004.

FIGUEIRÓ, S. D.; GÓES, J. C.; MOREIRA, R. A.; SOMBRA, A. S .B. On the physicochemical and dielectric properties of glutaraldehyde crosslinked galactomannan-collagen films. Carbohydrate Polymers, v. 56, p. 313-320, 2004.

FRIESS, W.; LEE, G. Basic thermoanalytical studies of insoluble collagen matrices. Biomaterials, v. 17, n. 23, p. 2289-2294, 1996.

FRIESS, W. Collagen - biomaterial for drug delivery. European Journal of Pharmaceutics and Biopharmaceutics, v. 45, p. 113-136, 1998.

FRIESS, W; SCHLAPP, M. Effects of processing conditions on the rheological behavior of collagen dispersions. European Journal of Pharmaceutics and Biopharmaceutics, v. 51, p. 259-265, 2001. 
GARCIA, T. Analysis of gelatine-based confections. Monofactured Confectionery, Glen Rock, p. 93-101, jun. 2000.

GRAESSLEY, W. W. Viscoelasticity and flow in polymer melts and concentrated solutions. In: EISENBERG, A.; GRAESSLEY, W. W.; MADELKERN, L.; KOENIG, J. L. Physical Properties of Polymers, American Chemical Society, Washington D. C., p. 97-153, 1984.

HERMANSSON, A.-M.; SVEGMARK, K. Developments in the understanding of starch functionality. Trends in Food Science \& Technology, v. 7, n. 11, p. 343-353, 1996.

JACKSON, E. B.; LEES, R. Sugar Confectionary and Chocolate Manufacture. Saint Edmundsbury: Press Limited, 1973, 379 p.

LEES, R. Faults, causes and remedies: in sweet and chocolate manufacture. England: Specialised Publications: Surbiton, 1980.

MENARD, K. P. Dynamic Mechanical Analysis: A Practical Introduction; CRC Press: Boca Raton, 1999; 208 pp.

MOHSENIN, N. N. Physical properties of plant and animal materials, $2^{\text {nd }}$ ed., Gordon and Breach Science Publishers, New York, 1986, 841 p. In: TELIS, V. R. N. Estudo das alterações estruturais na gema de ovo durante o congelamento. Tese de dourado. Universidade Estadual de Campinas/UNICAMP, Campinas, Março 1996.

MORITAKA, H.; NAITO, S. Agar and gelatin flavour release. Journal Texture Studies, 33, 2002.

MUÑOZ, A. M.; PANGBORN, R. M.; NOBLE, A. C. Sensory and mechanical attributes of gel texture. I. Effect of gelatin concentration. Journal Texture Studies, v. 17, 1986.

OLIVO, R.; SHIMOKOMAKI, M. No Caminho da Pesquisa. 2. ed. Cocal do Sul: Imprint, 2002. v. 1, 155 p.

QUEIROZ, M. B. São Paulo (Estado). Secretaria de Agricultura e Abastecimento. Centro de Tecnologia de Cereais e Chocolate. Balas de Gomas e Doces Gelificados: Ingredientes e Tecnologia de Fabricação. Manual técnico de tecnologia de fabricação de balas, São Paulo: ITAL, n. 17, p. 39-49, 1999. 
RAO, M. A.; COOLEY, H. J. Dynamic rheological measurement of structure development in high-methoxyl pectin/fructose gels. Journal Food Science, v. 58, p. 876-879, 1993. In: Rheology of fluid and semisolid foods, ed. Aspen Publication, Gaithersburg, Maryland, p. 105-139, 1999.

RAO, M. A. Measurement of Flow and Viscoelastic Properties. In: Rheology of fluid and semisolid foods, ed. Aspen Publication, Gaithersburg, Maryland, p. 105-139, 1999.

RENARD, D., VAN DE VELDE, F., VISSCHERS, R.W. The gap between food gel structure, texture and perception. Food Hydrocolloids, v. 20, p. 423-431, 2006.

RIX, A. Gelling and whipping agents. In Jackson, E. B. Sugar Confectionery Manufacture. New York: Van Nostrand Reinhold, Glasgow; Blackie, 1990.

RIX, A. Gelling and Whipping Agents. In: JACKSON, E. B. Sugar Confectionery Manufacture. Van Nostrand Reinhold, Glasgow, p. 57-76, 1990.

ROSS-MURPHY, S. B. Structure-property relationships in food biopolymer gels and solutions. Journal of Rheology, v. 39, n. 6, p. 1451-1463, 1998.

STEFFE, F.L. Rheological Methods in Food Process Engineering, Freeman Press, East Lansing, 1996. 418 p.

SZCZESNAIK, A. S.; BRANDT M. A.; FRIEDMAN, H. H. Development of standard ratting scales for mechanical parameters of texture and correlation between the objective and sensory methods of texture evaluation. Journal Food Science. v. 28, p. 397-403, 1963.

TELIS, V. R. N.; KIECKBUSCH, T. G. Viscoelasticity of Frozen/Thawed Egg Yolk. Journal of Food Science, v. 62, n. 3, p. 458-460, 1997.

TELIS, V. R. N., TELIS-ROMERO, J., GABAS, A. L. Solids Rheology for Dehydrated Food and Biological Materials. Drying Technology, v. 23, n. 4, p. 759-780, 2005.

TESTER, R. F.; KARKALAS, J.; QI, X. Starch - composition, fine structure and architecture. Journal Cereal Science, v. 39, n. 1, p. 151-165, 2004.

TROMP, R. H.; VAN DE VELDE, F.; RIEL, J. V.; PAQUES, M. Confocal scanning light microscopy (CSLM) on mixtures of gelatine and polysaccharides. Food Research International, v. 34, p. 931-938, 2001. 
VAN DE VELDE, F.; RIEL, J. V.; TROMP, R. H. Visualisation of starch granule morphologies using confocal scanning laser microscopy (CSLM). Journal of the Science of Food and Agriculture, v. 82, p. 1528-1536, 2002.

VÉLEZ-RUIZ, J. Relevance of rheological properties in food process engineering. In: WELTI-CHANES, J.; BARBOSA-CÁNOVAS, G. V.; AGUILERA, J. M. Engineering and Food for the 21st Century, CRC Press, Boca Raton, p. 307-326, 2002.

WESS, T. J.; ORGEL, J. P. Changes in collagen structure: drying, dehydrothermal treatment and relation to long term deterioration. Thermochimica Acta, v. 365, p. 119-128, 2000.

WILSON, C. E.; BROWN, W. E. Influence of food matrix structure and oral breakdown during mastication on temporal perception of flavor. Journal Sensory Studies, v. 21, 1997. 


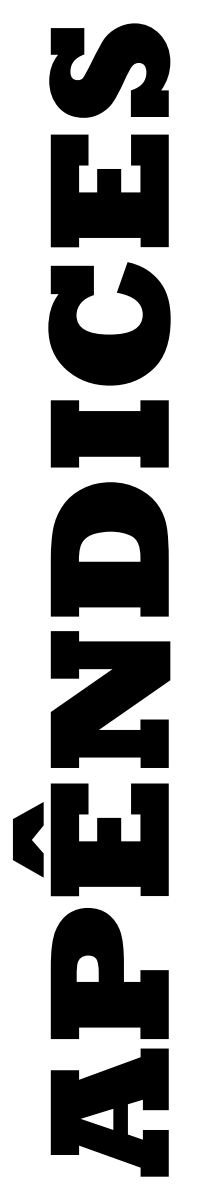




\section{APÊNDICE A}

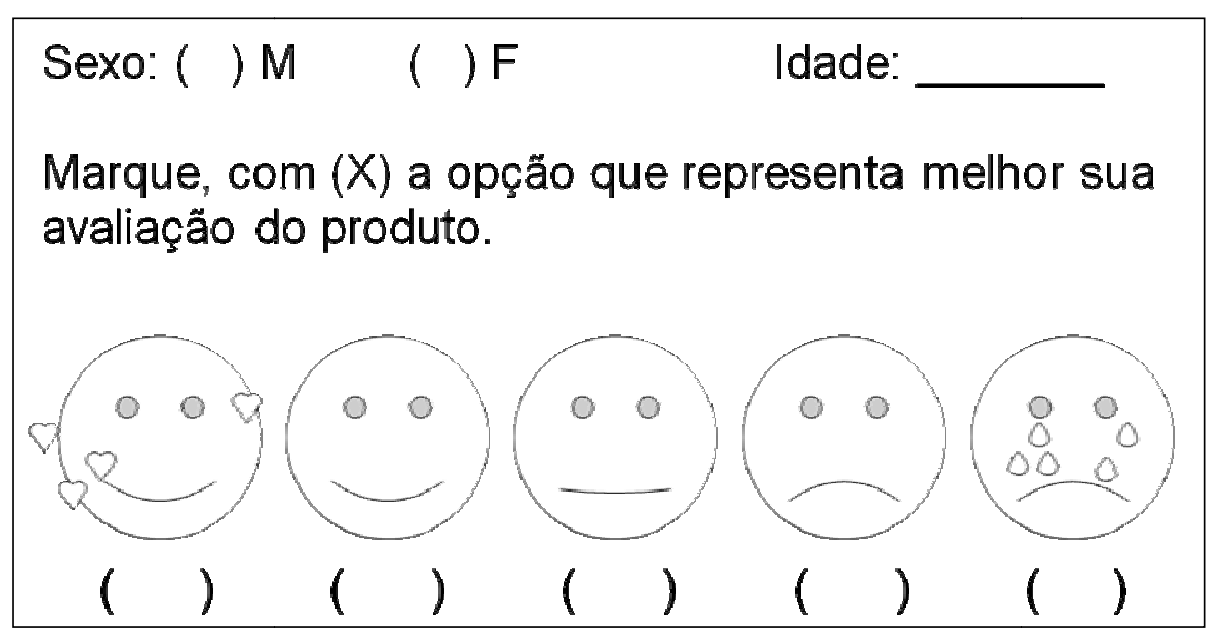

Figura A1 - Escala hedônica facial de cinco pontos utilizada para análise sensorial com crianças.

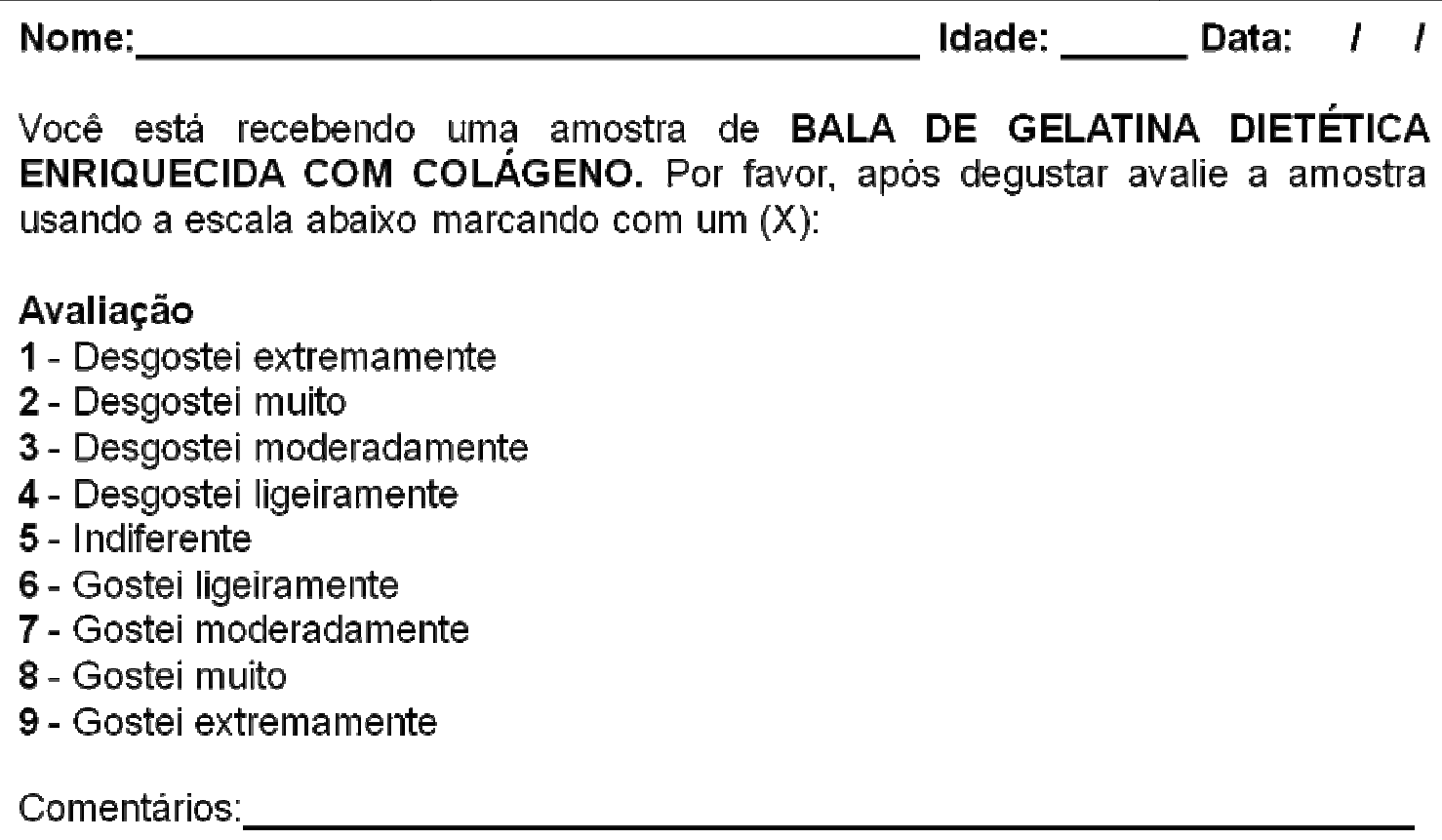

\section{Avaliação}

1 - Desgostei extremamente

2 - Desgostei muito

3 - Desgostei moderadamente

4 - Desgostei ligeiramente

5 - Indiferente

6 - Gostei ligeiramente

7 - Gostei moderadamente

8 - Gostei muito

9 - Gostei extremamente

Comentários:

$-$

Figura A2 - Escala hedônica de nove pontos utilizada para análise sensorial com adultos. 


\section{$\underline{\text { APÊNDICE B }}$}
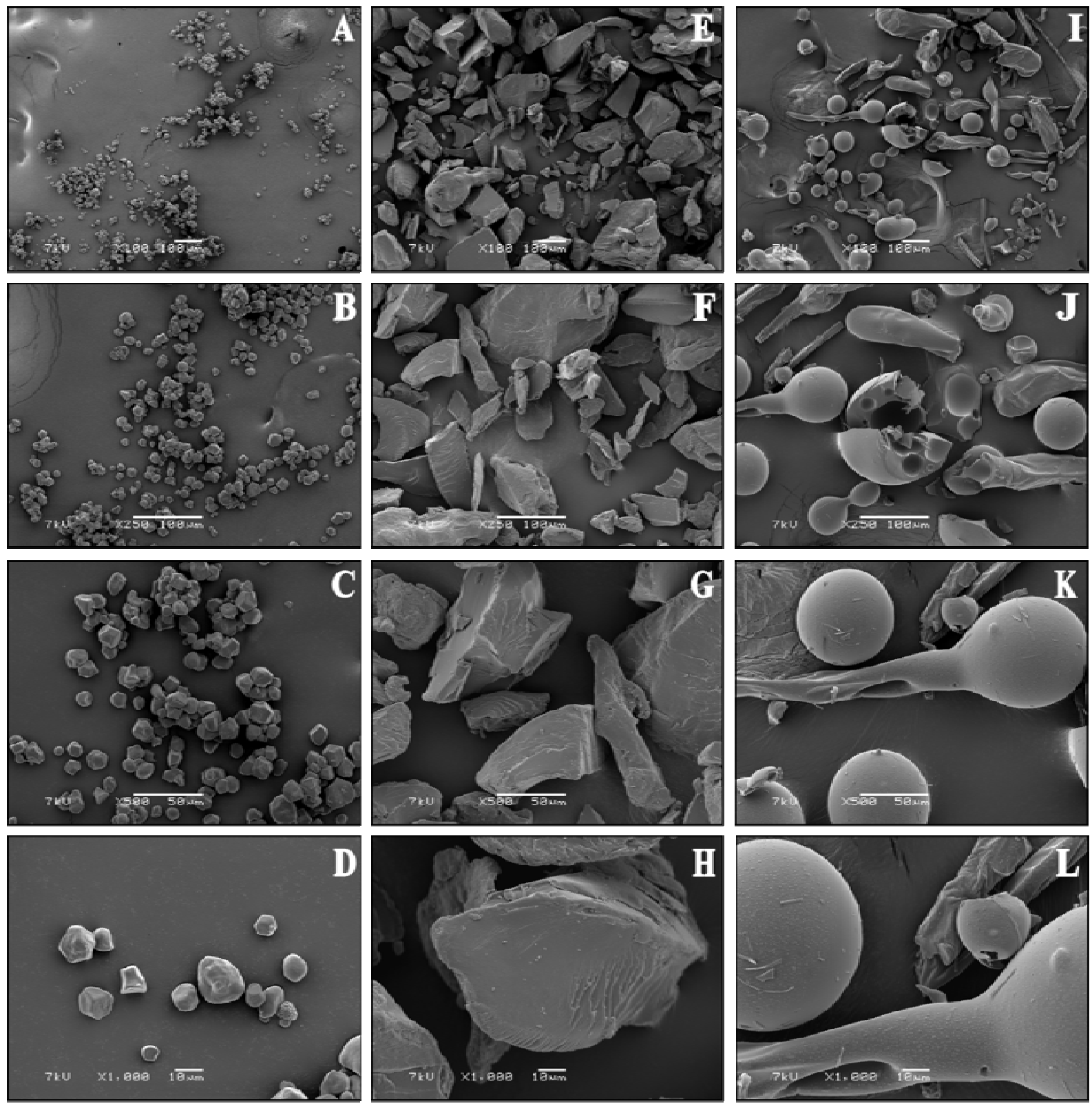

Figura B1 - Micrografias de varredura de grânulos de amido de milho modificado de forma ácida (A-D), gelatina (E-H) e colágeno hidrolizado (I-L) não tratados. 